FOOD SUPPLY CHAIN RESILIENCE IN AN ERA OF CLIMATE CHANGE:

RECOMMENDATIONS FOR TORONTO, ONTARIO

by

Christopher Michael Willett

BA, University at Buffalo, 2007

\author{
A major research paper \\ presented to Ryerson University \\ in partial fulfillment of the requirements for the degree of \\ Master of Planning \\ in \\ Urban Development
}

Toronto, Ontario, Canada, 2016

(c) Christopher Michael Willett 2016 


\section{Author's Declaration for Electronic Submission of an MRP}

I hereby declare that I am the sole author of this MRP. This is a true copy of the MRP, including any required final revisions.

I authorize Ryerson University to lend this MRP to other institutions or individuals for the purpose of scholarly research.

I further authorize Ryerson University to reproduce this MRP by photocopying or by other means, in total or in part, at the request of other institutions or individuals for the purpose of scholarly research.

I understand that my MRP may be made electronically available to the public. 


\title{
FOOD SUPPLY CHAIN RESILIENCE IN AN ERA OF CLIMATE CHANGE: RECOMMENDATIONS FOR TORONTO, ONTARIO
}

(C) Christopher Michael Willett, 2016

\author{
Master of Planning \\ in \\ Urban Development \\ Ryerson University
}

\begin{abstract}
The production of food, its delivery to markets, and its use by consumers depends on the proper functioning of numerous supply chains and critical infrastructure networks, many of which are threatened by a changing climate. To ensure the proper functioning of food supply chains during weather-related catastrophes, climate change adaptation and food security plans must consider risks to all elements of the chain and identify strategies for bolstering resilience. This paper explores the efforts of various North American cities to respond to this challenge and offers recommendations for improving food supply chain resilience in Toronto, Ontario.
\end{abstract}

Key words: food systems; food supply chains; climate change adaptation; resilience 


\section{ACKNOWLEDGEMENTS}

I would like to express my gratitude to my supervisor, Dr. Pamela Robinson, for

her wisdom and guidance. Pamela provided inspiration, direction, feedback, and boundless energy. Her contributions significantly strengthened this work.

Thanks also to Mary MacDonald, who generously agreed to be my second reader prior to having met me! A third pair of eyes is always appreciated.

Anthony, Sonia, Sunjay, and Tneshia: You have been such great friends, not least for having tolerated two years of my unsolicited commentary on issues large and small. Best wishes as we journey out into the world.

Special thanks to Aryo, whose love and counsel preserved my mental health through graduate school. And to Brian, Marie, and Michael, who have provided years of love and support. And to Molly, who I wish to know for many more. 


\section{DEDICATION}

By accident of birth and through no effort of mine, I have been fortunate to enjoy (and to squander) numerous luxuries - including plentiful food - available to only a fraction of the world's population. I dedicate this work to those who have made better use of their opportunities than I, and to those whose circumstances have not permitted luxuries like safety, opportunity, and hope. 


\section{TABLE OF CONTENTS}

TITLE PAGE

AUTHOR'S DECLARATION FOR ELECTRONIC SUBMISSION

ABSTRACT

iii

ACKNOWLEDGEMENTS

iv

DEDICATION

$\mathrm{V}$

LIST OF TABLES

vii

LIST OF FIGURES

viii

LIST OF APPENDICES

ix

CHAPTER 1: INTRODUCTION

CHAPTER 2: LITERATURE REVIEW

2.1 Food supply chains

2.2 Climate change

2.3 The vulnerability of food supply chains to climate change

2.4 The role of planners

CHAPTER 3: DATA COLLECTION

CHAPTER 4: SUMMARY OF FINDINGS 24

$\begin{array}{ll}4.1 \text { Vulnerabilities } & 26\end{array}$

4.1.1 Food production \& water supply $\quad 26$

$\begin{array}{ll}4.1 .2 \text { Supply chain infrastructure } & 29\end{array}$

$\begin{array}{ll}4.1 .3 \text { Consumer access } & 33\end{array}$

4.2 Responses $\quad 34$

4.2.1 Resilience Strategy A - Identify assets, opportunities, needs, and risks 35

4.2.2 Resilience Strategy B - Adapt processes, structures, and infrastructure 40

4.2.3 Resilience Strategy C - Increase regional self-sufficiency in food and water 44

4.2.4 Resilience Strategy D - Create redundancies and alternatives 46

4.2.5 Resilience Strategy E - Improve consumer access $\quad 47$

4.3 A useful aggregate 49

CHAPTER 5: RECOMMENDATIONS FOR TORONTO

5.1 Continue to strive for self-sufficiency 53

5.2 Harden each link in the food supply chain 56

5.3 Ensure residents are prepared for emergencies 62

5.4 Call to action 64

APPENDIX A: VULNERABILITY \& RESPONSE TABLES, SELECTED NORTH AMERICAN CITIES 68

REFERENCE LIST 


\section{LIST OF TABLES}

3.1 Vulnerabilities and responses relevant to the resilience of food supply chains: Synopsis for all cities reviewed

4.1 Frequency of vulnerability entries, categorized by phase of the food supply chain.

4.2 Frequency of response entries, categorized by phase of the food supply chain.

4.3 Frequency of response entries, categorized by strategy for increasing resilience.

4.4 Five strategies for increasing resilience that emerged from the cities' collective responses.

A.1 Vulnerabilities and responses relevant to the resilience of food supply chains: Edmonton, $A B$

A.2 Vulnerabilities and responses relevant to the resilience of food supply chains: Greater Sudbury, ON

A.3 Vulnerabilities and responses relevant to the resilience of food supply chains: Halifax, NS

A.4 Vulnerabilities and responses relevant to the resilience of food supply chains: Iqaluit, $\mathrm{NU}$

A.5 Vulnerabilities and responses relevant to the resilience of food supply chains: Miami (city) \& Miami-Dade County, FL

A.6 Vulnerabilities and responses relevant to the resilience of food supply chains: New Orleans, $L A$

A.7 Vulnerabilities and responses relevant to the resilience of food supply chains: New York, NY

A.8 Vulnerabilities and responses relevant to the resilience of food supply chains: San Francisco, $C A$

A.9 Vulnerabilities and responses relevant to the resilience of food supply chains: Seattle (city) \& King County, WA

A.10 Vulnerabilities and responses relevant to the resilience of food supply chains: Toronto, ON

A.11 Vulnerabilities and responses relevant to the resilience of food supply chains: Vancouver, $B C$ 


\section{LIST OF FIGURES}

2.1 Major elements in a food supply chain

3.1 North American cities selected for investigation 


\section{LIST OF APPENDICES}

APPENDIX A. Vulnerability \& response tables, selected North American cities 


\section{INTRODUCTION}

"In terms of the food available within the province in the event of an emergency that would disrupt the food supply chains, the capacity to deal with such a situation is currently unknown" (Halifax Food Policy Alliance, 2015, p. 86).

Natural disasters are endemic to our planet. Many are beyond our ability to adequately predict or control. Consider, for example, the severe earthquake and possible tsunami expected to someday devastate the northwest coast of the United States (Schulz, 2015). Other catastrophes are more preventable - at least in hindsight - because they were caused or exacerbated by human activities. One can trace a long history of human societies that collapsed because they spent the natural resources and undermined the natural processes that sustained them (Diamond, 2005). Climate change, if we're not careful, could open up a new chapter in that history, perhaps in ways not yet foreseen.

Thanks to forward-looking leadership, Toronto possesses a study identifying likely climate-related impacts specific to its region. During the 2040s, Toronto is expected to experience warmer average temperatures, more extreme heat (but less extreme cold), more frequent heat waves, and summer rainstorms of much greater intensity (City of Toronto Environment Office, 2012). In other words, the primary impacts will be more heat and more intense rainfall, though heavy storms will be less frequent during the winter (ibid.). Compared to the risks facing low-lying coastal cities like Miami and New Orleans, the challenges of Toronto's future appear relatively mild. Of course, it is important to remember that Toronto routinely experiences stormwater flooding and power outages during inclement weather (Deschamps, 2015; Flavelle, 2014; Gerster, 2013).

Recognizing the risks associated with climate change, Toronto and many other cities have taken measures to reduce emissions of greenhouse gases and adapt infrastructure networks to manage expected impacts. Such efforts require contributions from many 
different municipal departments, including those responsible for planning, public works, public health, and the environment. Food supply chains, the essential infrastructure for delivering food to city residents, must also be adapted to function effectively amid changing conditions. Though municipal planners may be accustomed to thinking of critical infrastructure networks in terms of capital assets used for transportation, electricity, water delivery, and wastewater collection, etc., food supply chains - which are just as vital to city function - entail a broader range of assets and actors, many of which operate in the private sphere in a decentralized fashion (e.g. corner bodegas).

Thanks to growing municipal interest in the sufficient provision of healthy and nutritious food to residents, planners in many cities have become familiar with issues of food availability and may even have collaborated with municipal staff or residents to create and

implement food-related policies (Soma \& Wakefield, 2011). Many municipalities (and presumably their planners) also recognize that buildings and infrastructure will require retrofit or overhaul to remain resilient in the face of climate-related impacts (Shi, Chu, \& Debats, 2015). Because the supply chains that produce and deliver food to urban populations depend upon the proper functioning of buildings and infrastructure - and upon numerous other systems vulnerable to climate change (e.g. ecosystem services, labor, and governance) they too will need to be adapted. Therefore, this investigation aims to determine the extent to which cities have begun assessing climate-related threats to food supply chains and devising strategies to increase resilience. In other words:

1. What climate-related vulnerabilities have cities identified with respect to their food supply chains?

2. What strategies can municipal governments employ to make food supply chains more resilient?

By assessing risks to their food supply chains and investing in resilience initiatives, municipalities can protect public health by ensuring that food delivery systems function 
effectively amid climate-related catastrophes. Further, understanding the complex workings of a city's food supply chains and identifying points of vulnerability will inform infrastructure restoration priorities and the provision of aid when a disaster does strike. By strengthening the elements and pathways that keep food supply chains operating, a city may be able to reduce its reliance on emergency relief. That hardiness could prove critical should aid be limited, delayed, or unavailable in the event of widespread catastrophe (Chandra et al., 2011). Finally, relief efforts that depend on the proper functioning of existing chains will be more effective if those chains are resilient to disruption (City and County of San Francisco, 2010; City and County of San Francisco, 2011).

To investigate municipal consideration of food supply chain vulnerability - and the extent to which strategies have been devised to address that vulnerability - I have conducted a thorough examination of the climate change adaptation and food security work undertaken in eleven North American cities. After reviewing related literature in Chapter 2, I provide a detailed methodology in Chapter 3, discussing how the eleven cities were chosen and how relevant data were collected. Chapter 4 provides a summary of findings, and Chapter 5 applies this research to the Toronto context, offering recommendations for improving the resilience of food supply chains operating in the city where I attended graduate school. 


\section{LITERATURE REVIEW}

\subsection{FOOD SUPPLY CHAINS}

Food is a critical ingredient for human survival and human civilization. In addition to providing the fuel for day-to-day functioning, proper nutrition plays an important role in growth, health, learning, and reproduction. When food can be obtained efficiently on a large scale, excess human labor can be devoted to other occupations, allowing society to advance (Diamond, 1997; FAO, 2013). Indeed, food surpluses ensure that most of the human population can labor in pursuits other than agriculture (FAO, 2013). In developed nations in particular, agriculture accounts for a small fraction of total employment; in Canada, the figure is under three percent (ibid.).

The term food system refers to the complex life-cycle of food products from production through consumption and then disposal (City of Toronto Public Health, 2010; MacRae \& Donahue, 2013). In developed nations such as Canada, the food system is heavily industrialized, and major firms exercise substantial control over certain markets or product types (City of Toronto Public Health, 2008; Hawkes, 2009; Humphrey \& Memedovic, 2006; USDOC, 2008). Canada's food system is also globalized. Although producers and manufacturers in Canada generate enough calories to feed the nation's population, many products are exported to serve markets abroad, while other products are imported to serve Canadian consumers. ${ }^{1}$ The supremacy of globalized trade is illustrated by Xuereb (2005), who found that, for the Waterloo Region, "imports of 58 commonly eaten foods travel an average of $4,497 \mathrm{~km}$ " even though "all of the studied food items could be grown or raised" locally (p. 3).

Food supply chains are critical components of the food system, comprising all of the inputs, actors, processes, transactions, and transport between raw inputs and consumption

\footnotetext{
1 Agriculture and Agri-Food Canada, 2015; City of Toronto Public Health, 2008; City of Toronto Public Health, 2010; Hawkes, 2009; Martinez et al., 2010; Toronto Food Policy Council, 1999a; World Bank, 2008
} 
(Hawkes, 2009). Figure 2.1, below, illustrates the common processes - or elements - that may be found in a food supply chain, though the form and complexity of an individual chain depends on the product and the actors involved (ibid.). Each element is fueled by various inputs, such as energy, labor, machinery, materials, and packaging (ibid.). Between elements, the food product (or the goods that will become a food product) may be transported from one location to another.

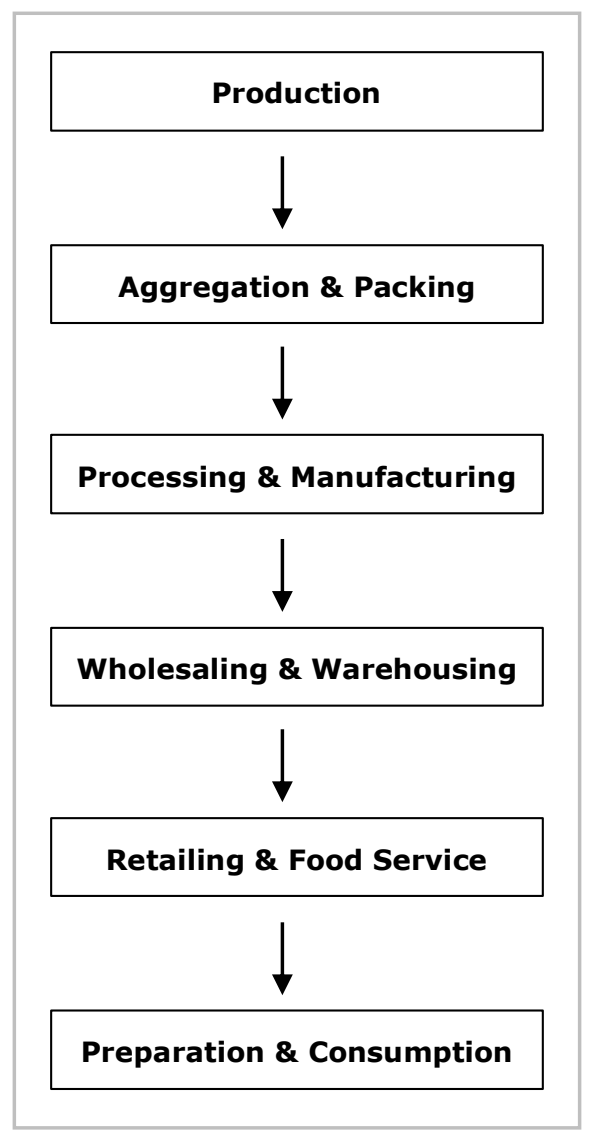

Figure 2.1. Major elements in a food supply chain. Arrows may entail transportation and storage. Diagram is conceptual: The chain varies by product and market. Sources: City of New York, 2013a; City of Toronto Public Health, 2008; Gunders, 2012; Hawkes, 2009; Humphrey \& Memedovic, 2006; Kamizaki, 2014; King et al., 2010; MacRae \& Donahue, 2013; Toronto Food Policy Council, 1999a; USDOC, 2008.

Food production, the first major element in the chain, employs or capitalizes on natural resources like sunlight, land, water, and vegetation to grow food (e.g. agriculture or horticulture), raise food (e.g. livestock or aquaculture), or harvest food (e.g. hunting or fishing) (Hawkes, 2009; NOAA Office of Aquaculture, 2011). Production may also rely upon 
other industries to provide necessary inputs like seeds, equipment, pesticides, fertilizers, and animal feed (City of Toronto Public Health, 2008; Hawkes, 2009; King et al., 2010).

Depending on the product, the rest of the chain can be simple or complex. Some foods, like fruits and vegetables, can be sold and consumed immediately after harvest. Alternatively, products may pass through aggregators, brokers, or packers who purchase from various producers and sell large quantities to actors further down the chain (King et al., 2010). Many food products are sent for processing, which adds value by way of a transformation process - freezing vegetables, packing meat, or milling flour, for example (Hawkes, 2009). The complexity of the processing or manufacturing stage varies: canning, for instance, is much less elaborate than techniques used to create snack foods (USDOC, 2008).

The next major element in the chain is wholesaling and warehousing. Wholesalers accept large quantities of goods from producers, aggregators, or processors and repackage them for sale to medium- and large-scale consumers such as retailers, restaurants, specialty manufacturers, and institutions (City of New York, 2013a). Warehousing refers to the storage of food products. Some apples, for instance, may not be sold for an entire year after harvest (King et al., 2010). Storage can be useful to hedge against drops in production that occur because of bad weather (ibid.).

Retailing and food service entails the provision of food products to small-scale consumers, like households, event attendees, and food bank recipients. This element is a diverse subsector of the chain, encompassing grocery stores, convenience shops, specialty retailers, farmers' markets, food trucks, caterers, restaurants, vendors, and institutions, etc. (Hawkes, 2009; Toronto Food Policy Council, 1999a). Pathways to this element of the chain vary, as do the participants. Retailers and food service providers may purchase from wholesale markets, distributors, vendors, or intermediaries, or (as is often the case in large grocery chains) they may conduct warehousing and distribution functions internally (Barron et al., 2010; City of New York, 2013a; King et al., 2010). Stores and restaurants may rely 
upon multiple producers or distributors to supply a single product, and those sources may change with the seasons (Barron et al., 2010; King et al., 2010). Institutional consumers, like schools and charitable organizations, may purchase from wholesalers, distributors, or retailers (City of New York, 2013a; Kamizaki, 2014).

In the final element of the chain, preparation (if necessary) occurs to make food suitable for consumption. Examples include peeling, chopping, cooking, and baking. This stage may occur prior to the product's sale (as in the case of items ready to eat) or it may occur at a food retailer, within a household, or at some other location where kitchen equipment is available. As in the rest of the chain, inputs are often required, including tools (e.g. knives, spatulas, pots), machines (e.g. microwaves, ovens, toasters), and fuels (e.g. wood, gas, electricity). Special equipment may also be required for the final act consumption - as required to feed some medical patients (Trento \& Allen, 2014).

As mentioned, Figure 2.1 is intended to be conceptual. Not all supply chains entail all of these elements and not all entail long distances between production and consumption (King et al., 2010). The structure of the chain varies by product (Hawkes, 2009). There may even be additional steps, as in the case of cows raised in two different places prior to slaughter, or circuitous routes (King et al., 2010). In addition, products crossing international borders may be subject to government inspections (Humphrey \& Memedovic, 2006).

Hence, in practice, boundaries and pathways may not be as clear or direct as pictured in the figure (Barron et al., 2010; Hawkes, 2009; Toronto Food Policy Council, 1999a). And while it might be intuitive to assume that each step in the process entails a new actor, this is not always the case. In instances of vertical integration, a single firm may control or manage multiple elements in the chain - and these elements may not even be consecutive (King et al., 2010; The Economist, 2009). Further, Figure 2.1 excludes the inspection, labeling, and marketing of products, which could be considered part of a food supply chain (Hawkes, 2009). There is also the issue of waste management, as a substantial portion of food product is never 
consumed (Buzby, Wells, \& Hyman, 2014). Though not pictured, energy, labor, and equipment are vital to every step of the process.

Though complex, industrialized, and globalized food production and delivery systems are efficient, there is much to protest. Despite advances in production methods, storage technology, and logistics, food is distributed inequitably: undernourishment exists in both the developing and the developed world (World Bank, 2008). The challenges of overconsumption and associated health problems - which have been well documented - are also global phenomena (World Bank, 2008).

At the local and regional level, disparities in access to nutritious foods, the resulting impacts on public health, and other food-related challenges - including declines in the viability of local agriculture - have caught the attention of governments and NGOs (MacRae \& Donahue, 2013). Indeed, more than 200 North American cities have conducted food policy work, in which researchers commonly employ food systems thinking to holistically evaluate the processes and consequences of our food systems (City of Toronto Public Health, 2010, MacRae \& Donahue, 2013). Much of this work concerns food security, which entails much more than meeting a population's basic caloric requirements (MacRae \& Donahue, 2013; World Bank, 2008). To be food-secure, a person must have access to food that satisfies nutritional needs, cultural preferences, and the energy requirements of an active lifestyle (World Bank, 2008).

Many households are food insecure because they lack access to markets or outlets offering fresh, unprocessed foods (like fruits and vegetables) that are important for maintaining good health and nutrition. The suboptimal food retail environments in such communities - many of which are already marginalized by race or class - are reflected in the terms used to describe them: Food deserts lack sizable grocery stores and other affordable sources of healthy foods, while food swamps are dominated by retail outlets offering less healthy options (Food and Urban Agriculture Advisory Committee, 2012; Parent \& Barthé- 
Prevost, 2015). It is also recognized that diverse populations in some urban areas may lack access to food that is culturally appropriate (Halifax Food Policy Alliance, 2015).

In Canada and the US, many strategies have been devised at the local and regional levels to address food-related challenges. Examples include expanding the local food economy, preserving agricultural land, recruiting new farmers, promoting urban agriculture, supporting farmers' markets, incentivizing food retailing in underserved communities, conducting public outreach on proper nutrition, providing subsidies to low-income consumers, and ensuring that healthy foods are offered on menus at institutions like schools and daycare facilities. While these initiatives are sometimes carried out by independent groups like food policy councils, those that benefit from government support tend to be more effective (MacRae \& Donahue, 2013).

This food policy work has coincided with - and perhaps benefits from - increasing consumer interest in food to foster better personal health, improve the treatment of labor and livestock, reduce exposure to pesticides and additives, and limit the environmental costs of food production and transport (Agriculture and Agri-Food Canada, 2012; Jäggi, 2013; Martinez et al., 2010). Indeed, emissions generated from agricultural activities and food delivery contribute to global climate change, which is expected to pose severe threats to human food systems (IPCC, 2014; Vermeulen, Campbell, \& Ingram, 2012).

\subsection{CLIMATE CHANGE}

In its Fifth Assessment Report, the IPCC (2014) reiterated the scientific consensus on

climate change: The documented warming trend is certain and it is highly likely that human activities are predominantly responsible. Many impacts of climate change have already been observed, and projected impacts under likely future emissions scenarios will entail even greater consequences for human and natural systems (IPCC, 2014; UN-Habitat, 2011). Even if humanity ceased producing greenhouse gases today, the consequences of past emissions 
will be present for centuries (IPCC, 2014). Further, there may be "tipping points" (i.e. thresholds in the climate system) that, if exceeded, could lead to dramatic and unprecedented outcomes (IPCC, 2014; Nickson et al., 2011; Nordhaus, 2012a; UN-Habitat, 2011).

Projected climate-related impacts include more frequent heat waves, more intense tropical and extra-tropical storms, changes in the frequency and intensity of precipitation, pressures on ecosystems and food sources, and coastal sea level rise (IPCC, 2014; UNHabitat, 2011). Expected consequences include increases in poverty, displacement, and conflict (ibid.). In cities - vital components of civilization housing large concentrations of people, infrastructure, industry, and culture - existing environmental problems (e.g. impaired ecosystems, stormwater runoff, and the urban heat island effect) are expected to worsen, underscoring the need for adaptation (Brown, Dayal, \& Rumbaitis Del Rio, 2012; Carter, 2011; Carter et al., 2014; Gremillion, 2011; Hallegatte \& Corfee-Morlot, 2010; Reckien et al., 2014; Romero-Lankao, 2012).

The potential for catastrophes to disrupt urban life is well documented. Failures in the electric grid, for example, can cause serious hazards and hardships. In addition to knocking out critical building systems such as lights, elevators, water pumps, appliances, and security devices, power outages can render heating and air conditioning systems useless, leaving people and equipment vulnerable to the influence of outdoor temperatures - as experienced in Auckland in 1998, when a blackout caused temperatures in some buildings to exceed $50^{\circ} \mathrm{C}$ (Bozikovic, 2015; Carss, 2014; King, 2014; Oved, 2014; Roaf, Crichton, \& Nicol, 2009; Spears, 2014; Zerbisias, 2014).

Depending on the type and scale of the disaster, communication and travel may be difficult or impossible (Barron, 2003; City of New York, 2013a; Flynn, 2011; Spears, 2014). During the 2003 power outage in Ontario and the northeastern US - caused in part by the August heat - New York City subways were inoperable, forcing thousands to commute home by foot (Barron, 2003; Fertig, 2013; Spears, 2013). In events where water or other debris 
(like fallen tree limbs) block roadways, vehicular travel is obstructed. Unable to communicate or travel, city residents cannot restock supplies of food or medicine or obtain rapid assistance during an emergency. Further, relief from government agencies and aid organizations may be unavailable during the immediate aftermath of a catastrophic event (Bozikovic, 2015).

Interdependencies among human systems - and our dependence on certain natural systems - mean that one type of catastrophe can have unexpected, seemingly unrelated consequences (Brown, Dayal, \& Rumbaitis Del Rio, 2012; Carter et al., 2014; Romero-Lankao, 2012). A drought in Texas, for example, caused changes in soil conditions that resulted in damages to roads, building foundations, and underground pipes (Auber, 2011). The reality of cascading impacts - Romero-Lankao (2012) uses the term "concatenated hazards" underscores the importance of comprehensive preparation for disaster ( $p .15)$. Indeed, given many cities' dependence on distant resources and complex infrastructure networks for their delivery, destructive events can threaten supply lines for food, water, and other goods (Hunt \& Watkiss, 2010; Surjan, Sharma, \& Shaw, 2011).

Given these threats, it is widely recognized that cities must become more resilient. Resilience, a persistent theme in the climate change and hazards literature, refers to the ability of a system to resist disturbances, rebound from disturbances, and reform to better address disturbances in the future, without losing form or function in the process (Brown, Dayal, \& Rumbaitis Del Rio, 2012; Joakim, Mortsch, \& Oulahen, 2015; Saavedra, Budd, \& Lovrich, 2012). Resilient urban systems, which are flexible, adaptable, resourceful, and robust, have many facets: The physical (e.g. gray and green infrastructure), the economic (e.g. access to capital), the social (e.g. trust, relationships, and leadership), and the institutional (e.g. governments, businesses, and NGOs) (Archer et al., 2014; Cutter et al., 2008; Joakim, Mortsch, \& Oulahen, 2015; Matheny \& Homewood, 2015). Fostering the resilience of such systems would be wise even in the absence of climate change, for cities are 
vulnerable to numerous other threats as well, including accidents, economic shocks, and terrorism.

Vulnerability, often described as a combination of exposure and sensitivity to a hazard, is not simply the inverse of resilience, though it may be tempting to view it this way (Joakim, Mortsch, \& Oulahen, 2015; Matheny \& Homewood, 2015). In other words, it is possible to be both vulnerable to a hazard (e.g. flooding) and resilient to that hazard (e.g. by elevating assets) simultaneously (Joakim, Mortsch, \& Oulahen, 2015). Although there are various ways to conceive of vulnerability - Joakim, Mortsch, and Oulahen (2015) document four, for instance - herein the term is used as it is commonly understood: to denote that a system is susceptible to a current or future hazard event.

It is well-recognized that vulnerability and resilience vary at the global and local scales, with the geography of risk often mirroring the geography of power (Brown, Dayal, \& Rumbaitis Del Rio, 2012; Carter et al., 2014; Castán Broto \& Bulkeley, 2013; Gremillion, 2011; IPCC, 2014; Joakim, Mortsch, \& Oulahen, 2015; Romero-Lankao, 2012; UN-Habitat, 2011). At the global scale, many populations at great risk (e.g. residents of coastal settlements in the developing world) have few resources to devote to cultivating greater resilience (Gremillion, 2011). This is particularly unjust given that responsibility for climate change often correlates inversely with levels of exposure and sensitivity to its impacts (Elver, 2015; IPCC, 2014; UNHabitat, 2011).

At the local or regional scale, levels of vulnerability and resilience may reflect underlying disparities - as in New Orleans, where poor communities were disproportionately affected by Hurricane Katrina - or they may vary with demographic and socioeconomic characteristics such as age, sex, race, health status, language ability, income, and wealth (Cutter, et al., 2008; Gremillion, 2011; King County \& KCIT DNRP GIS, 2015; Romero-Lankao, 2012; UN-Habitat, 2011). In Greater Manchester, for example, demographic and urban heat island mapping revealed a positive spatial correlation between poverty and above average 
temperatures (Carter et al., 2014). Indeed, poverty - and the built forms commonly associated with it (e.g. compact, crowded settlements on undesirable lands) - leaves some communities less able to cope with hazards in the short-term and less able to transform to accommodate changing conditions in the long-term (Hunt \& Watkiss, 2010; King County \& KCIT DNRP GIS, 2015; Romero-Lankao, 2012).

To address climate change, human efforts fall into two categories: mitigation and adaptation. Mitigation entails efforts to reduce the severity of climate change by curbing or capturing the greenhouse gas (GHG) emissions that drive it (Zimmerman \& Faris, 2011). Adaptation entails preparation for the impacts of climate change - i.e. increasing our resilience to projected hazards (Joakim, Mortsch, \& Oulahen, 2015). Adaptation can entail social interventions, like planning for community members to check on neighbors during a heat wave, or technical interventions, like the construction of barriers or restoration of coastal ecosystems to resist sea level rise and storm surges (Castán Broto \& Bulkeley, 2013).

With regard to urban settlements - the scale at which Gremillion (2011) argues that climate change work is most effective - most efforts have concerned mitigation rather than adaptation (Castán Broto \& Bulkeley, 2013; Carter, 2011; Hallegatte \& Corfee-Morlot, 2010; Hunt \& Watkiss, 2010). Indeed, incentives have favored mitigation work over adaptation work (Romero-Lankao, 2012). (It may be felt that prioritizing adaptation efforts implies that mitigation work is too difficult or no longer worthwhile (Stead, 2014).) Fortunately, many actions advance mitigation and adaptation objectives simultaneously (Gremillion, 2011).

A study of 200 European cities from 11 countries illustrates this uneven focus: Reckien et al. (2014) found that nearly two-thirds have a climate change mitigation plan, while only $28 \%$ have mitigation and adaptation plans. Further, mitigation strategies documented in the plans tended to be more specific than the adaptation strategies (ibid.). Cities in the US have also adopted mitigation and, more recently, adaptation measures, but much work remains to be done on adaptation (Gremillion, 2011; Zimmerman and Faris, 2011). At least 81 Canadian 
municipalities had begun the process of addressing GHG emissions by 1999; today, nearly 300 have pledged to act as part of the Partners for Climate Protection (PCP) program (FCM, 2016; Robinson \& Gore, 2005). PCP's latest National Measures Report indicates growing interest in adaptation as well (FCM, 2016).

Adaptation work at the municipal scale entails assessing risks and vulnerabilities, evaluating potential actions, creating and implementing action plans, and monitoring the results (UN-Habitat, 2011). Such efforts are often incremental and incomplete, in part because it is difficult to obtain accurate predictions of future climate and extreme weather risks at the local level (Carter, 2011; Gallucci, 2013; Gremillion, 2011; Hunt \& Watkiss, 2010; Joakim, Mortsch, \& Oulahen, 2015). Also, some topics have attracted more attention than others. Much research has been conducted on the impacts of coastal flooding and extreme temperatures, but less work exists on energy and water resources, biodiversity and ecosystems, air pollution, disease transmission, and the economic implications of climaterelated hazards (Hallegatte \& Corfee-Morlot, 2010; Hunt \& Watkiss, 2010). Inland cities have received much less attention than coastal cities (Hunt \& Watkiss, 2010).

In general, cities in the developed world have enjoyed greater resources to investigate adaptation and have made more progress in doing so (UN-Habitat, 2011). Common strategies include infrastructure upgrades, building retrofits, investments in green infrastructure, better water management, public outreach, public health initiatives, and updates to land use policies (Brown, Dayal, \& Rumbaitis Del Rio, 2012; Carter, 2011; Gremillion, 2011; Reckien et al., 2014; Zimmerman \& Faris, 2011). Recognized leaders in adaptation work include Boston, Chicago, London, Miami, New York, Paris, Toronto, and King County, Washington. ${ }^{2}$ Municipal climate change networks are another important player, active in conducting research and

2 Gremillion, 2011; Hallegatte \& Corfee-Morlot, 2010; Hunt \& Watkiss, 2010; Saavedra, Budd, \& Lovrich, 2012; Zimmerman \& Faris, 2011 
sharing knowledge; more than 1000 cities and regions, for example, belong to ICLEI-Local Governments for Sustainability. ${ }^{3}$

As mentioned, Gremillion (2011) asserts that cities and regions are uniquely suited to address climate change, especially given the failure of national and international-scale agreements to effectively manage this challenge. Indeed, cities and regions possess many planning tools that can be administered to curb emissions and increase resilience: they can invest in new infrastructure and influence private investment through land use regulations and building codes (ibid.). It is also possible to incorporate or "mainstream" climate change considerations into existing municipal activities, as was done in King County, WA (Gremillion, 2011; Hunt \& Watkiss, 2010; Saavedra, Budd, \& Lovrich, 2012; Zimmerman \& Faris, 2011).

As with food policy work, actors outside of government have played a significant role in responding to the threat of climate change, although there has been less research into their activities (Castán Broto \& Bulkeley, 2013). In an investigation of innovative "climate change experiments" in 100 cities around the world, Castán Broto and Bulkeley (2013) found that local governments, while predominant, are not alone in contributing to local-level mitigation and adaptation efforts. In fact, private and civil society actors lead nearly a quarter of surveyed experiments and almost half of all experiments involved partnerships among actors (ibid.).

\subsection{THE VULNERABILITY OF FOOD SUPPLY CHAINS TO CLIMATE CHANGE}

Climate change has the potential to disrupt every aspect of a food supply chain. Its impacts will threaten farms and fisheries all over the world, potentially causing severe production shortfalls (Elver, 2015; IPCC, 2014; Tacoli, Bukhari, \& Fisher, 2013; World Bank,

3 ACCCRN, n.d.; C40 Cities, 2015; Carter et al., 2014; Castán Broto \& Bulkeley, 2013; CDP Worldwide, 2015; Coastal Cities at Risk, n.d.; European Commission, 2014; Gremillion, 2011; Hallegatte \& Corfee-Morlot, 2010; ICLEI, n.d.; International Development Research Centre, n.d.; KLIMZUG, 2015; Resilience Alliance, 2015; Resilient Communities for America, n.d.; Saavedra, Budd, \& Lovrich, 2012; UKCIP, 2014; United States Conference of Mayors, 2008; USAID, n.d.; Zimmerman \& Faris, 2011 
2015). Declines in productivity and ruined harvests could bankrupt small producers and increase prices, compounding the challenges of population growth and poverty (Tacoli, Bukhari, \& Fisher, 2013). And given the vulnerability of infrastructure networks to extreme weather - high winds, intense precipitation, extreme temperatures, storm surges, flooding, etc. - the proper functioning of a supply chain could break down during shipping, manufacturing, wholesaling, retailing, or even in the kitchen of a consumer.

Challenges to agricultural production include annual variations and damaging shortterm weather events driven or exacerbated by climate change and long-term shifts in baseline conditions such as average temperature and rainfall (Tacoli, Bukhari, \& Fisher, 2013). ${ }^{4}$ Shortlived events like storms and heat waves are challenging to predict and can cause severe damage to food crops (Ferreira, 2012; Müller \& Elliott, 2015; Wheeler, 2015). Long-term changes in temperature and precipitation patterns will alter the productivity of agricultural lands, benefiting some regions and impairing others (IPCC, 2014). Other risks include saltwater intrusion, changes in cloud cover, declines in livestock production, and altered ranges for pests and disease (Havlík et al., 2015; Müller \& Elliott, 2015; Tacoli, Bukhari, \& Fisher, 2013). Long-term impacts also threaten the viability of commercial fisheries, as changes in the temperature, acidity, and oxygen content of the oceans may alter species distributions and drive extinctions (Elver, 2015; IPCC, 2014).

An unfortunate consequence of globalized food systems is wide exposure to local calamities. In other words, a climate-related disaster at one point in a food supply chain at one particular location may result in cascading impacts for subsequent actors and processes along the chain, wherever they may be (Elver, 2015; London Assembly Economic Committee, 2015; Tacoli, Bukhari, \& Fisher, 2013). Therefore, it is not sufficient for planners to concern themselves merely with identifying and addressing local climate-related risks, however comprehensive their efforts. The delivery of a single food product may entail the function of

\footnotetext{
4 Thanks to Dr. Pamela Robinson, my supervisor, for reminding me to make this distinction.
} 
buildings, infrastructure, market transactions, and ecosystem services in multiple regions, perhaps on multiple continents.

While infrastructure vulnerabilities will be explored in more detail in Chapter 4, disruptions to electrical systems pose a tremendous risk to the food supply chain, especially in the case of perishables: refrigerated food spoils within several hours and frozen food within two days (City of Toronto Environment Office, 2012; City of Toronto OEM, 2015b; Toronto Hydro-Electric System Limited, 2015). Electric power is also required to run communication systems vital to food chain logistics and computer equipment needed to process economic transactions (City of New York, 2013a; King et al., 2010). Seemingly straightforward solutions like backup generators may not be sufficient, given that refrigeration is an energyintensive process (City of New York, 2013a). Further, backup generators require liquid fuels, whose delivery may also be impeded during a catastrophe (ibid.).

Even short-term disruptions to food supply chains may be sufficient to cause a crisis. Toronto and many other North American cities only have enough fresh food to last about three days in the absence of fresh deliveries (City of Toronto Public Health, 2008; Toronto Food Policy Council, 1999b). While this stems from retail adoption of "just in time" delivery systems, it is unclear from my research whether the three day measure indicates the supply available at retailers alone, or at wholesaling and warehousing facilities as well. ${ }^{5}$ Because nutrition is so vital to health, price spikes and food shortages could result in declines in physical and mental function, which will negatively affect a population's capacity for resilience (Chandra et al., 2011; Elver, 2015; GGLO Design, 2013; McKeown, 2015).

\subsection{THE ROLE OF PLANNERS}

By guiding decisions on land use, urban form, transportation, economic development, etc., municipal planners have long played a powerful role in shaping the built environment,

\footnotetext{
5 City of Toronto Public Health, 2008; L. Baker (Health Policy Specialist, Toronto Food Policy Council), personal communication, March 15, 2016. Thanks to Dr. Pamela Robinson for raising these important questions.
} 
thus contributing to the drivers of climate change and food insecurity. Despite this long history, planners have only begun to take an active role in addressing these two challenges in the past few decades. Just sixteen years ago, for instance, researchers and practitioners exhibited little interest in the food system (Kameshwari \& Kaufman, 2000). Municipal work on climate change began earlier, near the end of the 1980s, with the earliest Canadian examples occurring in 1988 (Bulkeley, Castán Broto, \& Edwards, 2012; Robinson \& Gore, 2015). Given that mitigation and adaptation activities intersect with numerous planning matters, from floor area ratios to green infrastructure, planners will certainly be involved in climate change work for the foreseeable future.

Within municipal climate leaders like London, New York, Boston, and King County, climate considerations are being integrated into decision-making processes in planning and other municipal departments (Gremillion, 2011; Hunt \& Watkiss, 2010; King County \& KCIT DNRP GIS, 2015). A similar process has been recommended for Vancouver with regard to food security, which would require planning staff to consider the food-related consequences of new development (MacRae \& Donahue, 2013). By circulating the relevant information and promoting interdepartmental collaboration, certainly it should be possible for municipalities to elevate awareness of food supply chain vulnerability as well (Gremillion, 2011; Hunt \& Watkiss, 2010).

Given that the planning profession originated to address crises of urban public health, and given the clear relation of climate-related threats (e.g. extreme heat, catastrophic flooding, and expanded ranges for disease vectors) and food insecurity to human health, it seems appropriate that planners are involved in managing these challenges (Whyte, 2011). The above literature review has demonstrated that many cities and regions have already undertaken numerous policy initiatives to address climate change and food insecurity. The extent to which they have considered the point at which those two challenges converge will be the focus of the remainder of this investigation. 


\section{DATA COLLECTION}

To determine the extent to which municipalities are assessing risks to their food supply chains and devising strategies to advance resilience, I conducted qualitative case study research, focusing on the climate change adaptation, resilience, and food policy work conducted in eleven North American cities and regions (Neuman, 2011). Limitations on the time available to complete the research necessitated the decision to restrict candidate cities to the United States and Canada.

ICLEI members in the United States and ICLEI BARC (Building Adaptive \& Resilient Communities) members in Canada provided an initial class of cities from which to select candidates (ICLEI Canada, n.d.; ICLEI USA, 2013). Given ICLEI's focus on sustainability and its consideration of climate change for over twenty years, it seemed an appropriate network from which to choose candidate municipalities (ICLEI, n.d.; ICLEI, 2012). Arbitrary sampling was used to ensure wide geographic and climatic coverage across North America (Neuman, 2011). Regional diversity permits an investigation of the threats and strategies for food supply chain resilience that spring from different contexts. Figure 3.1 (next page) provides a map of all cities chosen for review. Included are recognized leaders in climate change work (e.g. Miami, New York, and King County, WA).

To find research and initiatives relevant to the resilience of food supply chains, I searched the official websites of the selected cities for studies, staff reports, plans, and policy documents on the topics of climate change, resilience, and food. In some cases, relevant documents were located on the websites of organizations distinct from the municipality (e.g. climate change consortiums and food policy councils). To ensure that I found and reviewed those documents as well, I conducted internet searches with Google using the name of the city and key phrases such as "climate change," "resilience plan," and "food security." On occasion, internet searches uncovered media articles documenting a city's work. Articles that appeared to contain new information were reviewed. 
To understand all work occurring in Toronto, I conducted an exhaustive search of its efforts on the topics of climate change, resilience, and food systems. A thorough (but not exhaustive) search was conducted for all other cities. Because I am concerned with the resilience of the food supply chains that cities rely upon day-to-day, emergency management plans (and provisions for emergency food distribution during a crisis) were generally excluded. Content specific to climate change mitigation was also excluded.

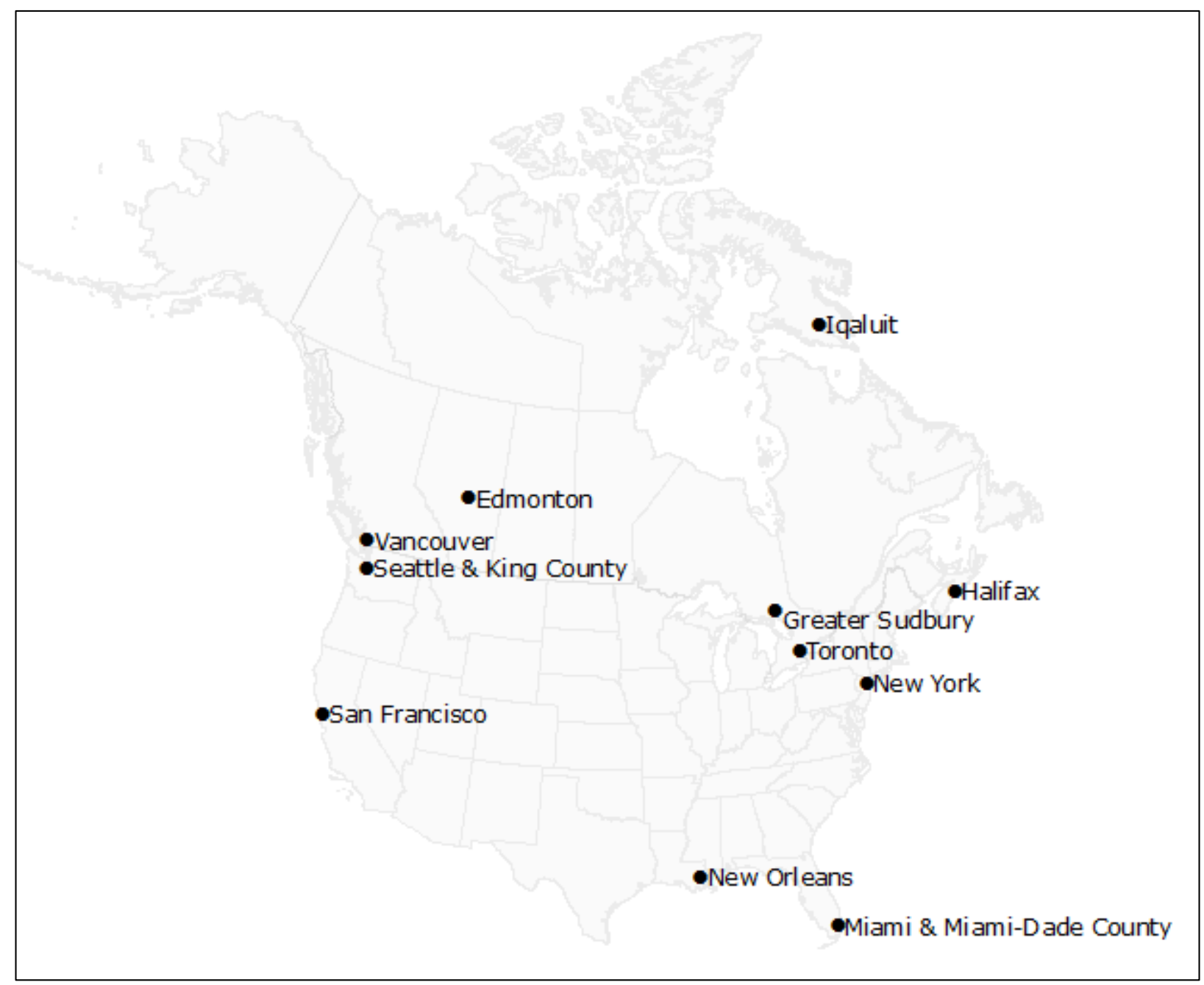

Figure 3.1. North American cities selected for investigation. Sources: Google, 2016; Statistics Canada, 2011; United States Census Bureau, 2014.

Because King County is a recognized leader in climate change research, its documents were reviewed in addition to the work conducted by the City of Seattle. Similarly, work 
conducted by Miami-Dade County and the Southeast Florida Regional Compact was included to supplement efforts of the City of Miami. In all other cases, the reports, plans, and policies published by higher orders of government or regional partnerships were not included, with the exception of Iqaluit, whose small size necessitated the inclusion of some work conducted at the territorial level.

Data collected for each city are summarized in Tables A.1 through A.11 (please see Appendix A). Each table is split into two major categories: vulnerabilities of food supply chains and responses for increasing their resilience. Any work conducted by a candidate city relevant to these two themes has been included. In most cases, the data were drawn from plans and policy documents written to pursue objectives other than the resilience of food supply chains. I opted for a generous approach when considering what threats, research, and policy work to include. Vulnerabilities, for example, did not need to be climate-specific, and responses need not have been implemented or evaluated. I have excluded considerations specific to supportive infrastructure networks (e.g. the hardiness of poles supporting the electric grid), as those details are simply beyond the scope of this study. Table 3.1 , on the next two pages, offers a synopsis of the more detailed tables available in the appendix.

All collected vulnerabilities and responses have been coded with numerical values (14) according to their association with the elements of a food supply chain discussed earlier. Responses have also been coded with letters (A-E) that correspond to the five general strategies for increasing resilience that have emerged from the collected data. The first strategy, A - identify assets, opportunities, needs, and risks, entails research beyond mere recognition of vulnerabilities. Instead, this category refers to efforts to collect and synthesize information necessary for or complementary to engaging in specific adaptation activities. One example is work conducted to identify and map assets critical to local food supply chains, as doing so is a prerequisite to hardening those assets. The other four strategies (B-E) are more 
adaptive in nature, entailing proposals for specific actions. Because these can overlap, they are defined in more detail in the next chapter, in which specific examples are provided.

Note that the contextual and cross-cutting nature of the catalogued vulnerabilities and responses makes categorization difficult (and thus inexact). Many entries fall into more than one category. They have been sorted within the Appendix A tables to promote easy assimilation. Collectively, the entries provide the appearance of a comprehensive attempt to address the resilience of food supply chains, but this is merely an artifact of the organizational strategy. Remember that the catalogued vulnerabilities and responses have been drawn from many different documents whose objectives may differ.

\begin{tabular}{|c|c|c|c|}
\hline & Strategies & Elements & \\
\hline  & & $\begin{array}{r}1 \\
1 \\
1,3,4 \\
1,2,3,4 \\
1,2,3,4 \\
1,2,3 \\
1,2,3,4 \\
1,2,3,4 \\
1,2,3 \\
3 \\
3 \\
3,4\end{array}$ & $\begin{array}{l}\text { Existing threats to agriculture, including declines in farming and loss of farmland. [ae, aq, au, ay, } \\
\text { bb, be, bj, bm, bo, cc, cd, cp, dk, eh, ej, ek] } \\
\text { Climate change threatens agriculture, fisheries, and harvesting. [a, b, i, j, p, a, s, v, x, al, am, bh, } \\
\text { bi, bq, bs, bt, bu, bv, bw, dq, du, dv, dw, dx, eg, ek, eo, er, et, ev, fj] } \\
\text { Climate change threatens water supply and water quality. [a, d, va, ac, al, am, bi, bo, bq, bs, bt, bv, } \\
\text { ch, cm, cp, cu, cy, da, db, dg, dj, dk, dp, dq, du, dw, dx, eg, ek, eo, er, ev, fa, fi, fj] } \\
\text { Climate-related catastrophes could damage or destroy food products. [c, ab, ad, al, bi, bo, bs, } \\
\text { bv, ch, da, dg, dj, eo, fj, fy] } \\
\text { Climate-related catastrophes threaten land, buildings, and infrastructure. [b, c, d, r, s, v, ad, ah, } \\
\text { al, am, be, bi, bm, bn, bo, bp, bs, bt, bv, da, dg, dj, dk, dp, dq, dr, du, dw, dx, em, eo, er, es, et, ev, } \\
\text { ew, ey, fa, fb, fg, fh, fi, fj, fl, fv, fw, fx, fy] } \\
\text { Dependence on food imports and supply chains vulnerable to calamities, energy costs, } \\
\text { political events, and market forces. [a, k, q, ad, ah, ay, az, ba, bb, be, bj, bm, bn, bp, bt, bw, ch, } \\
\text { cm, co, cp, cu, cw, cy, ej, ek, et, fv, fx] } \\
\text { Food spoilage and bacterial growth due to higher temperatures; disruptions to food and water } \\
\text { testing. [c, s, bh, bi, dx, er] } \\
\text { Residential and commercial income loss due to climate-related disasters; repair costs and } \\
\text { difficulties obtaining insurance. [al, bo, dr, dw, eu, fg, fj] } \\
\text { Increasing population, climate refugees, and rising food prices. [v, bm, bo, bw, cm, co, cr, dk, } \\
\text { dw, dx, ek, fx] } \\
\text { Changes in food price and availability due to climate impacts and supply chain disruptions; } \\
\text { consequences for health and equity. [a, b, ah, al, ay, az, ba, bb, et, ev, fj] } \\
\text { Unequal access to nutritious food; changes in the distribution of functional outlets in an } \\
\text { emergency. [f, g, } \mathrm{j}, \mathrm{k}, \mathrm{v}, \mathrm{x} \text {, ad, ae, al, ar, as, ay, bc, be, bj, bm, bq, bt, bu, bw, cn, co, cp, cr, cu, cy, } \\
\text { dd, de, dk, ds, eh, ej, fc, fg, fh, fi, fm, fo, fa, fu, fx, fy] } \\
\text { Residents unprepared for supply disruptions; declines in food skills. [j, k, y, ay, be, bm, bw, er] }\end{array}$ \\
\hline 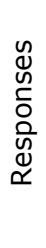 & $\begin{array}{l}\text { A } \\
\text { A }\end{array}$ & $\begin{array}{r}1,2,3,4 \\
1,3,4\end{array}$ & $\begin{array}{l}\text { Describe and diagram the regional food system, identifying key players, major assets, and } \\
\text { modes of transport. [j, } k, x, y, a d, \text { aj, an, as, ay, az, be, bj, bw, ck, co, cu, dc, eh, ex, fa, fv, fx, fy] } \\
\text { Inventory and map local food assets, including urban agriculture plots, retail stores, charitable } \\
\text { providers, and community kitchens. [f, } j, x, y, a l, a r, a s, b e, b j, b k, b m, b x, b y, c b, c f, c o, d d, d e, \\
\text { dk, ds, eh, ex, fa, fx] } \\
\text { Determine total food demand; assess food insecurity; measure dependence on assistance } \\
\text { programs. }[e, f, j, k, x, y, a g, a l, a r, a s, a t, b a, b b, b m, b e, b s, b w, b z, c b, c g, c n, c o, c r, d d, d e, d k \text {, } \\
\text { ds, eh, ej, ek, fc, fm, fo, fp, fq, fu, fx] }\end{array}$ \\
\hline
\end{tabular}




\begin{tabular}{|c|c|c|c|}
\hline & Strategies & Elements & \\
\hline 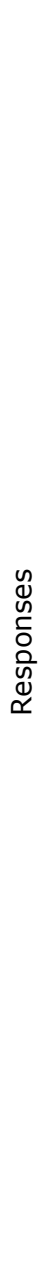 & $\begin{array}{r}\text { B, D, E } \\
\text { B, E } \\
\text { B } \\
\text { A, B, C, D } \\
\text { C } \\
\text { C }\end{array}$ & $\begin{array}{r}1,2,3,4 \\
1,2,3,4 \\
1,2,3,4 \\
2,3 \\
1,3,4 \\
1 \\
1,2,3 \\
1,3,4 \\
1,2,3\end{array}$ & 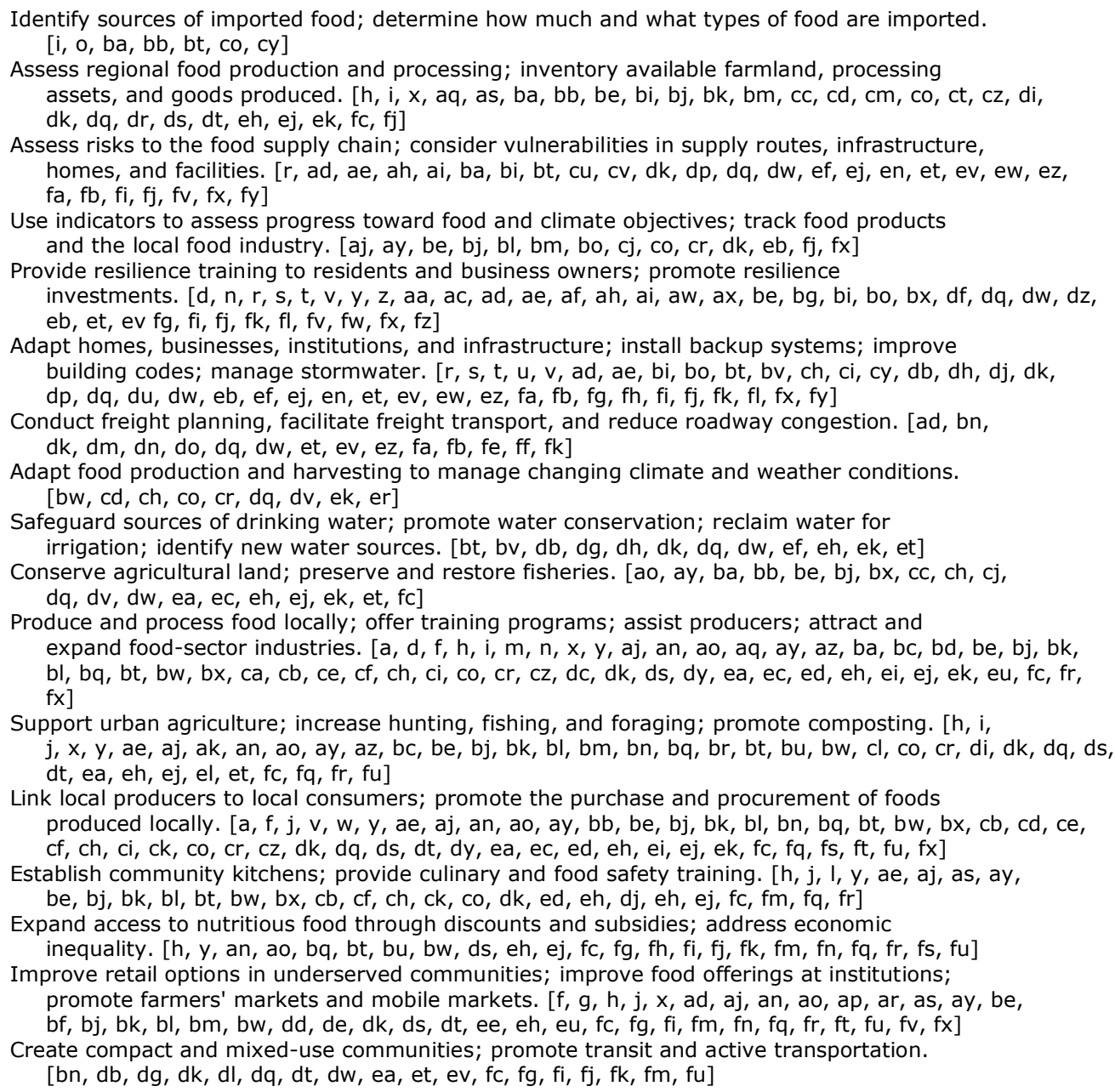 \\
\hline
\end{tabular}

Table 3.1. Vulnerabilities and responses relevant to the resilience of food supply chains: Synopsis for all cities reviewed. References shown in brackets are tied to parenthetical citations in appendix tables A.1 through A.11.

Coding Key:

\section{Phases of the food supply chain:}

1 - Production, aggregation, and processing

2 - Distribution, wholesaling, and warehousing

3 - Retailing, food service, and consumer access

4 - End user storage and preparation; consumption and waste

\section{Strategies for increasing resilience:}

A - Identify assets, opportunities, needs, and risks B - Adapt processes, structures, and infrastructure C - Increase regional self-sufficiency in food and water D - Create redundancies and alternatives E - Improve consumer access 


\section{SUMMARY OF FINDINGS}

Despite some recognition of overlap, the reviewed cities generally treat climate change adaptation and food security as distinct topics. The lone exception is New York, whose resilience plan, drawing heavily on the experience of Hurricane Sandy, comprehensively investigates risks to and proposes adaptations for many systems crucial to the city's day-today functioning - including food supply (City of New York, 2013a). The crisis permitted the city to see its vulnerabilities, which it now works to correct through a litany of specific initiatives (ibid.).

Although no other reviewed city integrated the two concerns as successfully and as comprehensively as New York, all have conducted sufficient research in the pursuit of either climate change adaptation or food security to begin detailed assessments of the risks to the daily operations of their food chains. Each city also identified numerous strategies for greater food supply chain resilience, often in pursuit of other objectives. Because the vulnerability of food supply chains stems in large part from their dependence on many other systems agriculture, transportation, buildings, electricity, water supply, etc. - efforts to harden those other systems have the added benefit of boosting the resilience of food supply chains.

The tables in Appendix A are valuable in summarizing eleven cities' work at the point of overlap between climate change and food security. Combined, the tables hold 501 entries, $37 \%$ of which are vulnerabilities and $63 \%$ of which are responses. Many vulnerabilities and responses are common across most of or all of the municipalities investigated. More interesting (and possibly of more value) are uncommon or unique entries, such as King County's concern that declines in water quality may not recognized by users of wells and small water utilities (King County OEM, 2013c).

A few general conclusions can be drawn from coding the data. Categorization by phase of the food supply chain reveals that phase three (retailing, food service, and consumer access) was the most common subject of both vulnerability entries (Table 4.1) and response 
entries (Table 4.2), followed by phase one (production, aggregation, and processing). Recall that an entry can fall into more than one category. A categorization of response entries by resilience strategy is shown in Table 4.3, but this information is less useful given that most entries come from plans for either climate change adaptation or food security, rather than from plans addressing the combination of these two concerns.

\begin{tabular}{|l|c|}
\hline Phase of the food supply chain & Number of entries \\
\hline 1- Production, aggregation, and processing & 108 \\
\hline 2- Distribution, wholesaling, and warehousing & 76 \\
\hline 3- Retailing, food service, and consumer access & 133 \\
\hline $4-$ End user storage and preparation; consumption and waste & 68 \\
\hline
\end{tabular}

Table 4.1. Frequency of vulnerability entries, categorized by phase of the food supply chain.

\begin{tabular}{|l|c|}
\hline Phase of the food supply chain & Number of entries \\
\hline 1- Production, aggregation, and processing & 163 \\
\hline 2 - Distribution, wholesaling, and warehousing & 124 \\
\hline 3 - Retailing, food service, and consumer access & 227 \\
\hline 4 - End user storage and preparation; consumption and waste & 99 \\
\hline
\end{tabular}

Table 4.2. Frequency of response entries, categorized by phase of the food supply chain.

\begin{tabular}{|l|c|}
\hline Strategy for increasing resilience & Number of entries \\
\hline A - Identify assets, opportunities, needs, and risks & 111 \\
\hline B - Adapt processes, structures, and infrastructure & 59 \\
\hline C - Increase regional self-sufficiency in food and water & 87 \\
\hline D - Create redundancies and alternatives & 89 \\
\hline E - Improve consumer access & 81 \\
\hline
\end{tabular}

Table 4.3. Frequency of response entries, categorized by strategy for increasing resilience. 


\subsection{VULNERABILITIES}

As discussed, the production and distribution of large quantities of food depends on particular environmental conditions, vital inputs and equipment, complex infrastructure networks, and the trade of goods and services (City of New York, 2013a; GGLO Design, 2013; IPCC, 2014). Delivery of just a single food product may entail the use of roads and highways, ports and airports, electrical power, potable and wastewater systems, natural gas delivery, and telecommunications - all of which themselves depend on other commodities and processes, such as liquid fuels, sensitive equipment, and human oversight (City of New York, 2013a; Toronto Food Policy Council, 1999a; Trento \& Allen, 2014). The cities reviewed here have demonstrated recognition of numerous vulnerabilities in their food systems, including those exacerbated by the impacts of climate change. These vulnerabilities are summarized in the following subsections.

\subsubsection{FOOD PRODUCTION \& WATER SUPPLY}

Numerous documents from the reviewed municipalities identified climate-related threats to supplies of food and water. Changes in weather and climate, including hazards like droughts and floods, have the potential to disrupt agriculture, livestock, and fisheries. ${ }^{6}$ Shifts in temperature and precipitation patterns can change habitat ranges for animals, crops, trees, pests, resulting in challenges like invasive species, crop disease, livestock illness, and fishery collapse. ${ }^{7}$ During disaster conditions, strong winds and floodwaters may spread hazardous materials that contaminate food products or harm crops, livestock, and seafood (King County

\footnotetext{
${ }^{6}$ City of New Orleans OHSEP et al., 2011; City of Toronto Environment Office, City of Toronto Climate Adaptation Steering Group, \& Clean Air Partnership, 2008; City of Toronto Public Health, 2010; City of Toronto Public Health, 2015a; Ekstrom \& Moser, 2012; GGLO Design, 2012; GGLO Design, 2013; King County, 2013a; King County, 2015d; King County \& KCIT DNRP GIS, 2015; King County \& King County Agricultural Commission, 2009; Lister, 2007; McKeown, 2015; Metcalf Foundation, 2008; Miami-Dade County Climate Change Advisory Task Force, 2008; Scioli, 2013; Seijas, Torriente, \& Hefty, 2010; Southeast Florida Regional Compact, 2012; Tomalty \& Komorowski, 2011; Toronto Food Policy Council, 1999b; Wolff \& Comerford, 2014

7 Dillon Consulting, de Romilly and de Romilly Ltd., \& ClimAdapt., 2007; Ekstrom \& Moser, 2012; King County OEM, 2013c; King County OEM, 2015a; UN-Habitat, 2011; Wolff \& Comerford, 2014
} 
OEM, 2013c; King County OEM, 2015a; City of New Orleans OHSEP et al., 2011). Environmental changes can also alter pollutant loads in food products (City of Iqaluit, 2014a).

Climate change presents an additional complication for many urban regions already struggling to support and maintain regional food production. Difficulties include challenges to the economic viability of farming, pressures to develop agricultural land, an aging or declining agricultural workforce, the use of farmland to grow non-food products, and (eventually) peak oil. ${ }^{8}$ Halifax, a coastal city, notes that fish processing is on the decline (Halifax Food Policy Alliance, 2015). Unfortunately, the viability of food production will fluctuate with environmental conditions and declines in production will threaten the economic viability of food businesses further down the supply chain (City of New Orleans OHSEP et al., 2011; Dillon Consulting, de Romilly and de Romilly Ltd., \& ClimAdapt., 2007).

Economic interdependencies ensure that producers are also vulnerable to climaterelated (and other) disruptions that may affect distant regions and nations. Agricultural operations may rely on distant suppliers for material, mechanical, and knowledge inputs, like seeds, fertilizers, equipment, and consulting (Harry Cummings and Associates Inc., 2009; King County \& King County Agricultural Commission, 2009). Producers whose income depends on access to far-off markets must hope that supply lines remain functional from source to point of sale (Elver, 2015; Tacoli, Bukhari, \& Fisher, 2013).

In Nunavut, where food security is already a major challenge, climate change may disrupt the hunting of animals and harvesting of fish as ranges change and stocks decline (City of Iqaluit, 2012; City of Iqaluit, 2014a; City of Iqaluit, 2014b; Eegeesiak, 2015a; Lewis \& Miller, 2010; Nunavut Food Security Coalition, 2014). Iqaluit already contends with increases in the expense of hunting, declines in professional hunters, and the loss of

\footnotetext{
8 Board of Supervisors of the City and County of San Francisco, 2006; City of Greater Sudbury, 2004; City of Vancouver, 2012a; City of Vancouver, 2013b; City of Vancouver Social Policy and Projects, 2015; Food and Urban Agriculture Advisory Committee, 2012; Foodshed Project, 2010; Halifax Food Policy Alliance, 2015; Harry Cummings and Associates Inc., 2009; King County, 2015a; King County \& King County Agricultural Commission, 2009; King County Farms and Food Roundtable, Staff Team Members, \& Cedar River Group, 2014; Randall, 2010
} 
traditional food-harvesting skills (City of Iqaluit, 2012; City of Iqaluit, 2014b; Eegeesiak, 2015a; Nunavut Food Security Coalition, 2014). Northern Ontario cites similar concerns, but with respect to agriculture: Few young people are becoming farmers and important agricultural skills may be lost (Foodshed Project, 2010; Harry Cummings and Associates Inc., 2009).

Many cities also identified water-related vulnerabilities, including climate change impacts on the supply and quality of water for drinking and irrigation. ${ }^{9}$ Climate change could exacerbate existing water management and supply issues, especially given impacts like droughts, floods, and sea level rise. ${ }^{10}$ Floodwaters could contaminate drinking water supplies and climate-related catastrophes could disrupt water testing (King County OEM, 2013c; King County OEM, 2015a). Saltwater intrusion accompanying storm surges and sea level rise threatens both drinking water and agriculture (Elver, 2015; Ruvin et al., 2014).

Shocks in supplies of food and water will only grow more severe over time, given increasing populations in many regions. ${ }^{11}$ Toronto, Vancouver, King County, and Miami-Dade County all recognized the prospect of climate refugees, whose presence will increase demands for food and water, and possibly prices as well. ${ }^{12}$ Fluctuations in price and availability could have consequences for public health, especially in low-income communities, where capacities

\footnotetext{
9 City of Iqaluit, 2014a; City of Iqaluit, 2014b; City of Toronto Environment Office, City of Toronto Climate Adaptation Steering Group, \& Clean Air Partnership, 2008; City of Toronto Public Health, 2015a; City of Vancouver, 2012a; Dillon Consulting, de Romilly and de Romilly Ltd., \& ClimAdapt., 2007; EarthCare Sudbury, 2010; Eegeesiak, 2015a; Ekstrom \& Moser, 2012; Foodshed Project, 2010; Greater Sudbury Climate Change Consortium, 2011; King County OEM, 2013c; Lewis \& Miller, 2010; Pinto, Penney, Ligeti, Gower, \& Mee, 2011; Toronto Hydro Electric System Limited \& City of Toronto OEM, 2015; Wolff \& Comerford, 2014; Seattle OEM, 2015; Stricker, 2013; Vasseur, 2007

10 City of Miami, 2008; City of New Orleans OHSEP et al., 2011; Climate Change Advisory Task Force, 2010; GGLO Design, 2012; King County, 2013a; King County, 2015d; King County \& KCIT DNRP GIS, 2015; King County \& King County Agricultural Commission, 2009; Miami-Dade County, 2010; Resilient Miami, Kresge Foundation, Catalyst Miami, \& Urban Impact Lab, 2015; Resilient Miami et al., 2015; Ruvin et al., 2014; Seijas, Torriente, \& Hefty, 2010; Southeast Florida Regional Compact, 2012

11 Barron et al., 2010; Foodshed Project \& Sudbury-Manitoulin FSN, 2007a; Foodshed Project \& SudburyManitoulin FSN, 2007b; King County, 2013a; King County \& KCIT DNRP GIS, 2015; King County \& King County Agricultural Commission, 2009; Nunavut Food Security Coalition, 2014; Stricker, 2013

12 City of Toronto Environment Office, City of Toronto Climate Adaptation Steering Group, \& Clean Air Partnership, 2008; City of Vancouver, 2012a; King County, 2013a; King County \& KCIT DNRP GIS, 2015; King County \& King County Agricultural Commission, 2009; Miami-Dade County, 2010
} 
to access and afford fresh, nutritious foods may already be limited (City of Toronto Public Health, 2015a; Margolies, 2014; McKeown, 2015; Wolff \& Comerford, 2014).

\subsubsection{SUPPLY CHAIN INFRASTRUCTURE}

Because food products must travel whatever distance separates producers and consumers, the entire supply chain is vulnerable to disruptions due to weather, politics, energy and fuel costs, and other market forces. ${ }^{13}$ King County, for instance, recognizes that its consumers rely upon the successful functioning of non-local aggregation, warehousing, and processing operations (King County Farms and Food Roundtable, Staff Team Members, \& Cedar River Group, 2014). Shipping delays and border closings - which should be expected in an age of terrorism and overreactions to it - can also pose challenges (City of Iqaluit, 2014b; Metcalf Foundation, 2008; Nunavut Food Security Coalition, 2014). In terms of value, more than half of Canada's agricultural imports come from the US (Agriculture and Agri-Food Canada, 2015).

Food importers - including the cities investigated - must hope that conditions remain stable in regions where their food is produced. ${ }^{14}$ Poor tracking of products moving through food supply chains means that product origins are often unknown, complicating efforts to even define this dependence (Barron et al., 2010). Further, the food needs of non-humans, including livestock, service animals, and pets, means that there are additional supply chains that likely depend on conditions elsewhere - both at the point of production and throughout the subsequent processing and delivery chains (King County OEM, 2013b; Seattle OEM, 2015).

\footnotetext{
13 City of Edmonton, 2010; City of Edmonton, 2011; EarthCare Sudbury, 2010; Food and Urban Agriculture Advisory Committee, 2012; Foodshed Project, 2010; Foodshed Project \& Sudbury-Manitoulin FSN, 2007a; Greater Sudbury Climate Change Consortium, 2011; Lipton, 2010; Stricker, 2013; Tacoli, Bukhari, \& Fisher, 2013; Vasseur, 2007

14 City of Toronto Environment Office, City of Toronto Climate Adaptation Steering Group, \& Clean Air Partnership, 2008; City of Toronto Public Health, 2008; City of Toronto Public Health, 2010; City of Toronto Public Health, 2015a; GGLO Design, 2013; Halifax Food Policy Alliance, 2015; King County \& King County Agricultural Commission, 2009; Lister, 2007; McKeown, 2015; Metcalf Foundation, 2008; Scioli, 2013; Tomalty \& Komorowski, 2011; Toronto Food Policy Council, 1999b
} 
Vulnerabilities within food supply chains can also undermine public health. In a crisis, climate-related or otherwise, routine food inspections may not occur (King County, 2013a; King County OEM, 2013c). Bacterial growth and food spoilage can result from higher temperatures, resulting in more food-borne illnesses (Dillon Consulting, de Romilly and de Romilly Ltd., \& ClimAdapt., 2007; Halifax Regional Municipality, 2007; McKeown, 2013a; Scioli, 2013). Complicating matters is the bidirectional relationship between food and health: Good nutrition is key to good health, of course, but good health is itself necessary for processing nutritious foods properly within the body (World Bank, 2008).

Hurricanes Katrina and Sandy caused breakdowns in the normal food distribution systems in New Orleans and New York, causing shortages and the loss or damage of food products (Bonini, 2014; City of New York, 2013a). Indeed, many of the reviewed cities recognized the potential for property loss due to flooding or fires, which could interfere with food storage and food preparation and contaminate, damage, or destroy food products. ${ }^{15}$ New York City noted that Hunts Point, the site of its major food wholesaling and distribution hub, is located on a peninsula subject to flooding (City of New York, n.d.; City of New York, 2013a; New York City Economic Development Corporation, 2014). That vulnerability, along with variations in distributors' adaptive capacity, means that poor communities may face greater food shortages than wealthier ones (City of New York, 2013a).

Over time, prices may rise with the increasing frequency and severity of climaterelated impacts on food production and transportation. ${ }^{16}$ Disasters and their consequences will also strain business and household budgets, and may increase the cost of insurance or make it more difficult to obtain (City of New Orleans, 2015b; City of New Orleans OHSEP et

\footnotetext{
15 City of Iqaluit, 2014a; City of Miami, 2008; City of New Orleans OHSEP et al., 2011; City of New York, 2013a; City of Vancouver, 2012a; Dillon Consulting, de Romilly and de Romilly Ltd., \& ClimAdapt., 2007; EarthCare Sudbury, 2010; King County OEM, 2015a; Lewis \& Miller, 2010; McKeown, 2013a; New York City Economic Development Corporation, 2014; Resilient Miami et al., 2015; Ruvin et al., 2014; Toronto and Region Conservation Authority \& City of Toronto OEM, 2014; Wolff \& Comerford, 2014

16 City of Edmonton, 2010; City of Edmonton, 2011; City of New Orleans OHSEP et al., 2011; City of Toronto Public Health, 2015a; Food and Urban Agriculture Advisory Committee, 2012; GGLO Design, 2012; GGLO Design, 2013; Lipton, 2010; Margolies, 2014; McKeown, 2015; Wolff \& Comerford, 2014
} 
al., 2011; City of Vancouver, 2012a; King County \& KCIT DNRP GIS, 2015; Morgenstern, 2013; Wolff \& Comerford, 2014). In addition, climate impacts may result in job and income losses for workers in food-related industries (City of New Orleans OHSEP et al., 2011; MiamiDade County, NOAA, \& NACO, 2011). Impacts on income and wealth could affect residents' ability to afford food. If a disaster is significant enough to drive away part of a city's population, there may also be consequences for the recovery period. Since Hurricane Katrina, New Orleans has experienced a labor shortage in the food retail sector (NOCSF \& CSO, 2014).

Every city investigating climate change recognizes that impacts like stronger storms, extreme temperatures, high winds, and flooding pose a threat to buildings and infrastructure. Aging and unmaintained buildings and systems, of course, will be even more vulnerable. ${ }^{17}$ The threats differ by city. Miami and New Orleans must prepare for storm surges and higher sea levels; Seattle and King County must prepare for landslides; Toronto must prepare for freezing rain and ice storms. Many infrastructure systems are interdependent, and their successful functioning allows us to produce, transport, and consume food.

Vulnerabilities to transportation differ by type and location. A few of the reviewed cities recognized threats to seaports and airports, including Iqaluit, which is inaccessible by road or rail and where the challenges of importing food have resulted in extremely high prices for basic goods like fruits, vegetables, and milk (Dillon Consulting, de Romilly and de Romilly Ltd., \& ClimAdapt., 2007; Lewis \& Miller, 2010; Shenker, 2012). In New York, where four of the city's five boroughs are on islands, one important concern is delays at bridges along important trucking routes (City of New York, n.d.; City of New York, 2013a). Congestion on city roadways also complicates food distribution in New York, as do limits to truck parking and maneuverability (Barron et al., 2010). New Orleans noted that its ports play a significant role in US imports and exports, while King County observed that its transportation assets are vital

\footnotetext{
17 Barron et al., 2010; City of Iqaluit, 2014a; City of New Orleans, 2015a; City of New Orleans, 2015b; City of New Orleans, 2015c; City of New Orleans OHSEP et al., 2011; City of New York, n.d.; City of New York, 2013a; Lewis \& Miller, 2010; New York City Economic Development Corporation, 2014
} 
to the shipment of food to Alaska (City of New Orleans, 2015b; City of New Orleans, 2015c; City of New Orleans OHSEP et al., 2011; King County OEM, 2013c). Indeed, successful food delivery may rely on transportation infrastructure both inside and outside of a region. ${ }^{18}$

Roads, rails, and ferries are also necessary for the movement of people, permitting easy access to grocery stores and other food outlets for employees and consumers (City of Vancouver Social Policy and Projects, 2015). If employees are unable to reach production, processing, wholesaling, or retailing facilities, there may be delays in distribution and shortages (City of New York, 2013a; UN-Habitat, 2011). Damage to transportation networks could restrict access to isolated areas, and as King County noted, local governments may not have sufficient resources to relocate or redesign vulnerable roadways (Ekstrom \& Moser, 2012; King County \& KCIT DNRP GIS, 2015; Miami-Dade County, NOAA, \& NACO, 2011). In cases of evacuation, the patterns of food demand will shift, rendering normal distribution pathways insufficient (McKeown, 2013a; UN-Habitat, 2011). On a related note, food distributed during an emergency may not meet the needs of residents with special dietary requirements (Bonini, 2014).

Electricity is another critical infrastructure network, required for cold storage and various other food business needs, including lights, inventory equipment, and electronic payment systems (City of Greater Sudbury, n.d.(d); City of New York, 2013a; King County, 2013b; King County OEM, 2015a; Seattle OEM, 2014). If electrical outages interfere with refrigeration and freezing, food will spoil, possibly resulting in illnesses. ${ }^{19}$ Because the energy requirements of cooling food are high, backup power systems at retail outlets may not be tied into refrigeration systems (City of New York, 2013a). Power failures may also prevent proper treatment of potable water, which is used for drinking and cooking (City of New Orleans,

\footnotetext{
18 City of Toronto Environment Office, City of Toronto Climate Adaptation Steering Group, \& Clean Air Partnership, 2008; City of Vancouver, 2012b; Northwest Hydraulic Consultants, 2014

19 City of New York, n.d.; City of New York, 2013a; City of New York MOLTPS \& NYSDAM, 2014; Margolies, 2014; McKeown, 2013a; McKeown, 2015; New York City Economic Development Corporation, 2014; Pinto, Penney, Ligeti, Gower, \& Mee, 2011; Scioli, 2013
} 
2015c). Electrical appliances for food preparation will also be useless (City of New York, 2013a; New York City Economic Development Corporation, 2014).

Electric power is required to operate transportation assets, including traffic signals, transit lines, and fueling stations (City of New York, 2013a; Seattle OEM, 2014; Washington State Homeland Security Region 6, 2005). When unavailable, it can disrupt telecommunications equipment, which is also vulnerable to climate-related impacts like high winds and floodwaters (City of New York, 2013a). As Iqaluit noted, telecommunications service is necessary for phone and internet service, commercial transactions, cable television, flight control, and emergency response (City of Iqaluit, 2014b). If households and businesses manage outages by employing backup power generators, they will require access to liquid fuels, which also power automobiles and other modes of transport. ${ }^{20}$ Natural gas supplies may be necessary for cooking and for sterilizing food handling equipment (Washington State Homeland Security Region 6, 2005). Even consumers growing vegetables in their backyard may depend on infrastructure to deliver water.

\subsubsection{CONSUMER ACCESS}

Investigations into food insecurity reveal that existing supply chains fall short in comparison to need: Some communities lack access to full service grocers and other outlets selling fresh, healthy products; some households lack the financial resources required to purchase nutritious options; and some individuals face mobility challenges that constrain travel or special dietary requirements that are difficult to satisfy. ${ }^{21}$ Other barriers to food

\footnotetext{
20 City of New York, 2013a; City of Vancouver, 2012a; City of Vancouver, 2013b; City of Vancouver Social Policy and Projects, 2015; Fortin \& Gionet, 2012; Toronto Hydro Electric System Limited \& City of Toronto OEM, 2015; Vasseur, 2007; Washington State Homeland Security Region 6, 2005

21 Bates, 2014; City of Greater Sudbury, n.d.(b); City of Iqaluit, 2012; City of Iqaluit, 2014b; City of New Orleans, 2015a; City of New Orleans, 2015b; City of New Orleans, 2015c; City of New York, 2013a; City of New York, 2015; City of Toronto Public Health, 2008; City of Toronto Public Health, 2010; City of Toronto Public Health, 2015d; City of Vancouver, 2013b; City of Vancouver Social Policy and Projects, 2015; Eegeesiak, 2015a; Fit NOLA, 2015; Food and Urban Agriculture Advisory Committee, 2012; FoodShare, n.d.; Foodshed Project \& Sudbury-Manitoulin FSN, 2007a; Foodshed Project \& Sudbury-Manitoulin FSN, 2007b; Halifax Food Policy Alliance, 2015; Johnson \& Cain, 2015; Jones, Ona, Rimkus, \& Wells, 2005; King County, 2015a; King County Farms and Food Roundtable, Staff Team Members, \& Cedar River Group, 2014; Lerman, Haima, \& Mehus-Roe, 2012; Miami-Dade County, 2010; New
} 
access include fluctuations in charitable giving, limits in institutional capacities, and criminal activity, which discourages business investment and resident travel. ${ }^{22}$ Within households, there may not be sufficient space to store and prepare food (City of Vancouver Social Policy and Projects, 2015).

Climate change impacts can exacerbate these barriers. Flooding and power outages may reduce the supply of functional retailers, requiring consumers to travel farther during a period when transportation systems like subways and streetcars may not be operational (City of New York, 2013a; Wolff \& Comerford, 2014). New York noted that institutional food providers may be vulnerable to disasters, while King County observed that many households have not stored food and water for emergencies (City of New York, 2013a; King County OEM, 2013c). Declining food skills mean that many residents may lack knowledge on simple food processing and preparation methods, which may be valuable in times of crisis or displacement. ${ }^{23}$ Casualties and chaos during a crisis will compound many of these challenges.

\subsection{RESPONSES}

While tables A.1 through A.11 also code the reviewed cities' responses by phase(s) of the food supply chain, a more useful categorization scheme emerged from review of the data in its entirety. Collectively, the responses appear to fall into five general strategies for increasing the resilience of food supply chains. These strategies, summarized below in Table 4.4, are common to resilience and food security work, though they may not be explicitly referenced in plans and policies.

Orleans Food Policy Advisory Committee, 2008; New York City Economic Development Corporation, 2014; Nunavut Food Security Coalition, 2014; Parent \& Barthé-Prevost, 2015; San Francisco Department of Public Health, n.d.(b); Social Compact Inc., 2007; Social Compact Inc., 2009; Wolff \& Comerford, 2014; Young, Karpyn, \& Treering, 2012

22 Barron et al., 2010; City of New Orleans, 2015a; City of New Orleans, 2015c; Fit NOLA, 2015; New Orleans Food Policy Advisory Committee, 2008; Parent \& Barthé-Prevost, 2015

23 City of Toronto Public Health, 2008; City of Toronto Public Health, 2010; City of Vancouver Social Policy and Projects, 2015; Food and Urban Agriculture Advisory Committee, 2012; Halifax Food Policy Alliance, 2015;

Kamizaki, 2014; Nunavut Food Security Coalition, 2014 


\begin{tabular}{|c|c|}
\hline A - Identify assets, opportunities, needs, and risks & $\begin{array}{l}\text { Efforts to obtain information essential to the pursuit of } \\
\text { specific adaptation activities. Generally a prerequisite } \\
\text { to actions falling under strategies B-E. }\end{array}$ \\
\hline B - Adapt processes, structures, and infrastructure & $\begin{array}{l}\text { Efforts to strengthen assets and systems to better } \\
\text { resist or recover from the impacts of climate change. }\end{array}$ \\
\hline C - Increase regional self-sufficiency in food and water & $\begin{array}{l}\text { Actions that re-localize all aspects of a food system in } \\
\text { order to decrease or eliminate reliance on imports. }\end{array}$ \\
\hline$D$ - Create redundancies and alternatives & $\begin{array}{l}\text { Ensures that critical functions can or do occur in more } \\
\text { than one location and that backups are available in the } \\
\text { event of a disaster (Cutter et al., 2008; Joakim, } \\
\text { Mortsch, \& Oulahen, 2015; Macht, 2015; Matheny \& } \\
\text { Homewood, 2015). }\end{array}$ \\
\hline E - Improve consumer access & $\begin{array}{l}\text { Actions taken to ensure that residents can find and } \\
\text { obtain food and water in ordinary circumstances and } \\
\text { during a crisis. }\end{array}$ \\
\hline
\end{tabular}

Table 4.4. Five strategies for increasing resilience that emerged from the cities' collective responses.

As the reader may observe, the boundaries between these strategies are not distinct; many of the collected responses contribute to more than one strategy. Strategies B and D are particularly prone to overlap, given that the creation of redundancies and alternatives is a very useful technique for hardening assets and systems against failure. While I have attempted to minimize repetition in the following summary of responses, the emergence of strategies with some degree of coincidence ensures that some redundancy is inevitable.

\subsubsection{RESILIENCE STRATEGY A - IDENTIFY ASSETS, OPPORTUNITIES, NEEDS, AND RISKS}

As might be expected, any effort to boost the resilience of food supply chains must begin with a thorough study of the food system and its components. A few of the studied cities benefit from outlines, descriptions, or diagrams of their food systems, sometimes identifying key assets and agents (e.g. wholesale and distribution centers, food processors, and retail outlets). ${ }^{24}$ Modes of shipping and distribution may be identified, along with

\footnotetext{
24 Barron et al., 2010; City of Greater Sudbury, n.d.(c); City of Edmonton, 2010; City of New York, n.d.; City of New York, 2013a; City of New York, 2013b; City of Toronto Public Health, 2008; City of Toronto Public Health, 2010; City of Vancouver, 2013b; Food and Urban Agriculture Advisory Committee, 2012; Foodshed Project \& Sudbury-Manitoulin FSN, 2007a; Greater Sudbury Climate Change Consortium, 2011; Jones, 2010; Jones, Ona, Rimkus, \& Wells, 2005; Kamizaki, 2014; Lister, 2007; New York City Economic Development Corporation, 2014
} 
quantities of product transported (Barron et al., 2010; City of New York, n.d.; City of New York, 2013a; City of New York, 2013b; New York City Economic Development Corporation, 2014; Nunavut Food Security Coalition, 2014). A study solicited by New York even discusses expected future changes to the city's food supply chains (Barron et al., 2010).

By identifying local assets, cities know what to protect from shocks (Strategy $B$ ) and what resources are available to contribute to greater self-sufficiency (Strategy C). Useful information includes inventories of agricultural lands, aquaculture assets, fisheries, and food processing facilities. ${ }^{25}$ This includes assessments of places where food can be grown locally (e.g. unused urban plots) and statistics on the types and quantities of food currently produced and processed in the region. ${ }^{26}$ Halifax, for example, possesses detailed statistics on farms and other producers, while Greater Sudbury enjoys a comprehensive profile of agricultural activity in the greater region (Halifax Food Policy Alliance, 2015; Harry Cummings and Associates Inc., 2009).

Research has also been conducted on imports, including type, quantity, and source. ${ }^{27}$ As Barron et al. (2010) note, however, determining food origins can be challenging because products aren't necessarily tracked from source to sale. Edmonton discusses what types of food are produced within the province and what types of food, due to climate considerations, must be imported from elsewhere (City of Edmonton, 2011). As noted in the section on

25 Campbell, 2014; City of Greater Sudbury, n.d.(c); City of Greater Sudbury, 2004; City of New Orleans OHSEP et al., 2011; Dillon Consulting, de Romilly and de Romilly Ltd., \& ClimAdapt., 2007; EarthCare Sudbury, 2015; Foodshed Project \& Sudbury-Manitoulin FSN, 2007a; Greater Sudbury Climate Change Consortium, 2011; Harry Cummings and Associates Inc., 2009; King County, 2015a; King County \& King County Agricultural Commission, 2009; King County Farms and Food Roundtable, Staff Team Members, \& Cedar River Group, 2014; Miami-Dade County, NOAA, \& NACO, 2011; Uens, 2014

26 City of Greater Sudbury, 2004; City of Toronto Public Health, 2015b; City of Vancouver, 2013b; City of Vancouver Social Policy and Projects, 2015; Consortium for a Healthier Miami-Dade, 2011; Foodshed Project \& Sudbury-Manitoulin FSN, 2007a; Halifax Food Policy Alliance, 2015; Harry Cummings and Associates Inc., 2009; Jones, Ona, Rimkus, \& Wells, 2005; King County, 2015a; King County \& King County Agricultural Commission, 2009; King County Farms and Food Roundtable, Staff Team Members, \& Cedar River Group, 2014; Lerman, Haima, \& Mehus-Roe, 2012; Lister, 2007; Local Food Assets Task Force, 2013; Miami-Dade County, 2010; Miami-Dade County, 2015; Randall, 2010; Southeast Florida Regional Compact, 2012; Toronto Food Policy Council, 1999b; Young, Karpyn, \& Treering, 2012

27 City of Edmonton, 2011; Foodshed Project \& Sudbury-Manitoulin FSN, 2007a; Kubursi, Cummings, MacRae, \& Kanaroglou, 2015; Lipton, 2010; Toronto Food Policy Council, 1999b; Vasseur, 2007 
vulnerabilities, many cities recognize that climate change will threaten food imports. Adapting to that reality will require knowledge on local capacities and local dependence. In MiamiDade County, there is also data on how much food is exported, which represents local resources devoted to serving non-local needs (Miami-Dade County, 2010).

A few cities also benefit from efforts to identify distribution, wholesaling, and food storage infrastructure. ${ }^{28}$ Some have inventoried food retailers, restaurants, and other assets, including charitable food providers, community kitchens, and public benefit programs. ${ }^{29}$ Such inventories are vital to one of the most common undertakings observed in municipal food policy work: mapping inequities in the spatial distribution of full service grocery stores and other retail outlets selling fresh and nutritious food. ${ }^{30}$ After locating food deserts and food swamps, public officials can devise strategies for improving consumer access (Strategy $E$ ).

San Francisco enjoys a particularly comprehensive assessment of variations in residential access to food outlets and community gardens, incorporating statistics on poverty, benefit programs, and access to a vehicle (Jones, Ona, Rimkus, \& Wells, 2005). Miami-Dade County benefits from a report identifying communities where diet-related deaths are prevalent, indicating probable gaps in access to healthy food (Young, Karpyn, \& Treering, 2012). The City of Miami surveyed residents to determine where new groceries are needed and employed market data to identify viable sites for new outlets (Social Compact Inc., 2007; Social Compact Inc., 2009). King County measured another aspect of access by identifying isolated communities that may be inaccessible during a crisis (King County OEM, 2015b).

\footnotetext{
28 City of Miami DCED, 2014; Halifax Food Policy Alliance, 2015; Jones, Ona, Rimkus, \& Wells, 2005; King County, 2015a; Seattle OEM, 2012; Seattle OEM, 2015

29 Barron et al., 2010; Campbell, 2014; City of Vancouver, 2013b; City of Vancouver Social Policy and Projects, 2015; EarthCare Sudbury, 2015; Foodshed Project \& Sudbury and Area FSN, 2004; Foodshed Project \& SudburyManitoulin FSN, 2007a; Halifax Food Policy Alliance, 2015; Jones, Ona, Rimkus, \& Wells, 2005; King County, 2015a; Local Food Assets Task Force, 2013; Seattle OEM, 2012; Seattle OEM, 2015; Sudbury and District Health Unit, 2015

30 City of New York Department of City Planning, 2014a; City of Toronto Public Health, 2010; City of Toronto Public Health, 2015d; Fit NOLA, 2015; Johnson \& Cain, 2015; Jones, Ona, Rimkus, \& Wells, 2005; Kamizaki, 2014; Lister, 2007; Miami-Dade County, 2010; New Orleans Food Policy Advisory Committee, 2008; Parent \& Barthé-Prevost, 2015; San Francisco Department of Public Health, n.d.(b); Social Compact Inc., 2007; Social Compact Inc., 2009; Wolff \& Comerford, 2014; Young, Karpyn, \& Treering, 2012
} 
Transportation often plays a role in food access, which is why Sudbury has catalogued grocery van services and meal delivery resources (Sudbury and District Health Unit, 2015). Much of the food-related transportation work documented for the selected cities, however, concerns shipping, distribution, and emergency preparedness. New Orleans, for instance, inventories major transportation assets and identifies major routes for people and freight (City of New Orleans OHSEP et al., 2011). Miami-Dade County conducts freight planning and maps major freight hubs like seaports and airports. ${ }^{31}$ Seattle and King County have identified key infrastructure assets and plan for detours that may be necessary in a crisis (City of Seattle, 2009; GGLO Design, 2012; King County \& KCIT DNRP GIS, 2015; Seattle Department of Transportation, n.d.; Seattle OEM, 2015). Each of these efforts contributes to resiliencebuilding by identifying assets critical to the movement of food that may be threatened by climate-related impacts.

There are many examples of efforts to map risks and identify local assets vulnerable to specific hazards, especially sea level rise. ${ }^{32}$ A report for Seattle by GGLO Design (2015) provides detailed maps illustrating the homes, businesses, industries, and transportation assets (including bus stops!) threatened by flooding due to a combination of expected sea level rise and high tides or storm surges. Halifax has access to maps of farmland at risk from inundation and New Orleans has estimates of potential crop losses (City of New Orleans OHSEP et al., 2011; Dillon Consulting, de Romilly and de Romilly Ltd., \& ClimAdapt., 2007). The Orleans Parish 2010 Hazard Mitigation Plan Update, which draws upon knowledge obtained from previous crises, also identifies sources of hazardous materials whose release could threaten people and property (City of New Orleans OHSEP et al., 2011).

\footnotetext{
31 Florida Department of Transportation, 2013; Miami-Dade County, 2010; Miami-Dade MPO \& Gannett Fleming, 2009; Parsons Brinkerhoff, Cambridge Systematics, Inc., \& Quest Corporation of America, 2014

32 City of New Orleans, 2015c; City of New Orleans OHSEP et al., 2011; City of Seattle, 2009; Climate Change Advisory Task Force, 2010; Dillon Consulting, de Romilly and de Romilly Ltd., \& ClimAdapt., 2007; GGLO Design, 2012; GGLO Design, 2013; GGLO Design, 2015; King County OEM, 2013a; King County \& KCIT DNRP GIS, 2015; King County Farms and Food Roundtable, Staff Team Members, \& Cedar River Group, 2014; Miami-Dade County, 2010; Rossini, 2014; Seattle Department of Transportation, n.d.; Seattle OEM, 2015; Southeast Florida Regional Compact, 2012; Wastewater Treatment Division, 2015
} 
Most useful is research assessing vulnerabilities and resilience with regard to buildings and infrastructure specifically related to the proper functioning of food supply chains. Edmonton has examined the resiliency of its food system, as has New York, whose efforts are particularly comprehensive (City of Edmonton, 2011; City of New York, 2013a). To date, New York has identified supply routes, wholesaling and distribution assets, and food outlets at risk - and identified potential equity implications (Barron et al., 2010; City of New York, 2013a; City of New York, 2014; City of New York, 2015; Margolies, 2014; New York City Economic Development Corporation, 2014). New York is also soliciting a study that will specifically address food supply chain resilience (City of New York, n.d.; New York City Economic Development Corporation, 2014).

Efforts to adapt food supply chains to threats like climate change must also consider existing shortcomings and potential restraints. Several cities possess information on food insecurity, including where it occurs and who is impacted; also relevant are statistics quantifying dependence on direct provision and other food aid programs. ${ }^{33}$ Particularly pertinent to the issue of food security is cost. Consequently, some cities assess the cost of groceries needed for maintaining a healthy diet. ${ }^{34}$ Toronto provides an online tool - the "Nutritious Food Basket" - that estimates the cost of groceries based on the demographic characteristics of a household (City of Toronto Public Health, 2015c).

Estimating a city's aggregate needs - which may be possible in the US using federal statistics - can inform efforts to increase regional self-sufficiency (Strategy C) (Barron et al., 2010). King County has compared total local production to total local demand for each food

\footnotetext{
33 City of Edmonton, 2011; City of Greater Sudbury, n.d.(b); City of Iqaluit, 2014a; City of Toronto Public Health, 2008; City of Vancouver Social Policy and Projects, 2015; Foodshed Project \& Sudbury-Manitoulin FSN, 2007a; Foodshed Project \& Sudbury-Manitoulin FSN, 2007b; Greater Sudbury Food Policy Council, 2014b; Halifax Food Policy Alliance, 2015; Jones, Ona, Rimkus, \& Wells, 2005; Kamizaki, 2014; King County, 2015a; Lerman, Haima, \& Mehus-Roe, 2012; Lin-Conrad, Jones, O'Farrell, \& Ferreira, 2009; Lipton, 2010; Lister, 2007

34 City of Toronto Public Health, 2015c; City of Vancouver Social Policy and Projects, 2015; Foodshed Project \& Sudbury-Manitoulin FSN, 2007a; Foodshed Project \& Sudbury-Manitoulin FSN, 2007b; Halifax Food Policy Alliance, 2015; Nunavut Food Security Coalition, 2014; OMAFRA, CSCA, \& Ryerson University, 2010; Sudbury and District Health Unit, 2015
} 
group, which helps illustrate the extent of its regional self-sufficiency (King County \& King County Agricultural Commission, 2009; King County Farms and Food Roundtable, Staff Team Members, \& Cedar River Group, 2014). Greater Sudbury knows that local production is minuscule compared to local demand (Keown, 2015; Stricker, 2013). It also knows - as does Toronto - that its existing stocks of fresh food will only last three days in the absence of fresh deliveries (City of Toronto Public Health, 2008; Toronto Food Policy Council, 1999b; Vasseur, 2007). The brevity of that period underscores the importance of resisting and recovering from short-term disruptions to the regular transport and distribution of food.

In addition to existing research for plans and policies, many of the studied cities also use (or expect to use) indicators to track conditions over time and assess progress toward environmental and food policy objectives. ${ }^{35}$ In some cases, additional research is planned but has not yet been conducted. Vancouver and Nunavut, for example, intend to investigate potential improvements to the food distribution system (City of Vancouver, 2013b; Nunavut Food Security Coalition, 2014). Continuing research on the risks of climate change and the structure of food supply chains will be useful to planners and policymakers promoting greater resilience.

\subsubsection{RESILIENCE STRATEGY B - ADAPT PROCESSES, STRUCTURES, AND INFRASTRUCTURE}

To address identified threats, climate adaptation and risk management plans from the studied cities recommended upgrades to buildings and infrastructure, improvements to stormwater management, and measures to mitigate flooding and other hazards. ${ }^{36}$ To

\footnotetext{
35 City of Greater Sudbury, n.d.(e); City of New Orleans OHSEP et al., 2011; City of New York, 2013b; City of Vancouver, 2012a; City of Vancouver, 2013a; City of Vancouver, 2013b; City of Vancouver Social Policy and Projects, 2015; Food and Urban Agriculture Advisory Committee, 2012; Foodshed Project \& Sudbury-Manitoulin FSN, 2007a; Foodshed Project \& Sudbury-Manitoulin FSN, 2007b; Halifax Food Policy Alliance, 2015; King County DNRP, n.d.(b); Miami-Dade County, 2010

36 Barron et al., 2010; City of Iqaluit, 2014b; City of New Orleans, 2015a; City of New Orleans, 2015b; City of New Orleans, 2015c; City of New Orleans OHSEP et al., 2011; City of New York, 2013a; City of New York, 2015; City of Seattle, 2009; City of Toronto Environment Office, 2011; City of Toronto Environment Office, City of Toronto Climate Adaptation Steering Group, \& Clean Air Partnership, 2008; City of Vancouver, 2012a; Climate Change Advisory Task Force, 2010; Dillon Consulting, de Romilly and de Romilly Ltd., \& ClimAdapt., 2007; EarthCare Sudbury, 2008; EarthCare Sudbury, 2010; GGLO Design, 2012; GGLO Design, 2013; GGLO Design, 2015; Goody
} 
strengthen buildings, recommendations included updates to codes, incentives for resilience projects, and elevation above expected floodwaters. ${ }^{37}$ In some cases, relocation to safer areas may be appropriate. ${ }^{38}$ New York, which noted the stellar performance of the wellprepared Shorefront Center for Rehabilitation and Nursing Care during Hurricane Sandy, recommends elevating backup generators and electrical equipment in buildings at risk of flooding (City of New York, 2013a).

In New Orleans, where protective coastal wetlands are disappearing at a rapid rate, initiatives to protect and restore green infrastructure will complement improvements in grey infrastructure (City of New Orleans OHSEP et al., 2011). Miami-Dade County will benefit from programs to plant and protect trees, noting that their canopies can mitigate strong hurricane winds (Miami-Dade County, 2010). Environmental remediation can reduce risk by removing or securely confining hazardous substances that could otherwise contaminate wider areas if carried away by floodwaters (City of New Orleans OHSEP et al., 2011). Operating industrial facilities must also secure pipelines and storage tanks, as evidenced by the hundreds of oil spills caused by Katrina-related flooding (ibid.).

With regard to transportation infrastructure, freight planning and traffic management present opportunities to reduce delays that could affect food distribution. ${ }^{39}$ Investments in information technology can enable better freight management in the wake of a catastrophe

\footnotetext{
Clancy et al., 2013; King County \& KCIT DNRP GIS, 2015; King County DNRP, n.d.(b); King County Farms and Food Roundtable, Staff Team Members, \& Cedar River Group, 2014; King County OEM, 2013a; Lewis \& Miller, 2010; Miami-Dade County, 2010; Miami-Dade County, 2011; New York City Economic Development Corporation, 2014; NOCSF \& CSO, 2014; Resilient Miami, Kresge Foundation, Catalyst Miami, \& Urban Impact Lab, 2015; Rossini, 2014; Ruvin et al., 2014; Scioli, 2013; Seattle Department of Transportation, n.d.; Seattle OEM, 2015; Seijas, Torriente, \& Hefty, 2010; Southeast Florida Regional Compact, 2012; Vasseur, 2007; Wastewater Treatment Division, 2015

37 City of New Orleans, 2015b; City of New Orleans, 2015c; City of New Orleans OHSEP et al., 2011; GGLO Design, 2012; GGLO Design, 2013; Goody Clancy et al., 2013; King County \& KCIT DNRP GIS, 2015; King County DNRP, n.d.(b); NOCSF \& CSO, 2014

38 City of New Orleans OHSEP et al., 2011; GGLO Design, 2012; GGLO Design, 2013; King County \& KCIT DNRP GIS, 2015; King County DNRP, n.d.(b); NOCSF \& CSO, 2014

39 City of Seattle, 2009; City of Vancouver, 2012b; Florida Department of Transportation, 2013; GGLO Design, 2012; GGLO Design, 2013; King County \& KCIT DNRP GIS, 2015; Mazzella \& Pascal, 2014a; Mazzella \& Pascal, 2014b; Miami-Dade County, 2010; Miami-Dade MPO \& Gannett Fleming, 2009; NOCSF \& CSO, 2014; Parsons Brinkerhoff, Cambridge Systematics, Inc., \& Quest Corporation of America, 2014; Seattle Department of Transportation, n.d.; Seattle OEM, 2015; Southeast Florida Regional Compact, 2012
} 
(Parsons Brinkerhoff, Cambridge Systematics, Inc., \& Quest Corporation of America, 2014; Southeast Florida Regional Compact, 2012). Strategies noted by or pitched to New York include collaboration with wholesalers to identify alternate modes of shipping, exemptions from traffic restrictions for trucks hauling food products, and improvements to truck unloading at neighborhood retailers (Barron et al., 2010; City of New York, 2013a). Both New York and Vancouver intend to improve the availability of liquid fuels during a crisis (City of New York, 2013a; City of Vancouver, 2012a).

Because so much of a city's form and function is controlled by private interests, it is critical to engage non-municipal actors in resilience initiatives. In addition to the strategies mentioned above (e.g. tougher building codes, incentives for flood-proofing, etc.), methods for promoting resilience collected from the reviewed cities include educational campaigns, training programs, and advice on emergency preparation and response. ${ }^{40}$ King County, for instance, operates an informational website on crisis management, and many cities offer guidelines on food and water safety, discussing the risks associated with power outages. ${ }^{41}$ This knowledge can assist residents and food-related businesses in adapting facilities and operations to manage changing conditions and climate-related hazards.

While many institutions already consider the issues of food safety and food supply in their crisis plans, cities can collaborate with NGOs and other meal providers to ensure that their operations are resilient (Halifax Food Policy Alliance, 2015; Rapp, 2014). After studying

\footnotetext{
40 City of Miami Emergency Management, 2015; City of New Orleans, 2015b; City of New Orleans, 2015c; City of New Orleans OHSEP et al., 2011; City of New York, n.d.; City of New York, 2013a; City of New York, 2014; City of New York, 2015; City of New York Department of City Planning, 2014b; City of New York MOLTPS \& NYSDAM, 2014; City of Toronto Environment Office, City of Toronto Climate Adaptation Steering Group, \& Clean Air Partnership, 2008; City of Toronto Fire Services, n.d.; City of Toronto OEM, 2015a; City of Toronto OEM, 2015c; City of Vancouver, 2012a; Dillon Consulting, de Romilly and de Romilly Ltd., \& ClimAdapt., 2007; Goody Clancy et al., 2013; Halifax Food Policy Alliance, 2015; Halifax Regional Municipality, 2010; King County, 2015c; King County \& KCIT DNRP GIS, 2015; King County DNRP, n.d.(b); Pinto, Penney, Ligeti, Gower, \& Mee, 2011; Rossini, 2014; San Francisco Department of Public Health, n.d.(a); Scioli, 2013; Southeast Florida Regional Compact, 2012; Toronto Food Policy Council, 2015; Toronto Hydro Electric System Limited \& City of Toronto OEM, 2015

41 City of Toronto Environment Office, City of Toronto Climate Adaptation Steering Group, \& Clean Air Partnership, 2008; City of Toronto Fire Services, n.d.; City of Toronto OEM, 2015a; Pinto, Penney, Ligeti, Gower, \& Mee, 2011; San Francisco Department of Public Health, n.d.(a); Seattle \& King County Public Health, 2016; Toronto Food Policy Council, 2015; Toronto Hydro Electric System Limited \& City of Toronto OEM, 2015
} 
the community food sector in part of Toronto, Kamizaki (2014) recommended collaboration among providers to cross-train staff and pool information to improve operations. Certainly emergency preparedness and resiliency could be a part of those discussions. New York recommends collaborating with private industry and nearby municipalities to harden key points in the food supply chains serving the city (City of New York, 2013a).

New York also devised several specific proposals for increasing the resilience of various actors at different points in the chain. The city will make and promote investments to ensure continuous power supply and greater resilience at its major wholesaling and distribution hub (Barron et al., 2010; City of New York, 2013a). It will incentivize private investments in emergency preparedness by favoring resilient distributors during the procurement process (City of New York, n.d.; City of New York, 2013a; City of New York, 2014; Margolies, 2014). The city intends to push for new legislation requiring partial backup power at food retailers (as does Toronto) (City of New York, 2013a; City of Toronto, 2013). And New York has published preparedness advice for food retailers offering recommendations on the proper arrangement of foods to prevent contamination and spoilage (City of New York, n.d.; City of New York MOLTPS \& NYSDAM, 2014).

Other reviewed cities present responses more appropriate to the production end of food supply chains. In Nunavut, where climate change has the potential to reduce access to "country food," harvesting may be adapted to ensure the long-term survival of preferred species (Nunavut Food Security Coalition, 2014). In regions where the climate is favorable to agriculture, research will be necessary to maintain yields despite changing conditions. ${ }^{42}$ Preserving fertile lands and adopting sustainable agricultural practices can contribute to continued productivity (City of Greater Sudbury, n.d.(e); City of Greater Sudbury, 2004; EarthCare Sudbury, 2010; Foodshed Project \& Sudbury and Area FSN, 2004). There may

\footnotetext{
42 EarthCare Sudbury, 2010; Foodshed Project \& Sudbury-Manitoulin FSN, 2007a; Foodshed Project \& SudburyManitoulin FSN, 2007b; Harry Cummings and Associates Inc., 2009; King County \& King County Agricultural Commission, 2009; Miami-Dade County Climate Change Advisory Task Force, 2008; Southeast Florida Regional Compact, 2012
} 
also be a role for vaccines and pesticides to control livestock diseases and crop pests, which may spread as conditions change to favor previously absent vectors (King County OEM, 2013c).

\subsubsection{RESILIENCE STRATEGY C - INCREASE REGIONAL SELF-SUFFICIENCY IN FOOD AND WATER}

Regional self-sufficiency entails the successful operation of all phases of a food supply chain without relying upon external inputs. While complete self-sufficiency is impractical or impossible for many regions, cities can act to increase the ratio of local production to local demand while simultaneously expanding intraregional supply and distribution networks that permit reduced reliance on extra-regional food sources (and outside aid during emergencies). ${ }^{43}$

Several reviewed cities promoted greater regional self-sufficiency by expanding farmland and protecting fish habitat. ${ }^{44}$ In Iqaluit, investments in a greenhouse and a bridge will increase planting and harvesting capacity (Eegeesiak, 2015a). Numerous cities recommended urban agriculture, including private gardens, community plots, orchards, and edible landscaping. ${ }^{45}$ Other possibilities included hunting, fishing, foraging, and chickenkeeping (King County, 2015a; Lerman, Haima, \& Mehus-Roe, 2012).

43 City of Vancouver, 2013b; Foodshed Project, 2009; Foodshed Project \& Sudbury-Manitoulin FSN, 2007a; Foodshed Project \& Sudbury-Manitoulin FSN, 2007b; Halifax Food Policy Alliance, 2015; Tomalty \& Komorowski, 2011

44 City of Edmonton, 2011; City of Vancouver, 2013b; Food and Urban Agriculture Advisory Committee, 2012; GGLO Design, 2013; Halifax Food Policy Alliance, 2015; King County, 2015a; King County \& KCIT DNRP GIS, 2015; King County \& King County Agricultural Commission, 2009; King County - Cities Climate Collaboration, 2015; King County DNRP, n.d.(a); King County Farms and Food Roundtable, Staff Team Members, \& Cedar River Group, 2014; Lerman, Haima, \& Mehus-Roe, 2012; Lipton, 2010; Miami-Dade County Climate Change Advisory Task Force, 2008; Newsom, 2009; Southeast Florida Regional Compact, 2012

45 Bates, 2014; City of Edmonton, 2010; City of New York, 2013b; City of New York, 2015; City of Toronto Public Health, 2010; City of Toronto Public Health, 2015b; City of Vancouver, 2012b; City of Vancouver, 2013a; City of Vancouver, 2013b; City of Vancouver Social Policy and Projects, 2015; Consortium for a Healthier Miami-Dade, 2011; Food and Urban Agriculture Advisory Committee, 2012; GGLO Design, 2013; Halifax Food Policy Alliance, 2015; Johnson \& Cain, 2015; Jones, 2010; Kamizaki, 2014; King County, 2015a; King County - Cities Climate Collaboration, 2015; King County Farms and Food Roundtable, Staff Team Members, \& Cedar River Group, 2014; Lerman, Haima, \& Mehus-Roe, 2012; Lister, 2007; Local Food Assets Task Force, 2013; Miami-Dade County, 2010; Miami-Dade County, 2015; New Orleans Food Policy Advisory Committee, 2008; New Orleans Food Policy Advisory Committee, 2015; Newsom, 2009; San Francisco Department of the Environment, 2013; Southeast Florida Regional Compact, 2012; Toronto Food Policy Council, 1999b; Young, Karpyn, \& Treering, 2012 
Recommendations for promoting local food production and processing include recruitment programs, training initiatives, information-sharing, food-related economic development, incentives, and investments in food storage capacity. ${ }^{46}$ Further, efforts to expand the local aggregation, processing, and distribution subsectors will assist producers and could contribute to re-localizing a regional food system. ${ }^{47}$

Self-sufficiency requires that food produced within a region can reach local markets. Consequently, many of the reviewed cities recommended initiatives to link local producers to local consumers, including new food hubs and food terminals, farmers' and harvesters' markets, business incubators, marketing promotions, and changes in institutional procurement policies. ${ }^{48}$ Other strategies include prioritizing local markets over exports and growing products locally that are typically imported (Eegeesiak, 2015a; Lister, 2007; McKeown, 2013b; Toronto Food Policy Council, 2015).

\footnotetext{
46 Barron et al., 2010; Bates, 2014; Campbell, 2014; City of Edmonton, 2010; City of Edmonton, 2011; City of Iqaluit, 2012; City of Iqaluit, 2014b; City of Miami DCED, 2014; City of New York, 2013b; City of Toronto Public Health, 2015a; City of Toronto Public Health, 2015b; City of Toronto Public Health, 2015d; City of Vancouver, 2013b; Consortium for a Healthier Miami-Dade, 2011; EarthCare Sudbury, 2008; EarthCare Sudbury, 2010; Eegeesiak, 2015a; Eegeesiak, 2015b; Food and Urban Agriculture Advisory Committee, 2012; Foodshed Project \& Sudbury and Area FSN, 2004; Foodshed Project \& Sudbury-Manitoulin FSN, 2007a; Gagnon \& King, 2015; Greater Sudbury Food Policy Council, 2014a; Halifax Food Policy Alliance, 2015; Halifax Regional Municipality, 2015; Jones, 2010; King County, 2015a; King County \& King County Agricultural Commission, 2009; King County Farms and Food Roundtable, Staff Team Members, \& Cedar River Group, 2014; Lerman, Haima, \& Mehus-Roe, 2012; Local Food Assets Task Force, 2013; Miami-Dade County, 2010; Miami-Dade County, 2015; Newsom, 2009; Nunavut Food Security Coalition, 2014; Pinto, Penney, Ligeti, Gower, \& Mee, 2011; Randall, 2010; Southeast Florida Regional Compact, 2012; Sudbury and District Health Unit, 2015; Toronto Food Policy Council, 1999b; Young, Karpyn, \& Treering, 2012

47 King County, 2015a; King County \& King County Agricultural Commission, 2009; King County Farms and Food Roundtable, Staff Team Members, \& Cedar River Group, 2014; Lerman, Haima, \& Mehus-Roe, 2012;

Morgenstern, 2013

48 Barron et al., 2010; Campbell, 2014; City of Greater Sudbury, n.d.(c); City of Iqaluit, 2014b; City of New York, 2013b; City of New York, 2015; City of Toronto Environment Office, City of Toronto Climate Adaptation Steering Group, \& Clean Air Partnership, 2008; City of Toronto Public Health, 2010; City of Toronto Public Health, 2015a; City of Toronto Public Health, 2015d; City of Toronto Purchasing and Materials Management Division, 2013; City of Vancouver, 2012b; City of Vancouver, 2013a; City of Vancouver, 2013b; Consortium for a Healthier Miami-Dade, 2011; EarthCare Sudbury, 2008; EarthCare Sudbury, 2010; Eegeesiak, 2015a; Food and Urban Agriculture Advisory Committee, 2012; Foodshed Project \& Sudbury and Area FSN, 2004; Foodshed Project \& SudburyManitoulin FSN, 2007a; Foodshed Project \& Sudbury-Manitoulin FSN, 2007b; Gagnon \& King, 2015; Greater Sudbury Food Policy Council, 2014a; Halifax Food Policy Alliance, 2015; Harry Cummings and Associates Inc., 2009; Johnson \& Cain, 2015; Jones, 2010; Kamizaki, 2014; King County, 2015a; King County, 2015b; King County, 2015e; King County - Cities Climate Collaboration, 2015; King County \& King County Agricultural Commission, 2009; King County Farms and Food Roundtable, Staff Team Members, \& Cedar River Group, 2014; King County DNRP, n.d.(a); Lerman, Haima, \& Mehus-Roe, 2012; Lipton, 2010; Local Food Assets Task Force, 2013; Miami-Dade County, 2010; New Orleans Food Policy Advisory Committee, n.d.; New Orleans Food Policy Advisory Committee, 2008; New Orleans Food Policy Advisory Committee \& Market Umbrella, 2015; Newsom, 2009; Nunavut Food Security Coalition, 2014; Seattle \& King County Public Health, 2015b; Southeast Florida Regional Compact, 2012; Sudbury and District Health Unit, 2015; Uens, 2014; Young, Karpyn, \& Treering, 2012
} 
Greater self-sufficiency can also be achieved by ensuring that inputs into food production and consumption can be supplied locally. Responding to climate-related threats to water supplies, a few cities noted opportunities to conserve water, reclaim water for irrigation, and access new sources of water. ${ }^{49}$ Composting presents another strategy for cycling materials within a region. ${ }^{50}$ By reducing food waste - through charitable donation, for instance - and consuming imperfect fruits and vegetables typically slated for disposal, it is possible to reduce overall demand, and thus the amount that needs to be produced (GGLO Design, 2013; Kamizaki, 2014; King County, 2015a; King County Solid Waste Division, 2015; Lerman, Haima, \& Mehus-Roe, 2012). Self-sufficiency can also be improved by encouraging broader palates and consuming species and food products already available locally (Eegeesiak, 2015a; Nunavut Food Security Coalition, 2014).

\subsubsection{RESILIENCE STRATEGY D - CREATE REDUNDANCIES AND ALTERNATIVES}

Because redundancy is an important characteristic of resilience, many examples of infrastructure adaptation entail the installation of backups and alternatives. Therefore, numerous examples of creating redundancy have already been discussed in the section on Strategy B, and other examples will fall under Strategy $E$, below. A few approaches, however, are more appropriate to discuss here. The first, already in use in New York due to a shortage of space at the Hunts Point food terminal, is "flex storage," which is the practice of storing food in hundreds of diesel-powered trucks (Barron et al., 2010). Perhaps distributors and retailers can arrange for the use of several refrigerated trucks to keep products cool in the event of a power failure.

\footnotetext{
49 City of Iqaluit, 2014b; City of Miami, 2008; GGLO Design, 2013; King County, 2015a; King County \& King County Agricultural Commission, 2009; King County \& KCIT DNRP GIS, 2015; Lewis \& Miller, 2010; Miami-Dade County, 2010; Miami-Dade County, 2011; Resilient Miami, Kresge Foundation, Catalyst Miami, \& Urban Impact Lab, 2015; Southeast Florida Regional Compact, 2012; Wastewater Treatment Division, 2015

50 City of Edmonton, 2010; City of Greater Sudbury, n.d.(a); City of Vancouver, 2013a; City of Vancouver, 2013b; Food and Urban Agriculture Advisory Committee, 2012; Foodshed Project \& Sudbury-Manitoulin FSN, 2007a; Foodshed Project \& Sudbury-Manitoulin FSN, 2007b; GGLO Design, 2013; Halifax Food Policy Alliance, 2015; King County, 2015a; King County Solid Waste Division, 2015; Lerman, Haima, \& Mehus-Roe, 2012; Local Food Assets Task Force, 2013; Miami-Dade County, 2010
} 
The second example concerns additional investments in transportation infrastructure. If Miami-Dade builds new routes for freight transport, there may be additional avenues for food imports when traditional supply lines are blocked (Miami-Dade County, 2010). Proposals in New York's 2014 hazard mitigation plan include improvements to transportation infrastructure (e.g. new rail tracks and ferry landings) that will provide transit alternatives for New Yorkers during emergencies (Margolies, 2014). Because disaster-related infrastructure failures can isolate communities, it is important to have backup options for the movement of people and goods (ibid.).

Failures in electrical and water infrastructure could disrupt household food storage and preparation. Consequently, initiatives to establish community kitchens and install bake ovens in parks create redundancies by providing additional locations for storing and preparing food during a crisis. ${ }^{51}$ Similarly, culinary and food safety training increases the number of people available to assist with food preparation and service in the event of a catastrophe. ${ }^{52}$ Buildingand community-level readiness programs that encourage residents to look after one another creates redundancies as well - in the form of individuals who can retrieve and prepare food for those who cannot (City of Vancouver, 2012a; Scioli, 2013).

\subsubsection{RESILIENCE STRATEGY E - IMPROVE CONSUMER ACCESS}

To combat food deserts and food swamps, many of the studied cities have launched programs to attract grocery stores, fresh food markets, and other outlets to underserved

\footnotetext{
51 Campbell, 2014; City of Iqaluit, 2014b; City of Toronto Public Health, 2010; City of Toronto Public Health, 2015b; City of Vancouver, 2013a; City of Vancouver, 2013b; Foodshed Project \& Sudbury and Area FSN, 2004; Foodshed Project \& Sudbury-Manitoulin FSN, 2007a; Kamizaki, 2014; King County, 2015a; King County Farms and Food Roundtable, Staff Team Members, \& Cedar River Group, 2014; Local Food Assets Task Force, 2013; McKeown, 2012; Miami-Dade County, 2010; Nunavut Food Security Coalition, 2014; Seattle \& King County Public Health, 2015b; Sudbury and District Health Unit, 2015

52 City of Greater Sudbury, n.d.(c); City of Iqaluit, 2014b; City of New York, 2013b; City of New York, 2015; City of Toronto Public Health, 2010; City of Vancouver, 2013b; EarthCare Sudbury, 2010; Fit NOLA, 2015; Food and Urban Agriculture Advisory Committee, 2012; Foodshed Project \& Sudbury-Manitoulin FSN, 2007a; Halifax Food Policy Alliance, 2015; Johnson \& Cain, 2015; Jones, Ona, Rimkus, \& Wells, 2005; King County, 2015a; King County Farms and Food Roundtable, Staff Team Members, \& Cedar River Group, 2014; Lerman, Haima, \& Mehus-Roe, 2012; Local Food Assets Task Force, 2013; New Orleans Food Policy Advisory Committee, 2015; Nunavut Food Security Coalition, 2014; Sudbury and District Health Unit, 2015
} 
neighborhoods; additional initiatives aim to improve the quality of food sold at existing outlets. ${ }^{53}$ These efforts, which may entail incentives or require leveraging public leaseholds, expand access to healthy food with the objective of improving conditions for marginalized communities (Jones, 2010; Newsom, 2009). But given New York's recognition that climaterelated disasters can constrain travel and alter the distribution of functional retailers, the provision of additional food outlets expands opportunities for customer access during a crisis (City of New York, 2013a). Hence, efforts to ensure equitable access to food markets also represent an advancement in emergency preparedness.

In addition to increasing the number of stores with healthy food offerings, a few cities have adopted regulations or leveraged contracts to introduce nutritious choices to vending machines at public facilities like government offices, parks, schools, and recreation centers. ${ }^{54}$ These initiatives, along with efforts to improve food offerings at employers, schools, and child care centers, mean that more locations in a community are stocked with nutritious food and (possibly) kitchens for its preparation. ${ }^{55}$ Larger quantities of available food in a community could equate to greater endurance during disruptions in the food supply chain. Further, by ensuring that NGOs receive compensation for assistance rendered during a crisis, organizations that can help will not be constrained from doing so (Rapp, 2014).

Transportation and information are also vital to food access, especially during an emergency. Consequently, efforts to develop compact, mixed-use communities, expand

\footnotetext{
53 Barron et al., 2010; City of New Orleans, 2014; City of New Orleans, 2015b; City of New Orleans, 2015c; City of New York, n.d.; City of New York, 2013a; City of New York, 2013b; City of Toronto Public Health, 2010; City of Toronto Public Health, 2015b; City of Toronto Public Health, 2015d; City of Vancouver, 2013a; City of Vancouver, 2013b; City of Vancouver Social Policy and Projects, 2015; Consortium for a Healthier Miami-Dade, 2011; Fit NOLA, 2015; Food and Urban Agriculture Advisory Committee, 2012; FoodShare, n.d.; Halifax Food Policy Alliance, 2015; Johnson \& Cain, 2015; ones, 2010; Jones, Ona, Rimkus, \& Wells, 2005; King County, 2015a; Lerman, Haima, \& Mehus-Roe, 2012; Lister, 2007; Local Food Assets Task Force, 2013; Miami-Dade County, 2010; New Orleans Food Policy Advisory Committee, 2008; New Orleans Food Policy Advisory Committee, 2015; Newsom, 2009; Nunavut Food Security Coalition, 2014; San Francisco Department of Public Health, n.d.(b); Social Compact Inc., 2007; Social Compact Inc., 2009; Totten, 2015; Young, Karpyn, \& Treering, 2012

54 Consortium for a Healthier Miami-Dade, 2011; Fit NOLA, 2015; Jones, 2010; Lerman, Haima, \& Mehus-Roe, 2012; Local Food Assets Task Force, 2013; Morgenstern, 2013; Newsom, 2009; Newsom, 2010; Seattle \& King County Public Health, 2015a

55 Barron et al., 2010; Fit NOLA, 2015; King County, 2015a; Lerman, Haima, \& Mehus-Roe, 2012; New Orleans Food Policy Advisory Committee, n.d.; New Orleans Food Policy Advisory Committee, 2015
} 
public transit, improve public safety, and encourage active transportation eliminate barriers and shorten distances between consumers and food outlets. ${ }^{56}$ Technology and marketing can be used to inform consumers about healthy food retailers in their area (Fit NOLA, 2015; Johnson \& Cain, 2015; New Orleans Food Policy Advisory Committee, 2008). San Francisco runs an emergency preparedness website whose crisis map can inform residents of obstructed routes and other nearby challenges (San Francisco Department of Emergency Management, 2015).

Even if city residents have physical access to food retailers, they may not have financial access to nutritious foods. Hence, municipalities promote anti-poverty initiatives, foodsharing networks, subsidy programs, and links to direct providers. ${ }^{57}$ It's also important that retailers can accept payments via food aid programs like SNAP and WIC (Johnson \& Cain, 2015; King County, 2015a; New Orleans Food Policy Advisory Committee, 2008). New York is working to ensure that consumers can still access and use subsidy programs during infrastructure outages (City of New York, n.d.). Finally, cities can assist residents in financial security by promoting flood insurance and emergency savings (City of New Orleans, 2015b; City of New Orleans OHSEP et al., 2011).

\subsection{A USEFUL AGGREGATE}

While New York stands alone among the reviewed cities in having published a comprehensive strategy specifically focused on improving the resilience of its food delivery

\footnotetext{
56 City of Miami, 2008; City of New Orleans, 2015b; City of New Orleans, 2015c; City of New Orleans OHSEP et al., 2011; City of Vancouver, 2012b; Consortium for a Healthier Miami-Dade, 2011; Fit NOLA, 2015; GGLO Design, 2012; GGLO Design, 2013; King County - Cities Climate Collaboration, 2015; King County \& KCIT DNRP GIS, 2015; Lerman, Haima, \& Mehus-Roe, 2012; Miami-Dade County, 2010; Miami Intermodal Center, 2015; New Orleans Food Policy Advisory Committee, 2008; NOCSF \& CSO, 2014; Parent \& Barthé-Prevost, 2015; Resilient Miami, Kresge Foundation, Catalyst Miami, \& Urban Impact Lab, 2015; Southeast Florida Regional Compact, 2012

57 City of Iqaluit, 2012; City of Iqaluit, 2014b; City of New Orleans, 2014; City of New Orleans, 2015a; City of New Orleans, 2015b; City of New Orleans, 2015c; City of New Orleans OHSEP et al., 2011; City of Toronto Public Health, 2015b; Eegeesiak, 2015a; Fit NOLA, 2015; Johnson \& Cain, 2015; Jones, 2010; Kamizaki, 2014; King County, 2015a; King County Farms and Food Roundtable, Staff Team Members, \& Cedar River Group, 2014; Lerman, Haima, \& Mehus-Roe, 2012; New Orleans Food Policy Advisory Committee, 2008; New Orleans Food Policy Advisory Committee, 2015; New Orleans Food Policy Advisory Committee \& Market Umbrella, 2015; Newsom, 2009; NOCSF \& CSO, 2014; Nunavut Food Security Coalition, 2014; Young, Karpyn, \& Treering, 2012
} 
systems, the research and initiatives observed in the other ten cities do much to advance that objective, even if not tied together through the lens of supply chain resilience. Collectively, the vulnerabilities and responses identified in this investigation provide a broad pool of considerations that can inform municipal work on preparing food supply chains for an era of climate change. In the next (and final) chapter, I will draw on this pool of knowledge to provide recommendations for planners and other municipal staff working in Toronto. 


\section{RECOMMENDATIONS FOR TORONTO}

Toronto enjoys an advantageous position compared to many other cities. It does not sit on the coast of any ocean, it is less susceptible to major natural catastrophes (e.g. earthquakes, tsunamis, and hurricanes) than many other world cities, and it possesses a detailed report on expected future climate conditions in the region (City of Toronto Environment Office, 2012; International Federation of Red Cross and Red Crescent Societies, 2010). Further, Toronto released a detailed climate adaptation plan in 2008 and created a climate risk assessment tool soon after (City of Toronto Environment Office, City of Toronto Climate Adaptation Steering Group, \& Clean Air Partnership, 2008; Oates, 2010). And among North American cities, Toronto has been a pioneer in food policy work (City of Toronto Public Health, 2008).

While the Toronto region, like so many others, faces the challenges of food insecurity, overconsumption, and the loss of local farms, it benefits from an agriculturally-productive Greenbelt protected by provincial statute and sits in close proximity to large, freshwater lakes (City of Toronto Public Health, 2008; City of Toronto Public Health, 2010; Doumani \& Foran, 2014; Kamizaki, 2014). The food industry is a top employer in Toronto and consumer attention to food issues has fueled the growth of "niche markets" (City of Toronto Public Health, 2008; City of Toronto Public Health, 2010). The city has conducted extensive research on its food systems and is working to ensure that all residents have access to nutritious food.

Examination of Toronto's efforts reveals that it has identified numerous vulnerabilities to the operation of its food supply chains and many potential responses for increasing resilience. By comparing Toronto's work to the collective body of vulnerabilities and responses pulled from the ten other cities investigated, it is possible to identify threats and adaptation strategies whose consideration may benefit Toronto. The following recommendations reflect Toronto's location and urbanized context. Issues of agricultural production, for example, are more the purview of surrounding municipalities and higher orders of government, as very 
little farming takes place in Toronto (City of Toronto Public Health, 2008; Toronto Food Policy Council, 1999a).

While there is much the city and its planners can do to harden the food supply chains that feed Toronto's population, municipal influence (at least compared to that of higher orders of government), is limited: Globalized food supply chains are obviously transjurisdictional, and some elements are dominated by large, powerful private actors (City of Toronto Public Health, 2008; City of Toronto Public Health, 2010; Hawkes, 2009; Humphrey \& Memedovic, 2006; Internal Revenue Service, 2015; MacRae \& Donahue, 2013; USDOC, 2008). In Canada, for instance, four major firms dominate the retail grocery market (City of Toronto Public Health, 2008; Kamizaki, 2014)

Further, the department structure of city governments may also make it difficult to effectively improve the resilience of food supply chains (Dale \& Hill, 2001). Progress will necessitate the involvement of numerous departments, including those overseeing planning, public health, transportation, and economic development. There is also the question of integration with existing efforts: Should Toronto address the resilience of its food supply chains as part of a climate change adaptation strategy, or as an expansion of its food policy work? In either case, collaboration will be crucial, as information-sharing and coordinated action can lead to broader and more effective results (Brown, Dayal, \& Rumbaitis Del Rio, 2012; Dale \& Hill, 2001; Gremillion, 2011). Interdepartmental partnerships help to ensure that problems and proposed solutions are assessed and evaluated from multiple perspectives.

The following recommendations for city staff, categorized under three broad headings, build on the extensive climate adaptation and food security work already conducted in Toronto. Although these ideas emerged from research into ten other cities whose assets and vulnerabilities vary widely, many are applicable locally. Also discussed are challenges to change and strategies for countering likely resistance. The final section of the chapter (Call to action), concludes this investigation and offers directions for further research. 


\subsection{CONTINUE TO STRIVE FOR SELF-SUFFICIENCY}

Toronto can promote self-sufficiency by maintaining and expanding regional food production. Within the boundaries of the city itself, Toronto can advance urban agriculture by devoting additional land to food production (King County, 2015a; King County \& King County Agricultural Commission, 2009; King County Farms and Food Roundtable, Staff Team Members, \& Cedar River Group, 2014). This land need not be at ground-level. Opportunities include vertical, underground, and rooftop farming (Elton, 2012). Indeed, Toronto could devote 5,000 hectares of roof space to food production (City of Toronto Public Health, 2008). City staff should push council to amend the city's green roof bylaw, which is currently incompatible with rooftop agriculture (Oved, 2015).

Much greater yields spring from the fertile agricultural lands surrounding the Toronto region (City of Toronto Public Health, 2008). Toronto supports provincial efforts to preserve farmland by accommodating population and employment growth that, absent Ontario's planning regime, might end up on the urban fringe. Although the city government has no jurisdiction over the land outside its boundaries, Toronto can assist efforts to maintain the economic viability of regional agriculture by serving as a market for locally-grown products and by attracting and retaining businesses that supply producers with needed materials and equipment (Harry Cummings and Associates Inc., 2009; King County \& King County Agricultural Commission, 2009).

It has already been noted that Toronto can reduce its reliance on distant food sources by promoting local production of products typically imported (Lister, 2007; McKeown, 2013b; Toronto Food Policy Council, 2015). Because non-food and export agriculture are common in Ontario, some lands could be repurposed to produce food for local markets (City of Toronto Public Health, 2008). There is also the opportunity to consume aesthetically suboptimal fruits and vegetables, which are now beginning to appear in Ontario supermarkets (Carville, 2015; City of Toronto Public Health, 2008). 
Local agriculture, whether practiced at a large scale in the Greenbelt or at a small scale in urban garden plots, may need to adapt as the climate changes. Given the expertise of its staff and its major research universities, Toronto certainly has the capacity to investigate threats to regional food production and devise adaptation strategies (Elver, 2015). Greater resilience can also be achieved by planting local varieties of food crops and by practicing agroecology, a system that brings agriculture into greater harmony with natural processes (ibid.). Toronto must also assess risks to urban farms posed by floodwaters, which could transmit pollutants and other hazardous materials (City of New Orleans OHSEP et al., 2011).

While greater local production contributes to greater local self-sufficiency, this strategy can be challenged on economic, environmental, and equity grounds. Free trade and reliable, rapid modes of transportation have allowed various regions around the world to specialize in goods produced efficiently at those locations. Local sourcing tends to be more costly per unit, may use fuel less efficiently, and can emit more carbon than imports sourced along established supply chains (Barclay, 2012; King et al., 2010). While employing economies of scale can reduce costs and increase fuel efficiency, achieving the required scales may be difficult without sufficient market demand for local products, which can be more expensive at the point of sale than imports (King et al., 2010).

Diverse cities like Toronto should also consider that the availability of culturallyappropriate food may fall as reliance on locally-produced food rises (King et al., 2010). It may be difficult or costly, for instance, to grow food from the tropics in the Canadian climate, and falling market demand for distant products could impair the economies of scale that ensure their (relative) affordability (ibid.). Further, favoring local production starves producers in the developing world highly dependent upon agricultural income (Barclay, 2012). Thus, efforts to increase the resilience of food supply chains in wealthy Toronto could result in declining resilience (and declining standards of living) elsewhere. 
While rising consumer demand for local food in the US has spurred what Martinez et al. (2010) call "a relocalization of the food system" (p. 1), local production alone may not equate to greater resilience if producers and consumers rely upon non-local aggregation, processing, and warehousing operations (King County Farms and Food Roundtable, Staff Team Members, \& Cedar River Group, 2014). To be self-sufficient, cities must also invest in the subsectors between production and consumption to fill gaps in local capacity. ${ }^{58}$ In its efforts to develop food hubs and food business incubators, Toronto may already be forging entirely local chains (Kamizaki, 2014; Uens, 2014). Marketing initiatives, along with new opportunities to connect local producers and local markets - like a specialized food terminal - could contribute to even more "relocalization" (City of Vancouver, 2013b; King County, 2015a). Hawkes (2009) notes that many small changes, operating collectively to create new incentives, can promote supply chain restructuring at larger scales.

Numerous challenges, including the risks associated with change, constrain efforts to construct local chains (King County Farms and Food Roundtable, Staff Team Members, \& Cedar River Group, 2014). Competition from mass producers, along with the momentum of established supply and distribution networks (e.g. long-functioning relationships and specializations within the industry), limits the ability of local producers to break into the local market (Halifax Food Policy Alliance, 2015; King et al., 2010). For consumers such as institutions, local procurement can be challenging: in addition to learning what is produced locally and when, purchasers may need to source from multiple farms and at higher unit costs (King County, 2015a).

Existing interests may also constrain change, for there are numerous beneficiaries of any system as currently structured (Dale \& Hill, 2001). Moving to a more localized food system could spark objections from certain local interests, like importers and exporters, who

\footnotetext{
58 King County, 2015a; King County \& King County Agricultural Commission, 2009; King County Farms and Food Roundtable, Staff Team Members, \& Cedar River Group, 2014; Lerman, Haima, \& Mehus-Roe, 2012; Morgenstern, 2013
} 
may have political power. Further, the pursuit of local self-sufficiency could contradict existing economic development policies in cities looking to expand ports and trade (ibid.). Indeed, a possible drawback of relocalized chains is the deterioration of the logistics infrastructure required for imports, which could be vital to feeding a population in the event of a devastating regional catastrophe.

Given these challenges, it is apparent that neither Toronto nor any other city can simply adopt policies for promoting local food self-sufficiency without giving due consideration to the many implications of changing long-standing and economically successful systems, despite their many deficiencies. Now is the time for Toronto to undertake a cost-benefit analysis to this end.

\subsection{HARDEN EACH LINK IN THE FOOD SUPPLY CHAIN}

Whether Toronto's food is imported or produced regionally, city staff must ensure that each link in the chain between production and consumption is resilient to climate-related disruption. Given existing research into the city's food system, including identification of distribution centers, food processors, and retail outlets, and given plans to employ GISassisted risk assessment, Toronto is already well positioned to conduct this work (City of Toronto Public Health, 2008; City of Toronto Public Health, 2010; Kamizaki, 2014; Lister, 2007; Rossini, 2014). With a detailed understanding of supply chain operation within the city, it will be possible to identify vulnerable assets and promote adaptation.

Because Toronto depends on imported food, city staff must conduct additional research to determine the source of those imports, the risks to production at those sources, and the hazards that threaten transportation assets used to bring that food to Toronto. ${ }^{59}$ Research undertaken by ASDA, a firm that runs supermarkets in the UK, revealed that climate change

\footnotetext{
59 City of New York, 2013a; City of Toronto Environment Office, City of Toronto Climate Adaptation Steering Group, \& Clean Air Partnership, 2008; City of Toronto Public Health, 2015a
} 
could affect $95 \%$ of the fresh produce it sells (ASDA, 2015; London Assembly Economy Committee, 2015). It is particularly important to assess Toronto's dependence on food shipped from the US, as a large scale disaster (e.g. terrorism) or unpredictable political changes (e.g. Donald Trump) could result in a temporary halt to border crossings (Metcalf Foundation, 2008). A sudden spike in the price of oil - an input into both production and shipping - could also threaten the viability of imports (Toronto Food Policy Council, 2000).

Given these challenges, Toronto should follow the lead of New York and collaborate with other governments to prepare for disruptions and develop strategies for prevention and response (City of New York, 2013a). There may be mutual interest in discussion and adaptation, for Toronto's industrial and transportation infrastructure may be critical to the supply and delivery of food elsewhere, just as King County plays a role in the production or shipment of all but twelve percent of Alaska's food supply (King County OEM, 2013c). Toronto's work could also prove useful to smaller municipalities that lack the capacity for detailed research.

Drawing on the work conducted in New York, Toronto should identify alternate shipping routes and pinpoint traffic bottlenecks where trucks hauling food and medicine can be given first priority in a crisis (City of New York, 2013a). Staff must also examine food distribution pathways within the city, increase the resilience of associated infrastructure, and prepare detours to manage disruptions like flooding, road washouts, and obstructions (City of New York, n.d.; City of New York, 2013a; City of New Orleans OHSEP et al., 2011). While Toronto is not as dependent on bridges as is New York, there may be isolated areas - like the Toronto Islands - made less accessible by catastrophe (King County OEM, 2015b; Miami-Dade County, NOAA, \& NACO, 2011). Further, transportation assets like the Don Valley Parkway are vulnerable to flooding.

Toronto must collaborate with the food industry to identify and address climate-related vulnerabilities to processors, wholesalers, and retail markets (Chandra et al., 2011). Business 
operators should understand the infrastructure needs of employees, equipment, and suppliers, inform the city of those needs, and arrange for operational continuity during extreme events, perhaps through partnerships with other firms (Chandra et al., 2011; Flynn, 2011). In fact, resilience to hazards that could disrupt business can become a selling point for Toronto - and an economic development strategy (Humes, 2015). Resilience may already have value in Toronto's real estate market: A mixed-use development proposed by Stanton Renaissance will employ trigeneration (which adds the capacity for producing coolth to the cogeneration of heat and power) along with geothermal, solar, and perhaps wind energy protecting its residents from electric outages (City of Sydney, 2015; Mitanis, 2015).

Unfortunately for New York, one of its major food-related assets, the Hunts Point Food Distribution Center, is located on a peninsula subject to flooding (City of New York, n.d.; City of New York, 2013a; New York City Economic Development Corporation, 2014). The city is responding with resilience investments (Barron et al., 2010; City of New York, 2013a). Major assets in Toronto include food processing clusters in North York, at the Stockyards, and in South Etobicoke, which is also home to the Ontario Food Terminal (Toronto Food Policy Council, 1999a). The Ontario Food Terminal, Toronto's major distribution hub, is essential to the city's strong food economy and permits the widespread availability of fresh produce (City of Toronto Public Health, 2008; City of Toronto Public Health, 2010). Its daily conveyance of produce exceeds five million pounds (City of Toronto Public Health, 2010).

While it is unlikely that a storm surge will ever endanger the Ontario Food Terminal, its proximity to the Humber River and the Humber Treatment Plant might warrant a risk assessment for the facility - and for nearby roadways (Canadian Hydrographic Service Central and Arctic Region, 2007; Google, 2016; Ontario Ministry of Natural Resources, 2012). Despite the improbability of a major catastrophe, Toronto should consider what alternate facilities its wholesalers and distributors could use should the food terminal be destroyed or rendered inaccessible. Additional considerations include the availability of backup power, the threat of 
pests as temperatures increase, and the resilience of the distributors themselves (City of New York, 2013a; City of Toronto Public Health, 2008).

To prevent disruptions from causing food insecurity, city staff must also examine the extent to which retail food outlets, charitable providers, and community kitchens are vulnerable to climate-related hazards and associated infrastructure failures, and the spatial distribution of that vulnerability - especially given existing disparities in access to full service grocery stores and existing challenges to the reliability of transit service and electrical power (City of New York, 2013a; City of Toronto Public Health, 2010; Deschamps, 2015; New York City Economic Development Corporation, 2014). Residents without vehicles may not be able to access a functioning retailer if the closest options are out of service, especially if challenged by compounding factors like inclement weather or limited mobility (City of New York, 2013a; City of Toronto Public Health, 2010). (Imagine trying to carry groceries home after an ice storm.)

Continuing to promote the establishment of new retailers in underserved areas (and improving selections at existing retailers) will contribute to greater resilience by potentially shortening the trips consumers must make to purchase food during an emergency (City of New York, 2013a). Further, Toronto can expand access to nutritious food by promoting healthier choices at institutions and in vending machines. ${ }^{60}$ Increasing consumer choice will also assist residents with special dietary requirements. Residents must have knowledge of the closest several food retailers, and Toronto's transportation infrastructure, including transit service, should be prepared for emergencies (City of New York, 2013a). The city could also consider using mobile food markets in a crisis (City of New Orleans, 2015b).

In addition to pushing for backup power supply at food retailers, Toronto should ensure that community food providers and mobile operations (e.g. farmers' markets and food trucks)

\footnotetext{
60 Fit NOLA, 2015; King County, 2015a; Lerman, Haima, \& Mehus-Roe, 2012; Local Food Assets Task Force, 2013; Morgenstern, 2013; New Orleans Food Policy Advisory Committee, n.d.; New Orleans Food Policy Advisory Committee, 2015; Seattle \& King County Public Health, 2015a
} 
are adequately prepared for emergencies (City of New York, 2013a; Rapp, 2014). Food providers should know how to properly operate or connect to an emergency generator and if any risk of flooding necessitates the elevation of electrical equipment (City of Miami Emergency Management, 2015; City of New York, 2013a). Telecommunications assets should be hardened to ensure the reliability of commercial transactions (City of New York, 2013a). Businesses and residents should be informed of best practices for managing and preserving stored food during power outages (City of New York MOLTPS \& NYSDAM, 2014). And supply chains for liquid fuels and natural gas should be resilient (City of New York, 2013a; City of Vancouver, 2012a; Washington State Homeland Security Region 6, 2005).

City staff will need to overcome numerous obstacles to implement resilience strategies, and some responsibility will fall on households, businesses, and institutions to harden assets, reform processes, and prepare for emergencies. Many actors will be limited by financial constraints, and the expectation of disaster assistance can serve to counter incentives to prepare (City of New York, 2013a; Cutter et al., 2008; Goody Clancy et al., 2013). Another major challenge to enhancing resilience is the tendency for politicians and residents to underestimate hazard risks, especially when large infrastructure projects (e.g. seawalls) provide the perception of safety and thus promote complacency (Cutter et al., 2008). This "levee effect," which permitted the development of low-lying lands in New Orleans, could stymie progress if major investments in Toronto - reinforced hydro lines, flood control mechanisms, etc. - convince the populace that further resilience efforts are unnecessary (Colten, Kates, \& Laska, 2008; Cutter et al., 2008, p. 7).

Absent catastrophe, it can be difficult to convince communities of the importance of preparation and resilience (Bozikovic, 2015). The challenge of doing so is especially acute in many parts of the United States, where there is strong ideological opposition to the recognition and understanding of climate change, and by association, programs for mitigation and adaptation (El Akkad, 2015; Handwerk, 2013). Though this particular problem is much 
less acute in Canada, it is important to remember that addressing a long-term problem like climate change may be difficult when governments, private organizations, and households consider relatively short timelines when making decisions (Bozikovic, 2015; El Akkad, 2015). Further, residents may be tempted to focus only on improvements to individual homes and businesses, without considering that major investments may be required to harden the infrastructure systems that power daily life (El Akkad, 2015).

There is also the danger of maladaptation, which occurs when short-term initiatives to manage crises or changing conditions detract from long-term efforts to increase resilience (Nickson et al., 2011; Romero-Lankao, 2012). A commonly-cited example is air conditioning, an energy-intensive process used to manage heat waves and higher temperatures (Nickson et al., 2011; Roaf, Crichton, and Nicol, 2009). To attain resilience without contributing to additional climate change, it may thus be wiser to invest in building- or community-scale alternative energy generation than to install additional fuel-powered backup generators, as recommended for residences and businesses in Toronto (City of Toronto, 2013; Scioli, 2013; Spears, 2014; Zerbisias, 2014). Climate change mitigation initiatives can also thwart resilience efforts, as in the use of agricultural land for producing biofuels rather than food crops (Elver, 2015).

Given these challenges, Toronto must consider the long-term consequences of proposed resilience strategies. It makes little sense to invest in adaptive actions that contribute to climate change - or in adaptive actions that contribute to greater inequality. Unfortunately, it is possible to unintentionally reinforce (or exacerbate) existing structures of wealth and power in attempts to achieve greater resilience (Carter et al., 2014). Safeguarding economic assets, for instance, may disproportionately benefit the wealthy, who have a greater stake in them (Brown, Dayal, \& Rumbaitis Del Rio, 2012). Hence, when considering a regulation to require backup power at full service grocery stores, it is important to recall that this change does little to ensure greater food security for communities without full service 
grocery stores. Further, businesses in wealthy areas may enjoy greater capacity to pursue resilience initiatives than businesses serving low-income communities.

Ideally, Toronto should consider mainstreaming food and resilience thinking into all municipal operations (MacRae \& Donahue, 2013; UN-Habitat, 2011). During the development review process, city staff can consider how development proposals increase or reduce risk and enhance or detract from a community's ability to cope with and recover from crisis (UNHabitat, 2011). With regard to food security, this may entail the provision of sufficient grocery stores in a neighborhood, requirements for community energy planning, or consideration of how shadows and runoff could affect existing urban gardens. Food access should also be considered during the planning of transit routes (Young, Karpyn, \& Treering, 2012).

\subsection{ENSURE RESIDENTS ARE PREPARED FOR EMERGENCIES}

King County notes that many households have not stored food and water for emergencies (King County OEM, 2013c). It is unlikely that this problem is particular to King County. Toronto already works to promote emergency readiness among the population, in part by recommending the inclusion of food and water in household emergency kits (Odlum, 2015; Rossini, 2014). Given the human tendency to defer preparation and the possibility that the city's messaging will not reach all of its residents - like those who do not speak English it may be wise for the city to consider investing in stockpiles of water and nonperishable food products (Chandra et al., 2011; Colten, Kates, \& Laska, 2008; Vasseur, 2007). Low-income households and newcomers - including the thousands of Syrian refugees Canada has generously offered to resettle - may be especially vulnerable. To ensure the operation of emergency vehicles and backup power generators, Toronto may also wish to invest in fuel reserves (City of New York, 2013a; Vasseur, 2007).

Because existing dimensions of inequality (which may compound) can influence residents' exposure and sensitivity to climate-related hazards and their ability to cope with 
and recover from those hazards, Toronto should work to address structural causes of social and economic inequality (Carter et al., 2014; City of New Orleans, 2015b; UN-Habitat, 2011). Interventions to ensure greater equity in access to infrastructure, services, education, employment, health care, housing, and wealth can go a long way toward increasing a city's resilience (UN-Habitat, 2011). Different communities enjoy different levels of human, social, financial, physical, and natural capital, and Toronto already possesses the tools to identify priority neighborhoods for investment (Doolittle, 2014; UN-Habitat, 2011). It is vital to prioritize areas and populations with high vulnerability and low resilience to present and future hazards; this process is known as a "vulnerability based approach" (Carter et al., 2014, p. 52).

Toronto should continue to support efforts to build social resilience, which is the capacity of communities to prepare for and recover from crisis (Bozikovic, 2015). Social resilience - which depends upon relationships, trust, local knowledge, and an ethic of care offers numerous benefits (Bozikovic, 2015; Saavedra, Budd, \& Lovrich, 2012). If residents are trained to respond appropriately to a crisis, they can assist neighbors more quickly than first responders and contribute to community self-sufficiency during the emergency (Bozikovic, 2015; Flynn, 2011; USDHS, 2011; WHO, 2010). Often, members of the public will emerge during a crisis to assist neighbors and first responders; this valuable resource should not be squandered (Chandra et al., 2011; Colten, Kates, \& Laska, 2008).

Toronto's "tenant buddy system" and the "adopt a neighbor" program recommended for Greater Sudbury leverage existing relationships to strengthen communities (Scioli, 2013; Vasseur, 2007). Neighborhood-level emergency plans and community-based response teams can prove essential to young children and other vulnerable populations, including persons with disabilities and medical patients who cannot feed themselves or who cannot consume food orally (Trento \& Allen, 2014). Persons requiring homecare or special (and likely electricpowered) medical equipment may be endangered when transportation and utility 
infrastructure does not function as normal (King, 2014; Trento \& Allen, 2014). Therefore, city staff should also engage providers of homecare, health care, medical equipment, and specialty food supplies - whose delivery to patients in need may entail an entirely different food distribution network (Trento \& Allen, 2014).

Other examples of community resilience efforts already underway in Toronto include Faith \& the Common Good, a diverse group of religious congregations planning to offer worship sites as emergency shelters and service centers during extreme weather events (Cummings, 2015; Faith \& the Common Good, n.d.; Refuge in the Storm, 2015). Local officials should coordinate with this organization and identify other community assets especially those with refrigerators, freezers, and kitchens - that can serve a second function as an emergency shelter (Evan Weinberg, personal communication, July 20, 2015; USDHS, 2011). Online community spaces, such as the Facebook groups used by residents of CityPlace and Liberty Village, can also serve as a starting point to address community resilience (Pereira, 2015; USDHS, 2011). While online platforms would be useless during a disaster that knocks out electricity and internet access, the relationships and knowledge they help generate could serve as important community resources for endurance and recovery.

\subsection{CALL TO ACTION}

Despite the abundance of pressing concerns already on the city's agenda, now is the time for Toronto to begin addressing the resilience of its food supply chains. Climate change marches on, with 2015 setting new temperature records (Brown, Cabbage, \& Northon, 2016). Given the severity of expected impacts should nations continue to emit large quantities of GHGs, along with uncertainties in predictions and the possibility of climate "tipping points," urban settlements should begin preparing for both anticipated and unanticipated long-term challenges (Clos, 2011; IPCC, 2014; Nordhaus, 2012b). 
Resilience-building efforts should be comprehensive and thorough, sufficient to protect people and assets from catastrophes more severe than predicted (Clos, 2011; Colten, Kates, \& Laska, 2008; Nordhaus, 2012b). Unexpected events and unforeseen failures can complicate response and relief efforts; disasters like Hurricane Katrina have demonstrated how quickly problems can multiply (Colten, Kates, \& Laska, 2008). Emergency plans in New Orleans failed to anticipate the severity of storm impacts and relied on assumptions that turned out to be inaccurate (ibid.). Therefore, Toronto should review its plans with the knowledge that catastrophes can lead to cascade failures of infrastructure that may obstruct management and recovery efforts (ibid.).

To maximize efficacy, city staff must engage individual communities in resiliencebuilding efforts. Community input in adaptation planning is crucial because of the local nature of climate impacts and the value of local and indigenous knowledge, which can broaden the perspective of experts (Archer et al., 2014; IPCC, 2014). For residents and other interested parties to be involved in adaptation work, they must have knowledge of climate hazards and sufficient time and resources to participate in the planning process (Archer et al., 2014). As a start, Toronto should publicize its detailed report describing expected weather and climate conditions during the 2040s (City of Toronto Environment Office, 2012).

Fortunately, resilience work often overlaps with efforts to improve existing conditions (Brown, Dayal, \& Rumbaitis Del Rio, 2012). Promoting full service grocery stores in food deserts, for example, enhances daily access to nutritious food and provides redundant retail capacity that may prove vital during a crisis. Where possible, Toronto should leverage existing political will to simultaneously address immediate concerns and promote long-term resilience. Planners will play an important role in linking short- and long-term considerations, and in advising elected officials on the importance of addressing challenges whose impacts may not be felt for several election cycles. 
Intergenerational equity demands that today's planners guide development to be resilient to future conditions (Carter et al., 2014). If we promote an urban form that turns out to be the $21^{\text {st }}$ century equivalent of sprawl - wasteful, expensive, and unsustainable - we will leave our descendants unprepared for a future whose environmental challenges are likely to be far more severe than those experienced today (Carter et al., 2014; Gremillion, 2011). Toronto's planners should take advantage of the city's current development boom to promote sustainable practices and secure investments that increase the resilience of hard and soft infrastructure. Additionally, we must not become complacent, for resilience requires continuous learning, the flexibility to adapt to new conditions, and the acceptance of occasional crisis and instability (Matheny \& Homewood, 2015; Saavedra, Budd, \& Lovrich, 2012).

This investigation of the climate, resilience, and food policy work conducted in eleven North American cities offers a catalogue of knowledge on food supply chain vulnerabilities and strategies for greater resilience. It is my hope that this research fosters greater awareness of the need to prepare our food delivery systems for climate-related disruptions. The knowledge amassed here can serve as a starting point for planners interested in this topic. It is important that researchers and practitioners continue to gather and share information on hardening food supply chains and other infrastructure systems vital to maintaining civilization. As the consequences of climate change increase in severity, access to such information will be critical.

Researchers with additional time and resources will be able to investigate this topic more comprehensively, expanding the scope beyond a smattering of cities in North America. Particularly important will be assessments of food supply chains in the developing world, where climate-related catastrophes threaten populations already disadvantaged by centuries of economic exploitation. Wherever resilience strategies have been implemented, researchers must evaluate the extent to which they are effective at achieving stated objectives. And 
where investigations are conducted for specific municipalities, detailed inquiry will be necessary to determine the vulnerabilities and capacities of each individual element and process in the supply chain, many of which are wholly controlled by private actors.

Though this research will take time, there is one thing each of us can do today to protect ourselves against short-term disruptions to the food supply chain: Please visit the following URL (City of Toronto Fire Services, n.d.) to find out how you can put together a three-day emergency kit of food and water: $\underline{h t t p: / / g 00 . g l / d d 7 X Y I}$ 


\begin{tabular}{|c|c|c|c|}
\hline & Strategies & Elements & \\
\hline 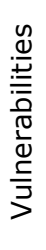 & & $\begin{array}{r}1,2,3,4 \\
1,2,3 \\
3 \\
1,2 \\
1 \\
3 \\
4\end{array}$ & $\begin{array}{l}\text { No standards for what constitutes resilience. [ay] } \\
\text { Disruptions in the supply chain due to calamities or changes in climate, energy costs, or political and market } \\
\quad \text { forces. [ay, az, ba, bb] } \\
\text { Price increases due to disruptions in the supply chain. [ay, az, ba, bb] } \\
\text { Insufficient local food system infrastructure. [ay, bb] } \\
\text { Loss of local farmland. [ay] } \\
\text { Unequal access to fresh food, with consequences for nutrition. [ay] } \\
\text { Lack of food skills. [ay] }\end{array}$ \\
\hline 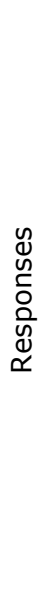 & $\begin{array}{r}\text { A } \\
\text { A } \\
\text { A } \\
\text { A, C } \\
\text { C, E } \\
\text { C, D } \\
\text { C, D } \\
\text { C } \\
\text { C } \\
\text { C } \\
\text { C } \\
\text { A } \\
\text { A } \\
\text { E } \\
\text { D } \\
\text { A }\end{array}$ & $\begin{array}{r}1,2,3,4 \\
1,2,3,4 \\
1,2,3,4 \\
1 \\
1,3 \\
1,2,3 \\
1,2,3 \\
1,2,3 \\
1,2,3 \\
1 \\
1,4 \\
3 \\
3 \\
3 \\
4 \\
1,2,3,4\end{array}$ & $\begin{array}{l}\text { Recognize interconnectedness of food systems with numerous other sectors, including land, infrastructure, } \\
\text { housing, and the economy. [ay, az] } \\
\text { Outline and map all elements of the local food system, large and small. [ay, az] } \\
\text { Examine the resiliency of the entire food system, from production to consumption and waste management. } \\
\text { [ba] } \\
\text { Determine what types of food must be imported and what types of food can be produced within the region. } \\
\text { [ba, bb] } \\
\text { Promote urban and regional agriculture. [ay, az] } \\
\text { Produce and process food locally; assist with the establishment and expansion of food-related businesses. } \\
\text { [ay, az, ba] } \\
\text { Promote food hubs to reap the benefits of spatial clustering and economies of scale. [ay] } \\
\text { Promote the procurement and purchase of foods produced in the region. [ay, bb] } \\
\text { Link local production with local markets. [ay, bb] } \\
\text { Preserve farmland of diverse uses. [ay, ba, bb] } \\
\text { Promote composting. [ay, az] } \\
\text { Evaluate extent of food security at present. [ba, bb] } \\
\text { Quantify existing dependence on direct provision. [bb] } \\
\text { Promote new food outlets and other food programs in underserved areas. [ay] } \\
\text { Provide culinary and other food-related training. [ay] } \\
\text { Develop indicators to measure progress. [ay] }\end{array}$ \\
\hline
\end{tabular}

Table A.1. Vulnerabilities and responses relevant to the resilience of food supply chains: Edmonton, AB.

Coding Key:

Phases of the food supply chain:

1 - Production, aggregation, and processing

2 - Distribution, wholesaling, and warehousing

3 - Retailing, food service, and consumer access

4 - End user storage and preparation; consumption and waste
Strategies for increasing resilience:

A - Identify assets, opportunities, needs, and risks B - Adapt processes, structures, and infrastructure C - Increase regional self-sufficiency in food and water D - Create redundancies and alternatives E - Improve consumer access

\section{References:}

[ay] (Food and Urban Agriculture Advisory Committee, 2012)

[az] (City of Edmonton, 2010)

[ba] (City of Edmonton, 2011)

[bb] (Lipton, 2010) 


\begin{tabular}{|c|c|c|c|}
\hline & Strategies & Elements & \\
\hline 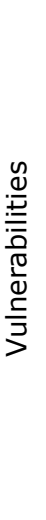 & & $\begin{array}{r}1,3,4 \\
2,3 \\
1,2,3,4 \\
1,2,3,4 \\
1,2,3,4 \\
1 \\
1 \\
1 \\
1 \\
1 \\
1 \\
1 \\
1,2,3 \\
3 \\
3,4 \\
3,4 \\
3\end{array}$ & $\begin{array}{l}\text { Climate change impacts on agriculture and water supply; various threats to water quality. [ch, cm, cp, cu, cy] } \\
\text { Food delivery relies on fuels and infrastructure networks. [cw, cy] } \\
\text { Property loss due to flooding. [ch] } \\
\text { Dependence on electric power for refrigeration/freezing. [cs] } \\
\text { Dependence on food imported from elsewhere; fuel costs. [ch, cm, co, cp, cu, cy] } \\
\text { Increasing dependence on more distant suppliers for agricultural equipment. [cd] } \\
\text { Dependence on agricultural consultants from outside the region. [cd] } \\
\text { Pressures to develop agricultural land. [cc, cp] } \\
\text { Movement from food to other agricultural products; less product diversity. [cd, cp] } \\
\text { Increase in the average age of farmers; loss of agricultural skills. [cp] } \\
\text { Insufficient support for the young to join the agriculture sector. [cd] } \\
\text { Challenges to the economic viability of farming. [cd, cp] } \\
\text { Increasing global population; resource limitations; rising food prices. [cm, co, cr] } \\
\text { Uneven spatial distribution of food outlets. [cn, co, cr] } \\
\text { Consumers with mobility limitations. [co, cr] } \\
\text { Households struggling financially; homelessness; inequity. [co, cr] } \\
\text { Climate-related impacts restricting food access for vulnerable populations. [co, cp, cr, cu, cy] }\end{array}$ \\
\hline & 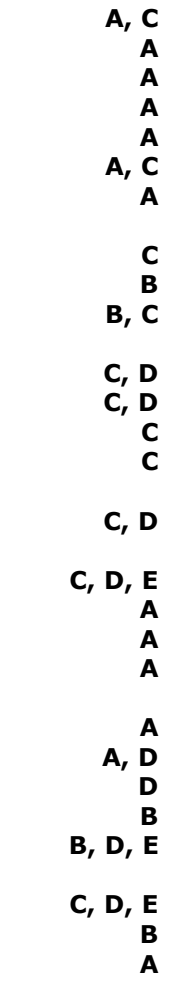 & $\begin{array}{r}1,2,3,4 \\
1,2,3 \\
1 \\
1 \\
1,2,3 \\
1 \\
1,2,3 \\
1 \\
1 \\
1 \\
1 \\
1 \\
1 \\
1,4 \\
1,2,3 \\
1,2,3 \\
1,3 \\
3 \\
3 \\
3 \\
3 \\
3 \\
4 \\
4 \\
1,2,3,4 \\
3,4 \\
2,3,4 \\
1,2,3,4 \\
1,2,3,4\end{array}$ & $\begin{array}{l}\text { Assess threats to the food supply chain; promote self-sufficiency. [cu, cv] } \\
\text { Study how local and imported food reaches consumers; inventory local processors. [ck, co, cu] } \\
\text { Identify sources of imported food. [co, cy] } \\
\text { Thoroughly inventory the uses and quality of agricultural lands in the region. [cc, cd, co] } \\
\text { Inventory or map local food assets, such as community gardens, markets, and food stores. [by, cf, co] } \\
\text { Determine the extent to which local needs are met by local production. [cm, ct] } \\
\text { Quantify the city's day-to-day food supply (i.e. how many days will it last in the absence of fresh deliveries?). } \\
\text { [cy] } \\
\text { Promote local food production and processing; offer training programs. [bx, ca, cb, cf, ch, ci, co] } \\
\text { Employ agricultural research; adapt production to mitigate climate impacts. [cd, ch, co, cr] } \\
\text { Ensure the preservation of agricultural lands and the efficient and responsible use of regional farmland. } \\
\text { [bx, cc, ch, cj] } \\
\text { Recruit and assist new farmers and agricultural businesses. [ce, co] } \\
\text { Use seed banks. [cp] } \\
\text { Promote composting. [cl, co, cr] } \\
\text { Link regional food producers with local consumers, promote local procurement, and create a food } \\
\quad \text { terminal to assist with these efforts. [bx, cb, cd, ce, cf, ch, ci, ck, co, cr] } \\
\text { Develop food hubs, food business incubators, and other economic development strategies. } \\
\text { [ca, cf, ci, co, cr] } \\
\text { Preserve foods to ensure their availability in other seasons. [cq] } \\
\text { Inventory charitable food providers and benefit programs available in the region. [cb, co] } \\
\text { Assess dependence on direct food provision (and other programs). [bz, cn, co, cr] } \\
\text { Assess the cost of groceries needed for maintaining a healthy diet; determine household food spending. } \\
\text { [cb, cg, co, cr] } \\
\text { Inventory public transit and other providers offering transportation to food stores. [cb] } \\
\text { Inventory and establish community kitchens. [bx, cb, cf, co] } \\
\text { Run culinary skills programs. [cb, ch, ck, co] } \\
\text { Conduct emergency planning specific to food. [bx] } \\
\text { Promote emergency readiness among the population; develop programs that organize neighbors to } \\
\text { assist one another during crises. [co, cr, cx, cy] } \\
\text { Maintain a reserve of food and water for emergencies. [cy] } \\
\text { Improve water and wastewater management. [ch, ci, cy] } \\
\text { Employ indicators to assess progress. [cj, co, cr] }\end{array}$ \\
\hline
\end{tabular}

Table A.2. Vulnerabilities and responses relevant to the resilience of food supply chains: Greater Sudbury, ON.

\section{Coding Key:}

\section{Phases of the food supply chain:}

1 - Production, aggregation, and processing

2 - Distribution, wholesaling, and warehousing

3 - Retailing, food service, and consumer access

4 - End user storage and preparation; consumption and waste

\section{Strategies for increasing resilience:}

A - Identify assets, opportunities, needs, and risks B - Adapt processes, structures, and infrastructure $C$ - Increase regional self-sufficiency in food and water D - Create redundancies and alternatives E - Improve consumer access

\section{References:}

[bx] (Foodshed Project \& Sudbury and Area FSN, 2004)

[by] (EarthCare Sudbury, 2015)

[bz] (Greater Sudbury Food Policy Council, 2014b)

[ca] (Greater Sudbury Food Policy Council, 2014a)

[cb] (Sudbury and District Health Unit, 2015)

[cc] (City of Greater Sudbury, 2004)

[cd] (Harry Cummings and Associates Inc., 2009) 
[ce] (Gagnon \& King, 2015)

[cf] (Campbell, 2014)

[cg] (OMAFRA, CSCA, \& Ryerson University, 2010)

[ch] (EarthCare Sudbury, 2010)

[ci] (EarthCare Sudbury, 2008)

[cj] (City of Greater Sudbury, n.d.(e))

[ck] (City of Greater Sudbury, n.d.(c))

[cl] (City of Greater Sudbury, n.d.(a))

[cm] (Stricker, 2013)

[cn] (City of Greater Sudbury, n.d.(b))

[co] (Foodshed Project \& Sudbury-Manitoulin FSN, 2007a)

[cp] (Foodshed Project, 2010)

[cq] (Foodshed Project, 2009a)

[cr] (Foodshed Project \& Sudbury-Manitoulin FSN, 2007b)

[cs] (City of Greater Sudbury, n.d.(d))

[ct] (Keown, 2015)

[cu] (Greater Sudbury Climate Change Consortium, 2011)

[cv] (McMillan, 2012)

[cw] (Fortin \& Gionet, 2012)

[cx] (Greater Sudbury Climate Change Consortium, 2014)

[cy] (Vasseur, 2007) 


\begin{tabular}{|c|c|c|c|}
\hline & Strategies & Elements & \\
\hline 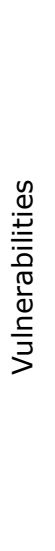 & & $\begin{array}{r}1,3 \\
1,2,3,4 \\
1,2,3 \\
1 \\
1 \\
1 \\
1 \\
1 \\
3 \\
3 \\
3 \\
1,2, \\
1,4 \\
1, \\
1, \\
1, \\
3 \\
4 \\
4\end{array}$ & $\begin{array}{l}\text { Climate-related impacts (including pests and invasive species) on local agriculture, aquaculture, and } \\
\text { forestry (both products and infrastructure), and associated economic consequences. [bi] } \\
\text { Climate-related impacts on critical infrastructure networks, including electricity and road, rail, and water } \\
\text { transport. [bi] } \\
\text { Dependence of the food system on transportation infrastructure. [be] } \\
\text { Dependence on food imports, which are vulnerable to changes in climate and geopolitics. [be] } \\
\text { Challenges to the viability of farming and fishing, including aging and declining labor force. [be] } \\
\text { Pressures to develop agricultural land. [be] } \\
\text { Fish processing on the decline. [be] } \\
\text { Competition limits the ability of local producers to break into the local market. [be] } \\
\text { Unequal access to healthy food, with negative consequences for health. [bc, be] } \\
\text { Factors influencing consumer access, including mobility, disability, and dietary requirements. [be] } \\
\text { Households lacking financial resources. [be] } \\
\text { Food spoilage due to higher temperatures; food-borne illness. [bh, bi] } \\
\text { Seafood with higher pollution concentration. [bh] } \\
\text { Property loss due to flooding, fires, etc. [bi] } \\
\text { Impacts on water quality and supply. [bi] } \\
\text { Decline in food skills. [be] }\end{array}$ \\
\hline & $\begin{array}{r}\mathbf{A} \\
\mathbf{A}, \mathbf{B} \\
\mathbf{A} \\
\mathbf{A} \\
\mathbf{A} \\
\mathbf{A}, \mathbf{C} \\
\mathbf{C}, \mathbf{D} \\
\mathbf{C} \\
\mathbf{C} \\
\mathbf{D} \\
\mathbf{C} \\
\mathbf{A} \\
\mathbf{C} \\
\mathbf{B} \\
\mathbf{B} \\
\mathbf{A} \\
\mathbf{A} \\
\mathbf{A} \\
\mathbf{A} \\
\mathbf{E} \\
\mathbf{D} \\
\mathbf{C}\end{array}$ & $\begin{array}{r}1,2,3,4 \\
1,2,3,4 \\
1 \\
1 \\
1 \\
1 \\
1,3 \\
1 \\
1 \\
1,2,3 \\
1,2,3 \\
1,2,3 \\
3,4 \\
3,4 \\
3 \\
3 \\
3 \\
3 \\
3 \\
4 \\
1,4\end{array}$ & $\begin{array}{l}\text { Identify processes and key elements in the local food system, including processors and major } \\
\text { distributors. [be] } \\
\text { Assess infrastructure vulnerabilities and adapt. [bi] } \\
\text { Identify and map coastal aquaculture assets. [bi] } \\
\text { Identify and map farmland at risk from inundation. [bi] } \\
\text { Gather statistics on local food production and processing; identify what products are output. [be] } \\
\text { Assess how much and where more food can be grown locally. [be] } \\
\text { Promote community gardens and urban orchards. [bc, be] } \\
\text { Encourage food production as a career interest; offer training programs. [be] } \\
\text { Protect farmland, fisheries, and seed varieties. [be] } \\
\text { Produce more food locally; grow the local food economy. [bc, bd, be] } \\
\text { Assess existing links between local producers and local consumers. [be] } \\
\text { Procure food from local sources and encourage consumers to do likewise. [be] } \\
\text { Promote emergency readiness among the population. [be, bg, bi] } \\
\text { Consider food needs in organizations' crisis plans. [be] } \\
\text { Inventory and map food outlets and resources. [be] } \\
\text { Use indicators to assess food security. [be] } \\
\text { Estimate dependence on direct provision. [be] } \\
\text { Assess the cost of groceries needed for maintaining a healthy diet. [be] } \\
\text { Expand access to food, especially in underserved areas. [be, bf] } \\
\text { Promote culinary and food safety training. [be] } \\
\text { Promote composting. [be] }\end{array}$ \\
\hline
\end{tabular}

Table A.3. Vulnerabilities and responses relevant to the resilience of food supply chains: Halifax, NS.

Coding Key:

\section{Phases of the food supply chain:}

1 - Production, aggregation, and processing

2 - Distribution, wholesaling, and warehousing

3 - Retailing, food service, and consumer access

4 - End user storage and preparation; consumption and waste

\section{Strategies for increasing resilience:}

A - Identify assets, opportunities, needs, and risks B - Adapt processes, structures, and infrastructure C - Increase regional self-sufficiency in food and water D - Create redundancies and alternatives $\mathrm{E}$ - Improve consumer access

\section{References:}

[bc] (Bates, 2014)

[bd] (Halifax Regional Municipality, 2015)

[be] (Halifax Food Policy Alliance, 2015)

[bf] (Totten, 2015)

[bg] (Halifax Regional Municipality, 2010)

[bh] (Halifax Regional Municipality, 2007)

[bi] (Dillon Consulting, de Romilly and de Romilly Ltd., \& ClimAdapt., 2007) 


\begin{tabular}{|c|c|c|c|}
\hline & Strategies & Elements & \\
\hline 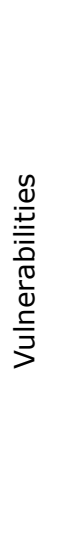 & & $\begin{array}{r}1,3,4 \\
2 \\
1,2,3,4 \\
1,2,4 \\
2,3 \\
1,3,4 \\
1,3 \\
1,3 \\
1,3 \\
1,3 \\
1,3 \\
1,4 \\
1,2 \\
3 \\
3 \\
1,2,3 \\
4\end{array}$ & $\begin{array}{l}\text { Infrastructure challenges, which may worsen with climate change. [bs, bv] } \\
\text { Climate-related impacts on seaport and airport infrastructure. [bv] } \\
\text { Damage to structures due to climate change impacts. [bs, bv] } \\
\text { Property losses due to flooding. [bs, bv] } \\
\text { Gaps and failures in telecommunications (needed for commercial transactions, phone and internet service, } \\
\text { flights, emergency response, etc.). [bt] } \\
\text { Potential climate-related impacts on water supply and water quality. [bq, bs, bt, bv] } \\
\text { Changes in the environment and wildlife due to climate change. [bq, bs, bt, bw] } \\
\text { Challenges to hunting and harvesting due to climate change. [bs, bt, bv, bw] } \\
\text { Onerous distance to food animals; potential declines in fish stocks. [bq, bu] } \\
\text { Decline in professional hunting; increasing expense of hunting. [bt, bu, bw] } \\
\text { Loss of traditional skills, such as proper hunting practices. [bq, bt, bw] } \\
\text { Changing pollutant loads in food. [bs] } \\
\text { Dependence on imported food; shipping delays. [bt, bw] } \\
\text { Food insecurity; limited supply in stores; resulting nutritional deficiencies. [bq, bt, bu, bw] } \\
\text { Financial insecurity; rising food costs; fruits and vegetables are expensive. [bq, bt, bu, bw] } \\
\text { Population growth. [bw] } \\
\text { Loss of food skills. [bw] }\end{array}$ \\
\hline 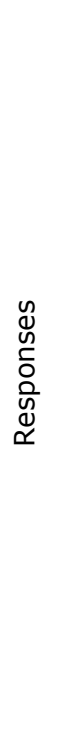 & $\begin{array}{r}\text { A } \\
\text { B } \\
\text { B, C, D } \\
\text { C, D } \\
\text { B, E } \\
\text { A } \\
\mathbf{C} \\
\mathbf{C} \\
\mathbf{A} \\
\mathbf{B} \\
\text { B, C, D } \\
\mathbf{C}, \mathbf{E} \\
\mathbf{C}, \mathbf{E} \\
\mathbf{C} \\
\mathbf{C} \\
\mathbf{C} \\
\mathbf{A} \\
\mathbf{E} \\
\mathbf{A} \\
\mathbf{E} \\
\mathbf{E} \\
\mathrm{C}, \mathrm{D}, \mathrm{E} \\
\mathbf{D} \\
\mathbf{D} \\
\mathbf{D}\end{array}$ & $\begin{array}{r}1,2 \\
1,3,4 \\
1,3,4 \\
1,2 \\
2,3 \\
2 \\
1 \\
1 \\
1 \\
1,3 \\
1,3,4 \\
1,3 \\
1,3 \\
1,2,3 \\
1,2,3 \\
1,2,3 \\
3 \\
3 \\
3 \\
3 \\
3 \\
3 \\
4 \\
4 \\
4\end{array}$ & $\begin{array}{l}\text { Identify key assets for food imports and assess climate-related risks. [bt] } \\
\text { Monitor and adapt infrastructure and buildings. [bv] } \\
\text { Promote water conservation and locate new water sources. [bt, bv] } \\
\text { Cooperate to construct or improve food storage infrastructure. [bq, bt, bw] } \\
\text { Improve communications infrastructure; grow the communications sector of the local economy. [bt] } \\
\text { Assess how food is transported and distributed; determine if improvements can be made. [bw] } \\
\text { Erect new infrastructure to improve access to food supply (a bridge). [bq] } \\
\text { Erect additional infrastructure for local food production (expand greenhouse). [bq] } \\
\text { Describe food sources. [bt] } \\
\text { Adapt harvesting to ensure long-term survival of species harvested. [bw] } \\
\text { Consider new species and food products; encourage broader palates. [bq, bw] } \\
\text { Train residents in fishing, hunting, and other traditional skills. [bq, br, bu, bw] } \\
\text { Disseminate local knowledge to ensure safe travel and hunts. [bt, bu] } \\
\text { Prioritize local markets over exports. [bq] } \\
\text { Pool resources to enhance the viability of hunting and food sales; establish local markets. [bq, bt, bw] } \\
\text { Procure locally-harvested food to improve viability of harvesting. [bw] } \\
\text { Assess the cost of groceries. [bw] } \\
\text { Employ anti-poverty programs and economic development; subsidies; direct provision. [bt, bw] } \\
\text { Assess dependence on direct provision. [bs] } \\
\text { Improve offerings at food outlets. [bw] } \\
\text { Promote food-sharing networks. [bq, bt, bu, bw] } \\
\text { Promote residential storage of extra food and water for emergencies. [bt] } \\
\text { Establish community kitchens. [bw] } \\
\text { Open up existing kitchens to the community. [bt] } \\
\text { Promote culinary skills programs. [bt, bw] }\end{array}$ \\
\hline
\end{tabular}

Table A.4. Vulnerabilities and responses relevant to the resilience of food supply chains: Iqaluit, NU.

\section{Coding Key:}

\section{Phases of the food supply chain:}

1 - Production, aggregation, and processing

2 - Distribution, wholesaling, and warehousing

3 - Retailing, food service, and consumer access

4 - End user storage and preparation; consumption and waste

References:

[bq] (Eegeesiak, 2015a)

[br] (Eegeesiak, 2015b)

[bs] (City of Iqaluit, 2014a)

[bt] (City of Iqaluit, 2014b)

[bu] (City of Iqaluit, 2012)

[bv] (Lewis \& Miller, 2010)

[bw] (Nunavut Food Security Coalition, 2014)

\section{Strategies for increasing resilience:}

A - Identify assets, opportunities, needs, and risks B - Adapt processes, structures, and infrastructure C - Increase regional self-sufficiency in food and water D - Create redundancies and alternatives

E - Improve consumer access 


\begin{tabular}{|c|c|c|c|}
\hline & Strategies & Elements & \\
\hline 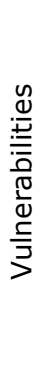 & & $\begin{array}{r}1,2,4 \\
1,2,3,4 \\
2,3 \\
1, \\
3 \\
1 \\
1,3 \\
1,3 \\
1,3,4 \\
3 \\
3 \\
3\end{array}$ & $\begin{array}{l}\text { Vulnerability of lands and infrastructure to flooding, sea level rise, stronger storms, and shoreline erosion. } \\
\quad \text { [da, dg, dj, dk, dp, dq, du] } \\
\text { Loss of property due to flooding. [da, dg, dj] } \\
\text { Isolated areas may not be accessible during or after a disaster. [dr] } \\
\text { Risks to fresh water supply due to sea level rise, droughts, and floods. [da, db, dg, dj, dk, dp, dq, du] } \\
\text { Climate change threatens agriculture and fisheries. [dq, du, dv] } \\
\text { Climate hazards may result in income losses for workers in agriculture and fishing. [dr] } \\
\text { Increasing demands due to climate refugees. [dk] } \\
\text { Market demand for unhealthy foods; low demand for fruits and vegetables. [dk] } \\
\text { Unequal access to outlets selling fresh and healthy food, with negative consequences for health. [dd, de, ds] } \\
\text { Some residents face mobility challenges. [dk] } \\
\text { Higher prices at convenience outlets. [ds] }\end{array}$ \\
\hline & $\begin{array}{r}\text { A } \\
\text { B, D } \\
\text { B } \\
\text { A, B, C, D } \\
\text { C, D } \\
\text { A, B, D } \\
\mathbf{C} \\
\mathbf{A} \\
\mathbf{A} \\
\mathbf{A} \\
\mathbf{B} \\
\mathbf{A}, \mathbf{C}, \mathbf{D}, \mathbf{E} \\
\mathbf{C} \\
\mathbf{C} \\
\mathbf{C} \\
\mathbf{A}, \mathbf{B} \\
\mathbf{A} \\
\mathbf{B}, \mathbf{D} \\
\mathbf{B}, \mathbf{E} \\
\mathbf{B} \\
\mathbf{A} \\
\mathbf{A} \\
\mathbf{A}, \mathbf{E} \\
\mathbf{A}, \mathbf{E} \\
\mathbf{E} \\
\mathbf{E} \\
\mathbf{E} \\
\mathbf{C} \\
\mathbf{E} \\
\mathbf{E} \\
\mathbf{E} \\
\mathbf{A}, \mathbf{B} \\
\mathbf{D} \\
\mathbf{C}\end{array}$ & $\begin{array}{r}1,2,3,4 \\
1,2,3,4 \\
1,2,3,4 \\
1,3,4 \\
1,3,4 \\
3,4 \\
1 \\
1 \\
1,2 \\
1,3 \\
1 \\
1,3 \\
1,2,3 \\
1,2,3 \\
1,2,3 \\
2 \\
\\
2 \\
2 \\
2 \\
2,3 \\
2 \\
3 \\
3 \\
3 \\
3 \\
3 \\
3 \\
3 \\
3 \\
3 \\
3 \\
3 \\
3,4 \\
4 \\
4\end{array}$ & 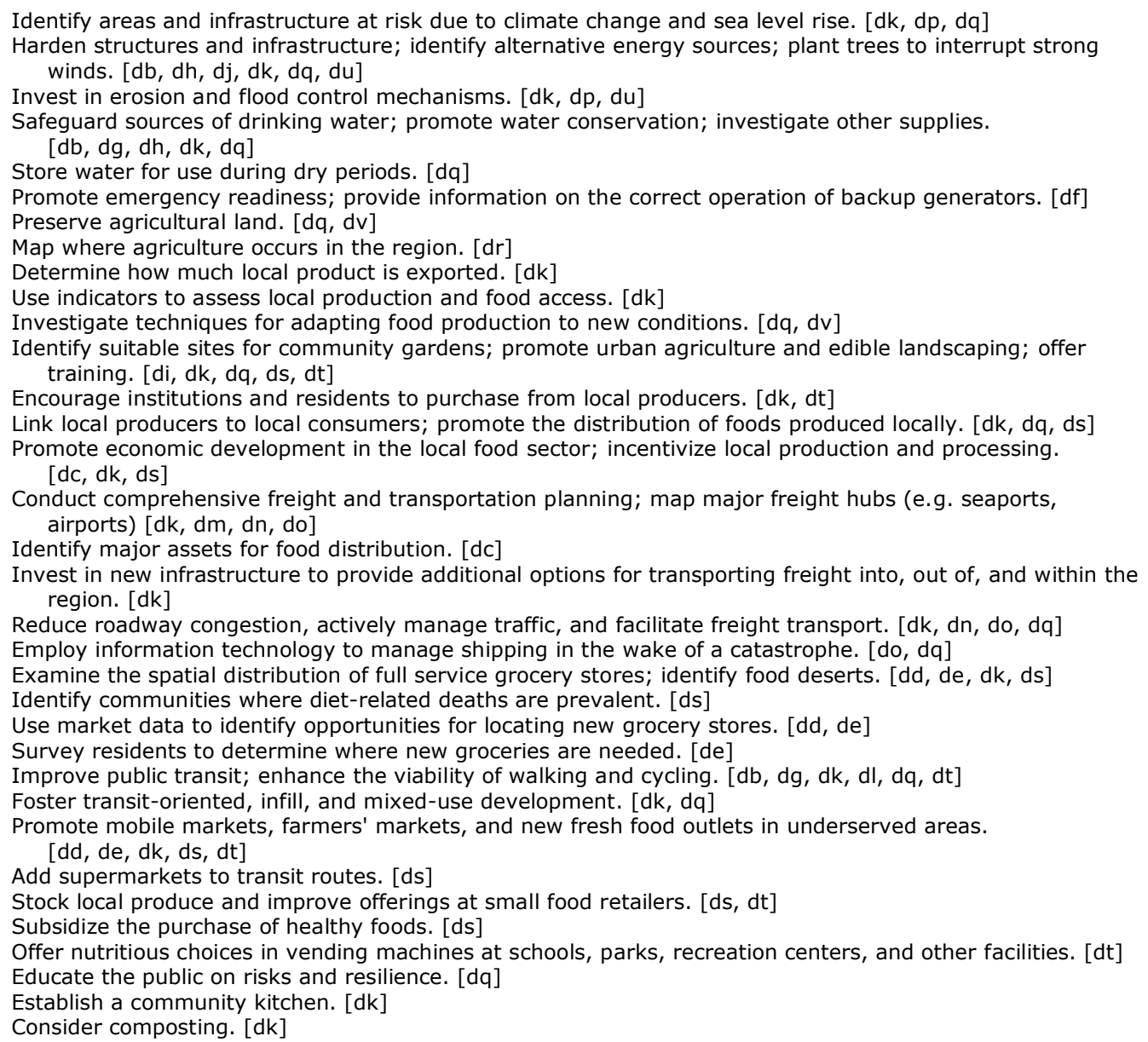 \\
\hline
\end{tabular}

Table A.5. Vulnerabilities and responses relevant to the resilience of food supply chains: Miami (city) \& Miami-Dade County, FL.

Coding Key:

Phases of the food supply chain:

1 - Production, aggregation, and processing

2 - Distribution, wholesaling, and warehousing

3 - Retailing, food service, and consumer access

4 - End user storage and preparation; consumption and waste
Strategies for increasing resilience:

A - Identify assets, opportunities, needs, and risks B - Adapt processes, structures, and infrastructure C - Increase regional self-sufficiency in food and water D - Create redundancies and alternatives $\mathrm{E}$ - Improve consumer access

\section{References:}

[da] (Resilient Miami et al., 2015)

[db] (Resilient Miami, Kresge Foundation, Catalyst Miami, \& Urban Impact Lab, 2015)

[dc] (City of Miami DCED, 2014)

[dd] (Social Compact Inc., 2009)

[de] (Social Compact Inc., 2007) 
[df] (City of Miami Emergency Management, 2015)

[dg] (City of Miami, 2008)

[dh] (Miami-Dade County, 2011)

[di] (Miami-Dade County, 2015)

[dj] (Ruvin et al., 2014)

[dk] (Miami-Dade County, 2010)

[dl] (Miami Intermodal Center, 2015)

[dm] (Florida Department of Transportation, 2013)

[dn] (Miami-Dade MPO \& Gannett Fleming, 2009)

[do] (Parsons Brinkerhoff, Cambridge Systematics, Inc., \& Quest Corporation of America, 2014)

[dp] (Climate Change Advisory Task Force, 2010)

[dq] (Southeast Florida Regional Compact, 2012)

[dr] (Miami-Dade County, NOAA, \& NACO, 2011)

[ds] (Young, Karpyn, \& Treering, 2012)

[dt] (Consortium for a Healthier Miami-Dade, 2011)

[du] (Seijas, Torriente, \& Hefty, 2010)

[dv] (Miami-Dade County Climate Change Advisory Task Force, 2008) 


\begin{tabular}{|c|c|c|c|}
\hline & Strategies & Elements & \\
\hline & & $\begin{array}{r}1,2,3,4 \\
1,2,3,4 \\
1,2,3,4 \\
1,2,3,4 \\
2,3,4 \\
1 \\
1,3,4 \\
1,3,4 \\
2 \\
2 \\
2 \\
1,3 \\
1,2,3 \\
3 \\
3 \\
3 \\
3 \\
3 \\
3 \\
3\end{array}$ & $\begin{array}{l}\text { Vulnerability to climate-related impacts like stronger storms and sea level rise, especially given land } \\
\text { subsidence and the loss of protective wetlands; devastating hurricanes and storm surges. [fg, fh, fi, fj, fl] } \\
\text { Climate-related disasters could spread hazardous materials harmful to agriculture, livestock, fisheries, and } \\
\text { food products. [fj] } \\
\text { Loss of food product inside affected buildings. [fj] } \\
\text { Aging and unmaintained buildings and infrastructure; infrastructure interdependencies. [fg, fh, fi, fj] } \\
\text { Urban development on low-lying lands. [fg, fi, fj] } \\
\text { Droughts and floods can harm agriculture and fisheries. [fj] } \\
\text { Droughts can threaten water supplies. [fj] } \\
\text { Decline in water quality during power failures. [fi] } \\
\text { Drought can interfere with shipping at New Orleans ports and along the Mississippi River. [fj] } \\
\text { Various food products are imported into the US at New Orleans. [fj] } \\
\text { The city's ports play a significant role in US exports. [fg, fi] } \\
\text { Climate impacts may cause job losses in the agricultural sector. [fj] } \\
\text { Businesses lose income while unable to operate. [fj] } \\
\text { Catastrophes can strain household budgets. [fg] } \\
\text { Climate impacts may result in higher food prices. [fj] } \\
\text { Poverty; substantial racial inequality. [fg, fh, fi, fm, fo] } \\
\text { Violence, which discourages resident travel and business investment. [fh, fi, fm, fo, fu] } \\
\text { Disparities in access to healthy food, with consequences for health. [fg, fi, fm, fo, fq, fu] } \\
\text { Food retail operations depend on electricity. [fi] } \\
\text { Post-Katrina labor shortage in the food retail sector. [fk] }\end{array}$ \\
\hline & $\begin{array}{r}\text { A } \\
\text { B } \\
\text { B, D } \\
\text { B, D } \\
\text { B } \\
\text { B } \\
\text { B } \\
\text { A } \\
\text { B } \\
\text { B, D } \\
\text { E } \\
\text { A } \\
\text { A } \\
\text { A } \\
\text { B, C } \\
\mathbf{C} \\
\mathbf{C} \\
\text { A } \\
\text { B, E } \\
\text { E } \\
\text { E } \\
\text { E } \\
\text { A } \\
\text { E } \\
\text { D, E } \\
\text { A } \\
\text { C, D, E } \\
\text { E }\end{array}$ & $\begin{array}{r}1,2,3,4 \\
1,2,3,4 \\
1,2,3,4 \\
1,2,3,4 \\
1,2,3,4 \\
1,2,3,4 \\
1,2,3,4 \\
1,2,3,4 \\
1,2,3,4 \\
1,2,3,4 \\
3 \\
1,2,3,4 \\
1 \\
1 \\
4 \\
1 \\
1,2,3 \\
2 \\
2,3 \\
3 \\
3 \\
3 \\
3 \\
3 \\
3 \\
3 \\
1,3 \\
3 \\
3 \\
3 \\
3 \\
3 \\
3 \\
3 \\
4\end{array}$ & 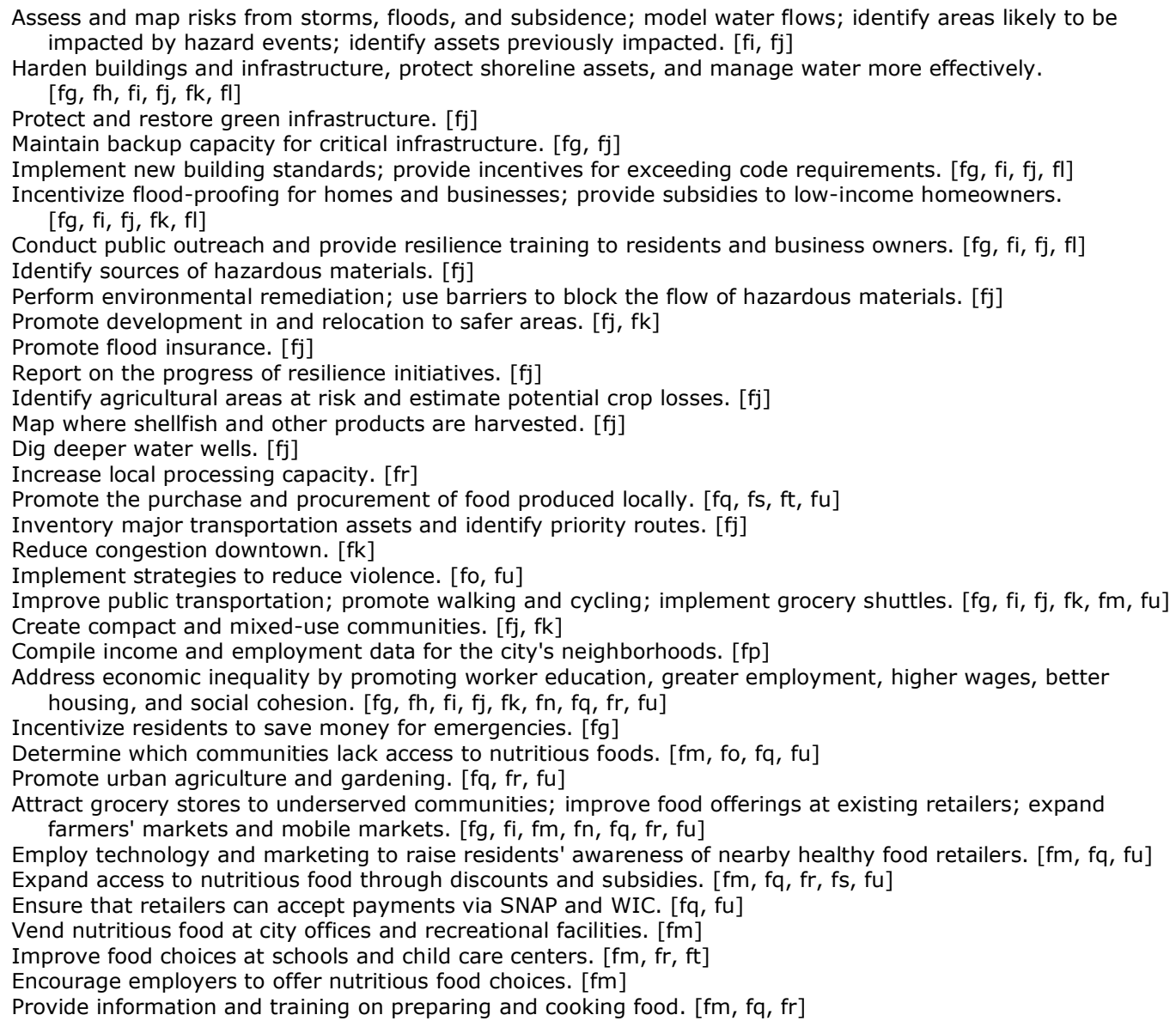 \\
\hline
\end{tabular}

Table A.6. Vulnerabilities and responses relevant to the resilience of food supply chains: New Orleans, LA.

Coding Key:

\section{Phases of the food supply chain:}

1 - Production, aggregation, and processing

2 - Distribution, wholesaling, and warehousing

3 - Retailing, food service, and consumer access

4 - End user storage and preparation; consumption and waste

\section{Strategies for increasing resilience:}

A - Identify assets, opportunities, needs, and risks B - Adapt processes, structures, and infrastructure C - Increase regional self-sufficiency in food and water D - Create redundancies and alternatives $\mathrm{E}$ - Improve consumer access 


\section{References:}

[fg] (City of New Orleans, 2015b)

[fh] (City of New Orleans, 2015a)

[fi] (City of New Orleans, 2015c)

[fj] (City of New Orleans Office of Homeland Security and Emergency Preparedness et al., 2011)

[fk] (NOCSF \& CSO, 2014)

[fl] (Goody Clancy et al., 2013)

[fm] (Fit NOLA, 2015)

[fn] (City of New Orleans, 2014)

[fo] (Parent \& Barthé-Prevost, 2015)

[fp] (New Orleans Health Department \& Healthy Start New Orleans, 2013)

[fq] (Johnson \& Cain, 2015)

[fr] (New Orleans Food Policy Advisory Committee, 2015)

[fs] (New Orleans Food Policy Advisory Committee \& Market Umbrella, 2015)

[ft] (New Orleans Food Policy Advisory Committee, n.d.)

[fu] (New Orleans Food Policy Advisory Committee, 2008) 


\begin{tabular}{|c|c|c|c|}
\hline & Strategies & Elements & \\
\hline & & $\begin{array}{r}1,2,3,4 \\
1,2,3,4 \\
1,2,3,4 \\
1,2,3,4 \\
1 \\
1 \\
1 \\
2,3 \\
2,3 \\
2,3 \\
2 \\
2 \\
3 \\
3 \\
3 \\
3 \\
\\
3 \\
3 \\
3 \\
1,2,3 \\
4\end{array}$ & $\begin{array}{l}\text { Dependence of the food supply chain on interdependent (and aging) infrastructure systems, including } \\
\text { electricity, communications, transportation, and liquid fuels. [ad, } \mathrm{fv}, \mathrm{fx}, \mathrm{fy} \text { ] } \\
\text { Dependence on electricity for refrigeration and freezing to prevent food spoilage, which could result in } \\
\text { illness. [ad, ah, fv, fw, fy] } \\
\text { Backup power generators depend on liquid fuels. [ad] } \\
\text { Loss of product due to flooding. [ad, fy] } \\
\text { Loss of upstate farmland. [ae] } \\
\text { Risks to the city's food supply. [ah] } \\
\text { Insufficient tracking; food origins often unknown. [fx] } \\
\text { Potential for delays at important routes and access points (e.g. bridges). [ad, fv] } \\
\text { Congestion on city roadways; limits to parking and maneuverability. [fx] } \\
\text { Insufficient storage capacity for distributors, wholesalers, and institutions. [fx] } \\
\text { Vulnerability of a major food wholesaling and distribution hub to flooding. [ad, fv, fy] } \\
\text { Distributors differ in ability to invest in resilience; equity implications. [ad] } \\
\text { Unequal geographic distribution of outlets selling fresh, healthy food; challenges for people with limited } \\
\quad \text { mobility. [ad, ae, fy] } \\
\text { Changes in the distribution of functional outlets as a result of hazard conditions. [ad] } \\
\text { Hazard risks to direct and emergency food providers (e.g. government programs and community } \\
\text { organizations). [ad] } \\
\text { Changes to cost and availability due to disruptions in supply, which could have health and equity } \\
\text { consequences. [ah] } \\
\text { Failures in transportation systems can restrict consumer mobility. [ad] } \\
\text { Households lacking financial resources. [ad, ae, fy] } \\
\text { Fluctuations in charitable giving. [fx] } \\
\text { Population increase. [fx] } \\
\text { Food preparation often requires electricity. [ad, fy] }\end{array}$ \\
\hline & $\begin{array}{r}\text { B, D } \\
\text { B } \\
\text { A } \\
\text { A } \\
\text { A } \\
\text { A } \\
\text { A } \\
\mathbf{C} \\
\mathbf{C} \\
\text { C, D, E } \\
\mathbf{C} \\
\mathbf{A} \\
\mathbf{A} \\
\mathbf{B} \\
\mathbf{D}, \mathbf{E} \\
\mathbf{B} \\
\mathbf{B}, \mathbf{D} \\
\mathbf{B} \\
\mathbf{B}, \mathbf{D} \\
\mathbf{B} \\
\mathbf{D} \\
\mathbf{B}, \mathbf{D} \\
\mathbf{A} \\
\mathbf{B} \\
\mathbf{B} \\
\mathbf{D} \\
\mathbf{B}, \mathbf{D} \\
\mathbf{A} \\
\mathbf{A} \\
\mathbf{E} \\
\mathbf{B}, \mathbf{E} \\
\mathbf{E} \\
\mathbf{E} \\
\mathbf{B} \\
\mathbf{D}\end{array}$ & $\begin{array}{r}1,2,3,4 \\
1,2,3,4 \\
1,2,3,4 \\
1,2,3,4 \\
1,2,3,4 \\
1,2,3,4 \\
1,2,3 \\
1,2,3 \\
1,3 \\
1,2,3 \\
1,2,4 \\
1,2,3 \\
2 \\
2,3 \\
2 \\
2 \\
2 \\
2 \\
2,3 \\
2,3 \\
2,3 \\
3 \\
3 \\
3 \\
3 \\
3 \\
3 \\
3 \\
3 \\
3 \\
3 \\
3 \\
3,4 \\
4\end{array}$ & 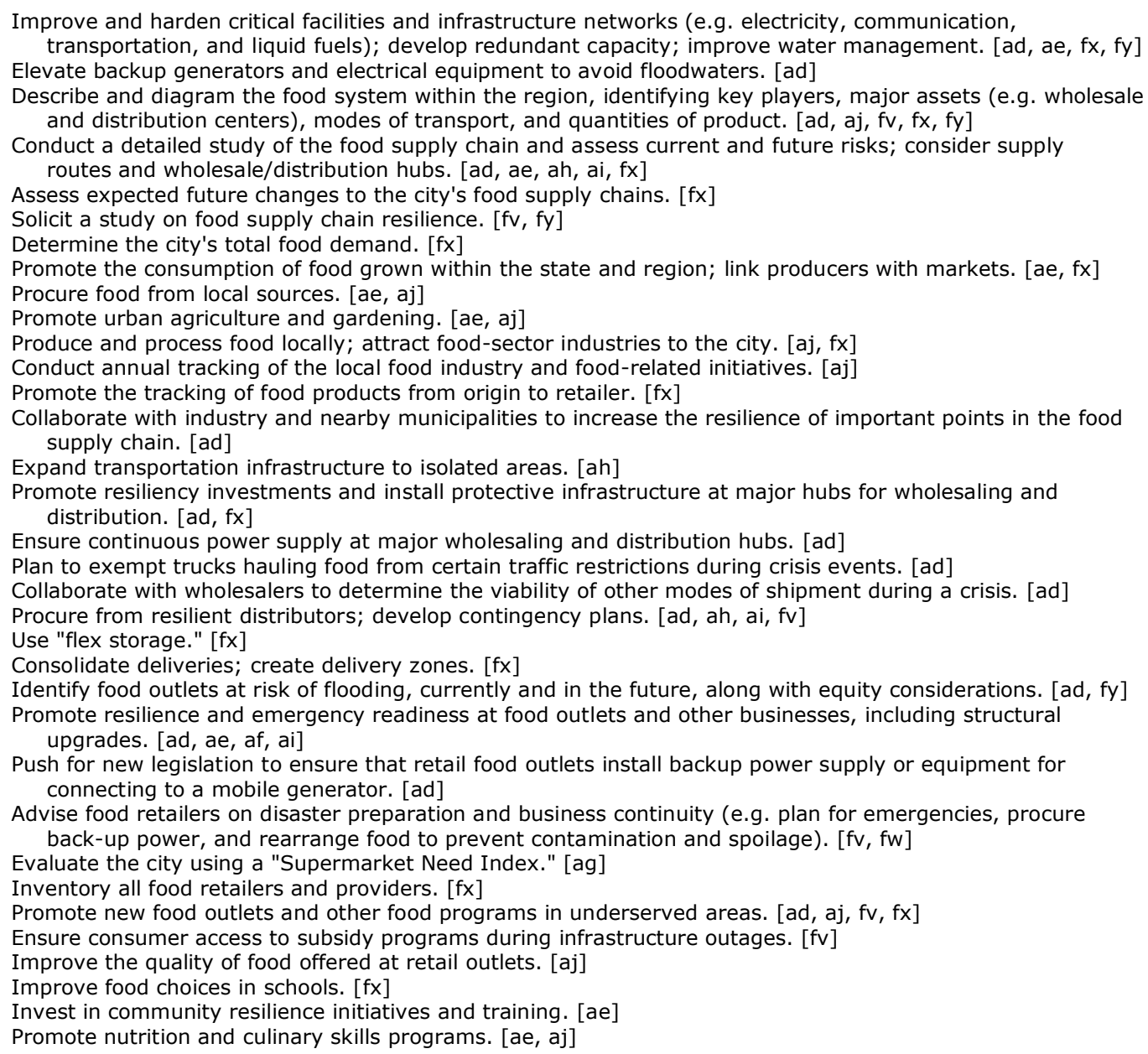 \\
\hline
\end{tabular}

Table A.7. Vulnerabilities and responses relevant to the resilience of food supply chains: New York, NY. 
Phases of the food supply chain:

1 - Production, aggregation, and processing

2 - Distribution, wholesaling, and warehousing

3 - Retailing, food service, and consumer access

4 - End user storage and preparation; consumption and waste

\section{Strategies for increasing resilience:}

A - Identify assets, opportunities, needs, and risks

B - Adapt processes, structures, and infrastructure

C - Increase regional self-sufficiency in food and water

D - Create redundancies and alternatives

$\mathrm{E}$ - Improve consumer access

\section{References:}

[ad] (City of New York, 2013a)

[ae] (City of New York, 2015)

[af] (City of New York Department of City Planning, 2014b)

[ag] (City of New York Department of City Planning, 2014a)

[ah] (Margolies, 2014)

[ai] (City of New York, 2014)

[aj] (City of New York, 2013b)

[fv] (City of New York, n.d.)

[fw] (City of New York MOLTPS \& NYSDAM, 2014)

[fx] (Barron et al., 2010)

[fy] (New York City Economic Development Corporation, 2014) 


\begin{tabular}{|c|c|c|c|}
\hline & Strategies & Elements & \\
\hline 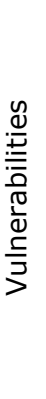 & & $\begin{array}{r}1,2, \\
1,2,3,4 \\
1,3,4 \\
1 \\
1 \\
3 \\
3 \\
3 \\
3 \\
3 \\
3\end{array}$ & $\begin{array}{l}\text { Damage to infrastructure networks, including water and wastewater, electric power, and land, sea, and air } \\
\text { transportation, which could increase the isolation of some communities. [am] } \\
\text { Property loss due to climate-related impacts. [al] } \\
\text { Impacts on water quality and supply. [al, am] } \\
\text { Impacts of climate change on regional agriculture and fish stocks. [al, am] } \\
\text { Other challenges to local food production, including peak oil. [aq, au] } \\
\text { Changes to cost and availability of food due to climate impacts on local agriculture, which could have } \\
\quad \text { consequences for equity, nutrition, and health. [al] } \\
\text { Unequal geographic distribution of outlets selling fresh, healthy food. [al, ar, as] } \\
\text { Financial constraints on households. [ar] } \\
\text { Income and property loss due to climate-related impacts. [al] } \\
\text { Mobility restrictions due to climate-related impacts. [al] } \\
\text { Mobility restrictions due to location or disability. [al, ar] }\end{array}$ \\
\hline & $\begin{array}{r}\mathbf{A} \\
\mathbf{C} \\
\mathbf{A} \\
\mathbf{C} \\
\mathbf{C} \\
\mathbf{C}, \mathbf{D}, \mathbf{E} \\
\mathbf{A} \\
\mathbf{A} \\
\mathbf{A} \\
\mathbf{A} \\
\mathbf{E} \\
\mathbf{E} \\
\mathbf{E} \\
\mathbf{E} \\
\mathbf{A} \\
\mathbf{B} \\
\mathbf{E} \\
\mathbf{E} \\
\mathbf{A}, \mathbf{B} \\
\mathbf{D}\end{array}$ & $\begin{array}{r}1,2,3,4 \\
1 \\
1 \\
1,2,3 \\
1,2,3 \\
1,3 \\
2 \\
2 \\
3 \\
3 \\
3 \\
3 \\
3 \\
3 \\
3 \\
3 \\
3 \\
3 \\
3,4 \\
4\end{array}$ & $\begin{array}{l}\text { Describe the local food system in detail, from production through consumption. [an, as] } \\
\text { Conserve fertile lands. [ao] } \\
\text { Assess what and how much food is produced and processed locally. [aq, as] } \\
\text { Produce and process food locally; attract and expand food-sector industries. [an, ao, aq] } \\
\text { Promote the procurement and purchase of foods produced in the region. [an, ao] } \\
\text { Promote urban agriculture and gardening. [ak, an, ao] } \\
\text { Identify major assets in the distribution system. [as] } \\
\text { Identify where wholesalers are located in the city. [as] } \\
\text { Inventory food retail outlets. [as] } \\
\text { Assess, describe, and map access to retail food outlets. [al, ar, as] } \\
\text { Promote new food outlets and improve existing outlets, especially in underserved areas. [an, ao, ar, as] } \\
\text { Leverage city lease holdings to upgrade food offerings at food retail outlets. [an, ao] } \\
\text { Improve vending machine offerings in city buildings. [an, ao, ap] } \\
\text { Assist residents in accessing food-related benefit programs. [an, ao] } \\
\text { Quantify dependence on food provision programs. [as, at] } \\
\text { Boost resilience of area NGOs. [ax] } \\
\text { Enact legislation to compensate NGOs for assistance rendered during a crisis. [ax] } \\
\text { Run an emergency preparedness website, including a "crisis map" with relevant layers. [av] } \\
\text { Provide information on food safety, including for power failures. [aw] } \\
\text { Offer nutrition and culinary training programs. [as] }\end{array}$ \\
\hline
\end{tabular}

Table A.8. Vulnerabilities and responses relevant to the resilience of food supply chains: San Francisco, CA.

Coding Key:

\begin{tabular}{|c|c} 
Phases of the food supply chain: & Strategies for increasing resilience: \\
1 - Production, aggregation, and processing & A - Identify assets, opportunities, needs, and risks \\
2 - Distribution, wholesaling, and warehousing & B - Adapt processes, structures, and infrastructure \\
3 - Retailing, food service, and consumer access & C - Increase regional self-sufficiency in food and water \\
4 - End user storage and preparation; consumption and waste & D - Create redundancies and alternatives \\
& E - Improve consumer access
\end{tabular}

\section{References:}

[ak] (San Francisco Department of the Environment, 2013)

[al] (Wolff \& Comerford, 2014)

[am] (Ekstrom \& Moser, 2012)

[an] (Jones, 2010)

[ao] (Newsom, 2009)

[ap] (Newsom, 2010)

[aq] (Randall, 2010)

[ar] (San Francisco Department of Public Health, n.d.(b))

[as] (Jones, Ona, Rimkus, \& Wells, 2005)

[at] (Lin-Conrad, Jones, O'Farrell, \& Ferreira, 2009)

[au] (Board of Supervisors of the City and County of San Francisco, 2006)

[av] (San Francisco Department of Emergency Management, 2015)

[aw] (San Francisco Department of Public Health, n.d.(a))

[ax] (Rapp, 2014) 


\begin{tabular}{|c|c|c|c|}
\hline & Strategies & Elements & \\
\hline & & $\begin{array}{r}1,2,3,4 \\
1,2,3,4 \\
1,2,3,4 \\
1,2,3,4 \\
1,3,4 \\
1,3,4 \\
1,3,4 \\
1,3,4 \\
1,2,3,4 \\
1,2,3 \\
1,3,4 \\
1,3,4 \\
1 \\
1 \\
1 \\
1 \\
1 \\
1 \\
1 \\
1,2 \\
2 \\
2 \\
2 \\
2,3 \\
2,3 \\
2,3 \\
2,3 \\
2,3 \\
3 \\
3 \\
3 \\
3 \\
3,4 \\
4\end{array}$ & 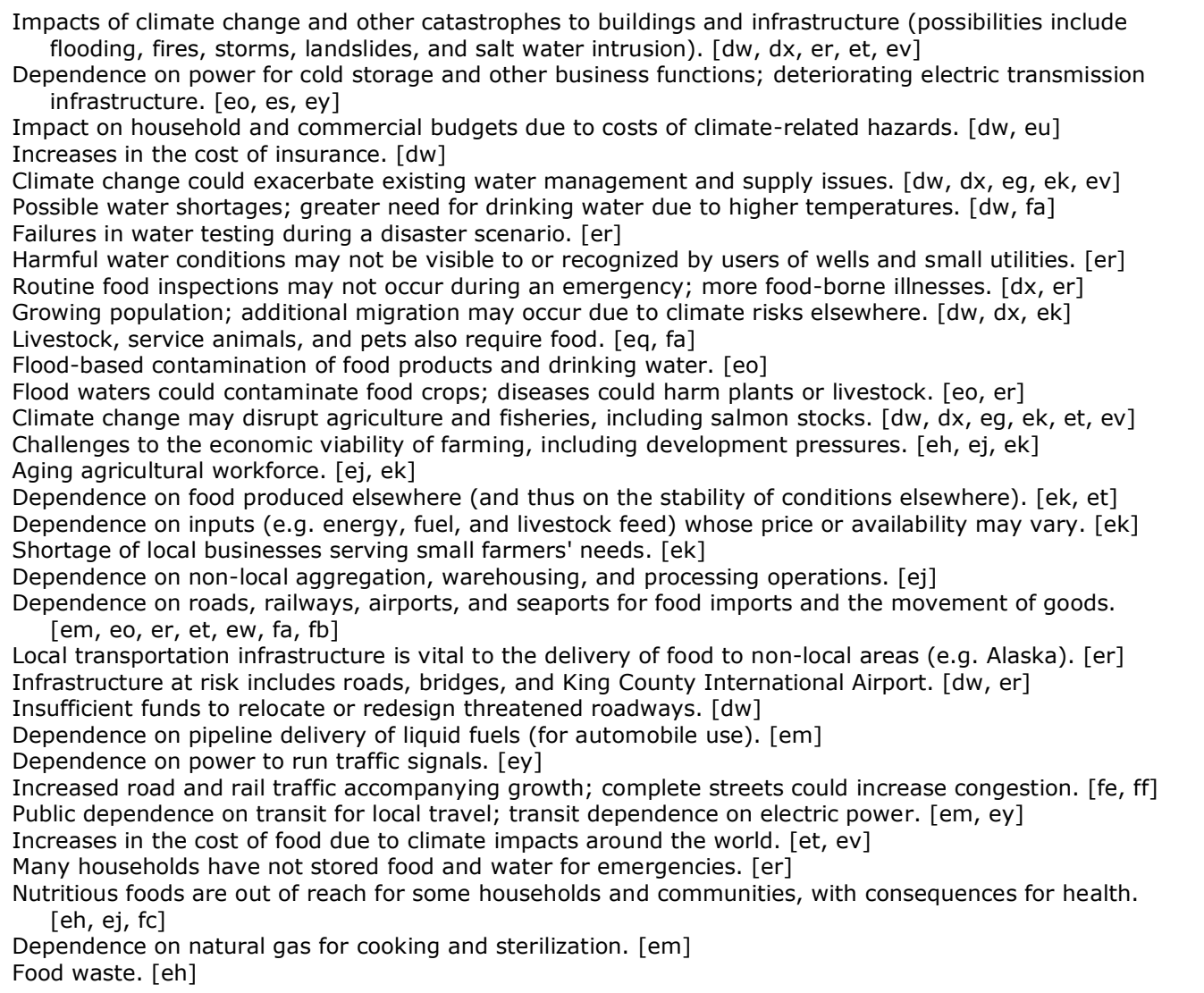 \\
\hline & $\begin{array}{r}\text { A, B } \\
\text { A, B, D, E } \\
\text { A, B } \\
\text { B } \\
\text { D } \\
\text { A, B, C, D } \\
\text { A } \\
\text { A } \\
\text { B } \\
\text { B } \\
\text { C } \\
\text { C } \\
\text { C } \\
\text { A, C } \\
\text { C } \\
\text { C, D } \\
\text { C, D } \\
\text { B, C, E } \\
\text { A } \\
\text { C, D, E } \\
\text { C, D, E } \\
\text { A } \\
\text { B, E } \\
\text { A } \\
\text { A } \\
\text { E } \\
\text { E }\end{array}$ & $\begin{array}{r}1,2,3,4 \\
2,3 \\
1,2,3,4 \\
1,2,3,4 \\
1,2,3,4 \\
1,3,4 \\
1 \\
1,4 \\
1 \\
1 \\
1 \\
1 \\
1 \\
1,2,3 \\
1,2,3 \\
1,2 \\
1,2,3 \\
1,2,3 \\
1 \\
1,3 \\
1,3 \\
2,3 \\
2,3 \\
2,3 \\
3 \\
3 \\
3\end{array}$ & 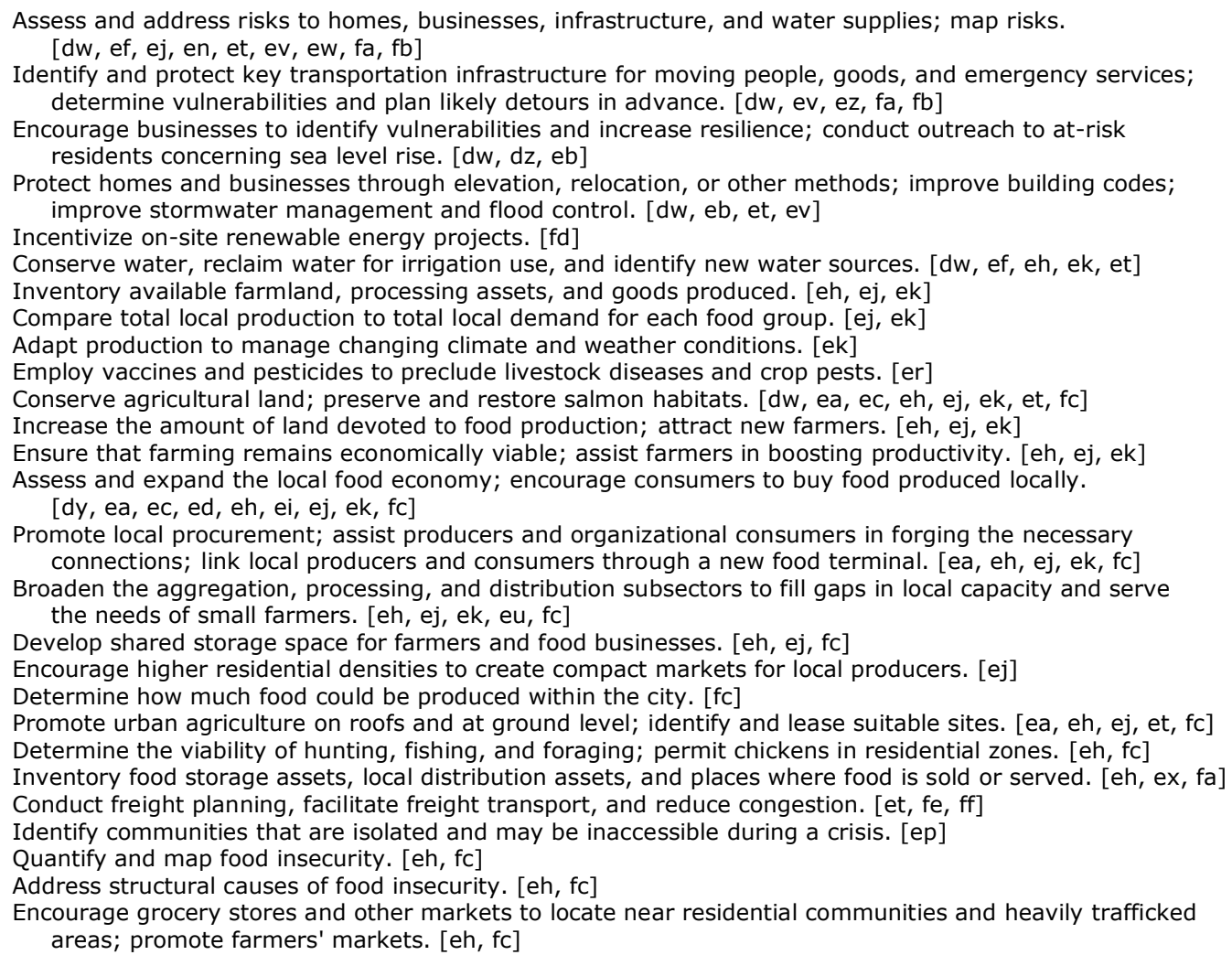 \\
\hline
\end{tabular}

(Table continues on next page) 


\begin{tabular}{|c|c|c|c|}
\hline & Strategies & Elements & \\
\hline 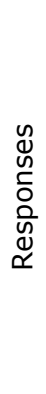 &  & $\begin{array}{r}1,3 \\
3 \\
3 \\
3 \\
3 \\
3 \\
3 \\
3 \\
3 \\
3,4 \\
1,2,3,4 \\
4 \\
4 \\
1,2,3,4\end{array}$ & $\begin{array}{l}\text { Bring fresh food markets and mobile processing operations to communities in need. [eh, ej, eu, fc] } \\
\text { Improve food offerings at institutions, restaurants, and retailers to promote better nutrition. [eh, fc] } \\
\text { Improve transit service and affordability; promote walking and cycling. [dw, et, ev, fc] } \\
\text { Create compact, mixed-use, and affordable urban neighborhoods; promote infill \& TOD. [dw, ea, et, ev] } \\
\text { Assist low-income and fixed-income households with accessing and purchasing healthy food. [eh, ej, fc] } \\
\text { Ensure that markets can accept payments via SNAP and similar programs. [eh] } \\
\text { Assist community food providers in obtaining cold storage. [eh] } \\
\text { Improve food choices in vending machines. [ee, eu, fc] } \\
\text { Conduct outreach to reduce food waste; promote charitable donation and composting. [eh, el, et, fc] } \\
\text { Consume imperfect produce typically slated for disposal. [eh] } \\
\text { Install kitchens in government and community institutions; establish community kitchens. [ed, eh, ej] } \\
\text { Run educational programs to enhance cooking skills. [eh, ej, fc] } \\
\text { Publish performance measures online to track environmental conditions and government initiatives. [eb] }\end{array}$ \\
\hline
\end{tabular}

Table A.9. Vulnerabilities and responses relevant to the resilience of food supply chains: Seattle (city) \& King County, WA.

\section{Coding Key:}

\begin{tabular}{|c|c|}
\hline Phases of the food supply chain: & Strategies for increasing resilience: \\
1 - Production, aggregation, and processing & A - Identify assets, opportunities, needs, and risks \\
2 - Distribution, wholesaling, and warehousing & B - Adapt processes, structures, and infrastructure \\
3 - Retailing, food service, and consumer access & C - Increase regional self-sufficiency in food and water \\
4 - End user storage and preparation; consumption and waste & D - Create redundancies and alternatives \\
& E - Improve consumer access \\
\hline
\end{tabular}

\section{References:}

[dw] (King County \& KCIT DNRP GIS, 2015)

[dx] (King County, 2013a)

[dy] (King County, 2015b)

[dz] (King County, 2015c)

[ea] (King County - Cities Climate Collaboration, 2015)

[eb] (King County DNRP, n.d.(b))

[ec] (King County DNRP, n.d.(a))

[ed] (Seattle \& King County Public Health, 2015b)

[ee] (Seattle \& King County Public Health, 2015a)

[ef] (Wastewater Treatment Division, 2015)

[eg] (King County, 2015d)

[eh] (King County, 2015a)

[ei] (King County, 2015e)

[ej] (King County Farms and Food Roundtable, Staff Team Members, \& Cedar River Group, 2014)

[ek] (King County \& King County Agricultural Commission, 2009)

[el] (King County Solid Waste Division, 2015)

[em] (Washington State Homeland Security Region 6, 2005)

[en] (King County OEM, 2013a)

[eo] (King County OEM, 2015a)

[ep] (King County OEM, 2015b)

[eq] (King County OEM, 2013b)

[er] (King County OEM, 2013c)

[es] (King County, 2013b)

[et] (GGLO Design, 2013)

[eu] (Morgenstern, 2013)

[ev] (GGLO Design, 2012)

[ew] (GGLO Design, 2015)

[ex] (Seattle OEM, 2012)

[ey] (Seattle OEM, 2014)

[ez] (Seattle Department of Transportation, n.d.)

[fa] (Seattle OEM, 2015)

[fb] (City of Seattle, 2009)

[fc] (Lerman, Haima, \& Mehus-Roe, 2012)

[fd] (Seattle City Light, 2015)

[fe] (Mazzella \& Pascal, 2014a)

[ff] (Mazzella \& Pascal, 2014b) 


\begin{tabular}{|c|c|c|c|}
\hline & Strategies & Elements & \\
\hline & & $\begin{array}{r}1,2,3,4 \\
1,2,3,4 \\
1,2,3,4 \\
1,2,3,4 \\
1,2,3,4 \\
1,3,4 \\
1 \\
1 \\
1,3 \\
2 \\
2,3 \\
3 \\
3 \\
3 \\
2,3,4 \\
1,2,3 \\
4\end{array}$ & $\begin{array}{l}\text { Disruptions to critical infrastructure networks, including electric power, communication, and land, water, and } \\
\text { air transportation. [c, } r, s, v] \\
\text { Electrical outages interfering with refrigeration and freezing, potentially causing food spoilage and illness } \\
\quad \text { (n.b. sensitivity to food-borne illness differs). [b, } c, d, s] \\
\text { Backup power generators depend on liquid fuels. [ac] } \\
\text { Bacterial growth due to higher temperatures. [c, s] } \\
\text { Loss of product due to flooding. [c, ab] } \\
\text { Changes in water quality. [a, } d, v, a c] \\
\text { Impacts of climate change and other disruptions on local and non-local agriculture and other food sources, } \\
\quad \text { like fisheries. [a, } b, i, j, p, q, s, v, x] \\
\text { Dependence on imported food. [a, } k, q] \\
\text { Declining knowledge of simple food processing methods (e.g. canning, juicing). [y] } \\
\text { Disruptions to transportation infrastructure outside the region. [v] } \\
\text { Dependence on liquid fuels for transportation. [ac] } \\
\text { Changes to food costs and availability due to disruptions in supply; consequences for nutrition. [a, b] } \\
\text { Unequal geographic distribution of outlets selling fresh, healthy food; challenges for people with limited } \\
\quad \text { mobility. [f, } g, j, k] \\
\text { Households lacking financial resources, including insurance. [f, } g, k, v, x] \\
\text { Challenges caused by evacuations and relocations. [c] } \\
\text { Climate refugees entail increased demand for goods and services. }[v] \\
\text { Many residents lack knowledge on food preparation and cooking, which may be valuable in times of crisis } \\
\text { or displacement. [j, } k \text { ] }\end{array}$ \\
\hline & 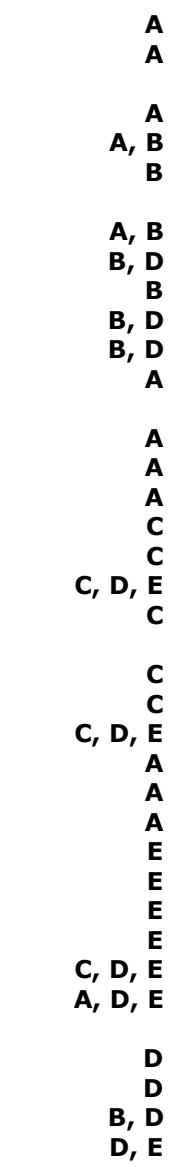 & $\begin{array}{r}1,2,3,4 \\
1,2,3 \\
1,2,3,4 \\
1,2,3,4 \\
1,2,3,4 \\
1,2,3,4 \\
3,4 \\
1,2,3,4 \\
3 \\
4 \\
1,2,3 \\
1 \\
1 \\
1 \\
1 \\
1,2,3 \\
1 \\
1,3,4 \\
1,2,3 \\
\\
1,2,3 \\
1,2,3 \\
1,3 \\
3 \\
3 \\
3 \\
3 \\
3 \\
3 \\
3 \\
3 \\
1,2,3,4 \\
2,3,4 \\
4 \\
4 \\
4 \\
3,4\end{array}$ & 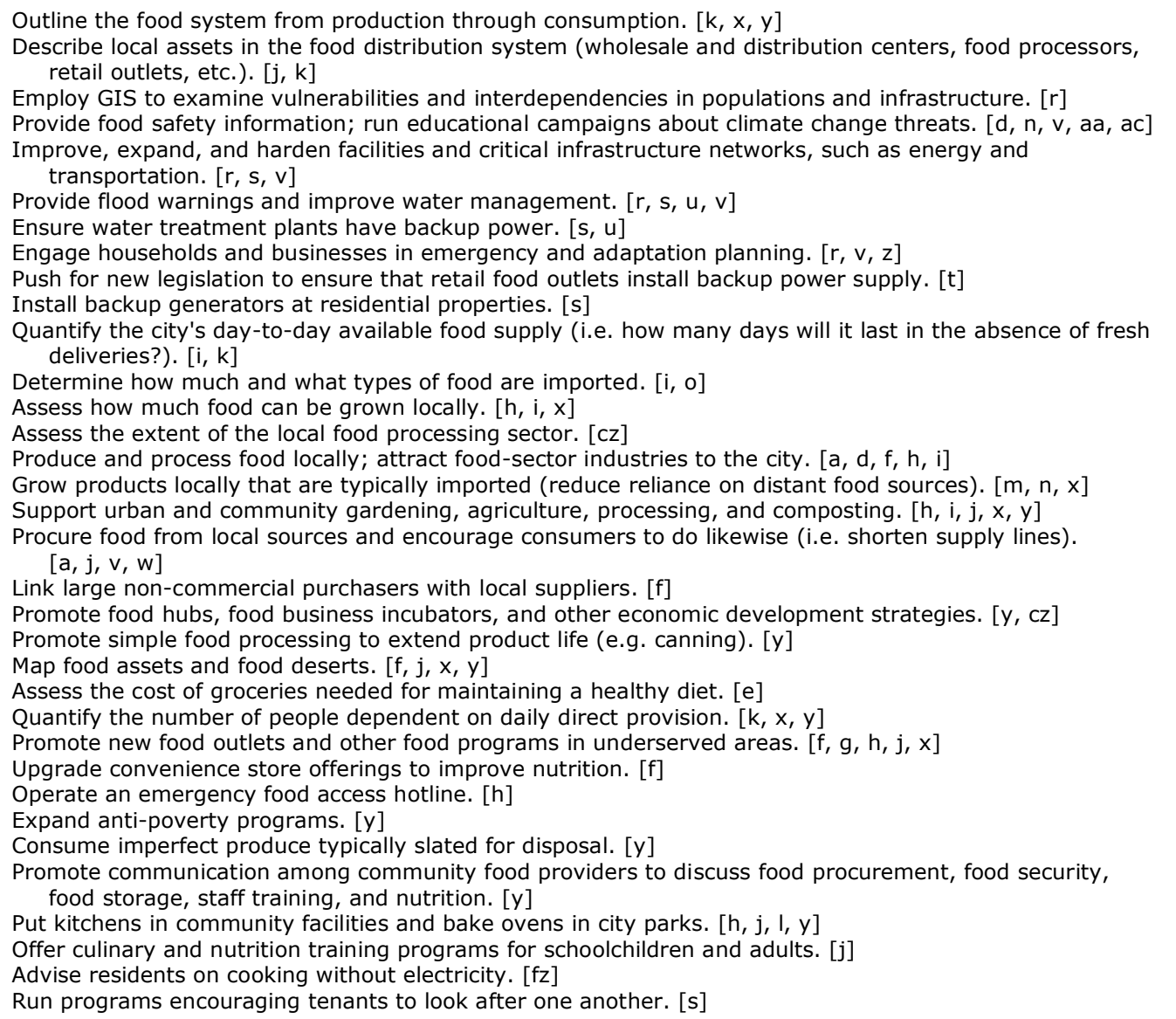 \\
\hline
\end{tabular}

Table A.10. Vulnerabilities and responses relevant to the resilience of food supply chains: Toronto, ON.

\section{Coding Key:}

Phases of the food supply chain:

1 - Production, aggregation, and processing

2 - Distribution, wholesaling, and warehousing

3 - Retailing, food service, and consumer access

4 - End user storage and preparation; consumption and waste
Strategies for increasing resilience:

A - Identify assets, opportunities, needs, and risks

$B$ - Adapt processes, structures, and infrastructure

C - Increase regional self-sufficiency in food and water

D - Create redundancies and alternatives

$\mathrm{E}$ - Improve consumer access 


\section{References:}

[a] (City of Toronto Public Health, 2015a)

[b] (McKeown, 2015)

[c] (McKeown, 2013a)

[d] (Pinto, Penney, Ligeti, Gower, \& Mee, 2011)

[e] (City of Toronto Public Health, 2015c)

[f] (City of Toronto Public Health, 2015d)

[g] (FoodShare, n.d.)

[h] (City of Toronto Public Health, 2015b)

[i] (Toronto Food Policy Council, 1999b)

[j] (City of Toronto Public Health, 2010)

[k] (City of Toronto Public Health, 2008)

[l] (McKeown, 2012)

[m] (McKeown, 2013b)

[n] (Toronto Food Policy Council, 2015)

[o] (Kubursi, Cummings, MacRae, \& Kanaroglou, 2015)

[p] (Tomalty \& Komorowski, 2011)

[q] (Metcalf Foundation, 2008)

[r] (Rossini, 2014)

[s] (Scioli, 2013)

[t] (City of Toronto, 2013)

[u] (City of Toronto Environment Office, 2011)

[v] (City of Toronto Environment Office, City of Toronto Climate Adaptation Steering Group, \& Clean Air Partnership, 2008)

[w] (City of Toronto Purchasing and Materials Management Division, 2013)

[x] (Lister, 2007)

[y] (Kamizaki, 2014)

[z] (City of Toronto OEM, 2015c)

[aa] (City of Toronto OEM, 2015a)

[ab] (Toronto and Region Conservation Authority \& City of Toronto OEM, 2014)

[ac] (Toronto Hydro Electric System Limited \& City of Toronto OEM, 2015)

[cz] (Uens, 2014)

[fz] (City of Toronto Fire Services, n.d.) 


\begin{tabular}{|c|c|c|c|}
\hline & Strategies & Elements & \\
\hline 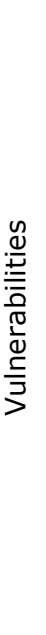 & & $\begin{array}{r}1,2,3,4 \\
1 \\
2 \\
1,2,3 \\
\\
1,2,3,4 \\
1,3,4 \\
1,2,3,4 \\
1,2,3,4 \\
1,2,3 \\
3 \\
3 \\
3 \\
3 \\
3 \\
4 \\
4 \\
4\end{array}$ & $\begin{array}{l}\text { Climate-related risks, including flooding and infrastructure damage. [bo] } \\
\text { Food supply vulnerabilities such as climate change, economic forces, and the loss of agricultural land. } \\
\text { [bj, bm, bo] } \\
\text { Dependency on transportation infrastructure for the movement of goods to local and distant markets. } \\
\text { [bn, bp] } \\
\text { Dependence on imported food and fossil fuels for transport; challenges to regional food self-sufficiency. } \\
\text { [bj, bm] } \\
\text { Dependence of backup power generators on liquid fuel supply chains. [bo] } \\
\text { Water supply shortages; water quality problems. [bo] } \\
\text { Loss of property due to flooding. [bo] } \\
\text { Property insurance may be difficult to obtain. [bo] } \\
\text { Climate refugees, which would increase local demand for food. [bo] } \\
\text { Unequal geographic distribution of outlets selling fresh, nutritious food, which has consequences for the } \\
\text { health of residents. [bj, bm] } \\
\text { Dependency on transportation modes other than walking to access food. [bm] } \\
\text { Mobility restrictions due to location, resources, age, or disability. [bj, bm] } \\
\text { Financial constraints on households. [bj, bm] } \\
\text { Rising food prices. [bm] } \\
\text { Insufficient storage space in the home. [bm] } \\
\text { Insufficient access to suitable preparation space. [bm] } \\
\text { Insufficient food skills. [bm] }\end{array}$ \\
\hline & $\begin{array}{r}\text { A } \\
\mathbf{A}, \mathbf{B} \\
\mathbf{B} \\
\mathbf{B} \\
\mathbf{B}, \mathbf{D} \\
\mathbf{A} \\
\mathbf{A} \\
\mathbf{C} \\
\mathbf{C} \\
\mathbf{C}, \mathbf{D} \\
\mathbf{C} \\
\mathbf{C} \\
\mathbf{B}, \mathbf{D} \\
\mathbf{A} \\
\mathbf{C}, \mathbf{E} \\
\mathbf{D}, \mathbf{A} \\
\mathbf{A} \\
\mathbf{E} \\
\mathbf{E} \\
\mathbf{E} \\
\mathbf{E} \\
\mathbf{E} \\
\mathbf{D}, \mathbf{E} \\
\mathbf{D} \\
\mathbf{D} \\
\mathbf{D} \\
\mathbf{C} \\
\mathbf{A}\end{array}$ & $\begin{array}{r}1,2,3,4 \\
1,2,3,4 \\
1,2,3,4 \\
1,2,3,4 \\
1,2,3,4 \\
1 \\
1,2 \\
1 \\
1,2,3 \\
1,2,3 \\
1,2,3 \\
1,2,3 \\
2 \\
1,2,3,4 \\
\\
1,3 \\
3 \\
3 \\
3 \\
3 \\
3 \\
3 \\
3 \\
3,4 \\
4 \\
4 \\
4 \\
4 \\
1,2,3,4\end{array}$ & $\begin{array}{l}\text { Outline and describe elements of the local food system. [bj] } \\
\text { Promote risk awareness and resilience among businesses and residents. [bo] } \\
\text { Adapt structures and infrastructure. [bo] } \\
\text { Improve water management. [bo] } \\
\text { Ensure liquid fuel supply during a crisis. [bo] } \\
\text { Assess where, what, and how much food is produced locally and regionally. [bj, bk, bm] } \\
\text { Investigate how the local food production, processing, and distribution system can be improved. [bj] } \\
\text { Preserve agricultural land. [bj] } \\
\text { Promote food hubs or incubators to enhance the local food system and the local food economy. [bj, bl] } \\
\text { Construct or provide facilities for businesses to store food. [bj, bk] } \\
\text { Procure food from local sources and assist other organizations in doing so. [bj, bk, bl, bn] } \\
\text { Link local producers and local consumers through marketing and other programs. [bj] } \\
\text { Open up additional streets to truck traffic. [bn] } \\
\text { Inventory and map assets such as urban agriculture plots, markets, retail stores, and community kitchens. } \\
\text { [bj, bk, bm] } \\
\text { Promote urban agriculture, gardening, and small-scale processing. [bj, bk, bl, bm, bn] } \\
\text { Determine areas of high food insecurity. [bm] } \\
\text { Assess the cost of groceries needed for maintaining a healthy diet. [bm] } \\
\text { Promote new food outlets and food programs, especially in underserved areas. [bj, bk, bl, bm] } \\
\text { Improve offerings at food outlets in underserved areas. [bj, bk] } \\
\text { Expand farmers' markets. [bj, bk] } \\
\text { Promote transit and active transportation. [bn] } \\
\text { Leverage contracts to improve offerings in vending machines. [bk] } \\
\text { Promote programs encouraging residents to look after one another. [bo] } \\
\text { Increase the number of community kitchens. [bj, bk, bl] } \\
\text { Install bake ovens at parks. [bk] } \\
\text { Support nutrition and culinary training programs. [bj, bk] } \\
\text { Promote composting. [bj, bk, bl] } \\
\text { Measure progress using indicators. [bj, bl, bm, bo] }\end{array}$ \\
\hline
\end{tabular}

Table A.11. Vulnerabilities and responses relevant to the resilience of food supply chains: Vancouver, BC.

Coding Key:

\begin{tabular}{|c|c|}
\hline Phases of the food supply chain: & Strategies for increasing resilience: \\
1 - Production, aggregation, and processing & A - Identify assets, opportunities, needs, and risks \\
2 - Distribution, wholesaling, and warehousing & B - Adapt processes, structures, and infrastructure \\
3 - Retailing, food service, and consumer access & C - Increase regional self-sufficiency in food and water \\
$4-$ End user storage and preparation; consumption and waste & D - Create redundancies and alternatives \\
& E - Improve consumer access
\end{tabular}

\section{References:}

[bj] (City of Vancouver, 2013b)

[bk] (Local Food Assets Task Force, 2013)

[bl] (City of Vancouver, 2013a)

[bm] (City of Vancouver Social Policy and Projects, 2015)

[bn] (City of Vancouver, 2012b)

[bo] (City of Vancouver, 2012a)

[bp] (Northwest Hydraulic Consultants, 2014) 


\title{
REFERENCE LIST
}

\author{
ACCCRN. (n.d.). About the ACCCRN network. Retrieved from http://acccrn. net/about-acccrn
}

Agriculture and Agri-Food Canada. (2012). Socially conscious consumer trends - sustainability. Retrieved from http://www.agr.gc.ca/eng/industry-markets-and-trade/statistics-and-market-information/byregion/global/socially-conscious-consumer-trends-sustainability/?id=1410083148827

Agriculture and Agri-Food Canada. (2015). An overview of the Canadian agriculture and agri-food system 2014. Retrieved from http://www.agr.gc.ca/eng/about-us/publications/economic-publications/alphabeticallisting/an-overview-of-the-canadian-agriculture-and-agri-food-system-2014/?id=1396889920372

Archer, D., Almansi, F., DiGregorio, M., Roberts, D., Sharma, D., \& Syam, D. (2014). Moving towards inclusive urban adaptation: Approaches to integrating community-based adaptation to climate change at city and national scale. Climate and Development, 6(4), 345-356. doi:10.1080/17565529.2014.918868

ASDA. (2015). ASDA groceries. Retrieved from http://groceries.asda.com/

Auber, A. (2011, August 4). Drought effects extend far beyond water restrictions. The Texas Tribune. Retrieved from http://www.nytimes.com/2011/08/05/us/05ttdrought.html

Barclay, C. (2012, June 14). Food miles (House of Commons Library note SN/SC/4984). Retrieved from www.parliament.uk/briefing-papers/SN04984.pdf

Barron, J. (2003, August 15). The blackout of 2003: The overview; power surge blacks out northeast, hitting cities in 8 states and Canada; midday shutdowns disrupt millions. The New York Times. Retrieved from http://www.nytimes.com/2003/08/15/nyregion/blackout-2003-overview-power-surge-blacks-northeasthitting-cities-8-states. html?pagewanted=all

Barron, M., Goldblatt, B., Ho, C., Hudson, R., Kaplan, D., Keberle, E., . . W Wilson, M. (2010, May). Understanding New York City's food supply. Retrieved from http://mpaenvironment.ei.columbia.edu/files/2014/06/ UnderstandingNYCsFoodSupply_May2010.pdf

Bates, J. (2014, January 28). Mayor's conversation on a healthy and livable community [council report, item no. 11.3.1]. Retrieved from https://www.halifax.ca/council/agendasc/documents/140128ca1131.PDF

Baxter, J., \& Bekkering, M. (2014). Resilient city - preparing for a changing climate [City of Toronto staff report]. Retrieved from http://www.toronto.ca/legdocs/mmis/2014/pe/bgrd/backgroundfile-70623.pdf

Blume, C. (2015, March 16). Innovations in humanitarian action: MSF's Missing Maps Project highlights the world's most vulnerable places. MSF Canada. Retrieved from http://www.msf.ca/en/article/innovationsin-humantiarian-action-msf-s-missing-maps-project-highlights-the-world-s-most

Board of Supervisors of the City and County of San Francisco. (2006, April 20). Resolution no. 224-06: Peak oil plan of response and preparation. Retrieved from http://sfgov.org/sites/sfgov.org.sffood/files/migrated/ $\mathrm{ftp} /$ uploadedfiles/sffood/policy_reports/PeakOil.pdf

Bonini, C. (2014). San Francisco disaster food system report: Analysis and recommendations to advance food resiliency for low-income and vulnerable populations. Walter and Elise Haas Fund. Retrieved from http://www.haassr.org/wp-content/uploads/2014/10/wehfDisasterFoodSystems.pdf

Bozikovic, A. (2015, July 18). Shelters from the storm. The Globe and Mail, pp. F1, F5, F6, \& F7.

Brown, A., Dayal, A., \& Rumbaitis Del Rio, C. (2012). From practice to theory: Emerging lessons from Asia for building urban climate change resilience. Environment \& Urbanization, 24(2), 531-556. doi: $10.1177 / 0956247812456490$

Brown, D., Cabbage, M., \& Northon, K. (2016, January 20). NASA, NOAA analyses reveal record-shattering global warm temperatures in 2015 [NASA press release]. Retrieved from http://www.nasa.gov/pressrelease/nasa-noaa-analyses-reveal-record-shattering-global-warm-temperatures-in-2015

Bulkeley, H., Castán Broto, V., \& Edwards, G. (2012). Bringing climate change to the city: Towards low carbon urbanism? Local Environment, 17(5), 545-551. doi:10.1080/13549839.2012.681464

Buzby, J. C., Wells, H. F., \& Hyman, J. (2014, February). The estimated amount, value, and calories of postharvest food losses at the retail and consumer levels in the United States. EIB-121, Economic 
Research Service, US Department of Agriculture. Available from

http://www.ers.usda.gov/publications/eib-economic-information-bulletin/eib121.aspx

C40 Cities. (2015). About C40. Retrieved from http://www.c40.org/about

Campbell, H. (2014). Food Policy Council aims for more local food and local tables. NorthernLife.ca. Retrieved from http://www.northernlife.ca/news/localNews/2014/05/15-food-policy-council-sudbury.aspx

Canadian Hydrographic Service Central and Arctic Region. (2007). Fluctuations in lake levels - types. Retrieved from http://www.waterlevels.gc.ca/C\&A/fluctuations_e.html

Carss, B. (2014, January 9). Toronto ice storm pelts residential managers: Tenants and assets were both vulnerable due to the cold. Canadian Property Management. Retrieved from https://www.reminetwork.com/articles/toronto-ice-storm-pelts-residential-managers/

Carter, J. G. (2011). Climate change adaptation in European cities. Current Opinion in Environmental Sustainability, 3(3), 193-198. doi:10.1016/j.cosust.2010.12.015

Carter, J. G., Cavan, G., Connelly, A., Guy, S., Handley, J., \& Kazmierczak, A. (2014). Climate change and the city: Building capacity for urban adaptation. Progress in Planning, 95, 1-66. doi:10.1016/j.progress.2013.08.001

Carville, O. (2015, March 12). Loblaws sells ugly fruit at a discount to curb food waste. The Toronto Star. Retrieved from http://www.thestar.com/life/food_wine/2015/03/12/loblaws-sells-ugly-fruit-at-a-discountto-curb-food-waste.html

Castán Broto, V., \& Bulkeley, H. (2013). A survey of urban climate change experiments in 100 cities. Global Environmental Change, 23(1), 92-102. doi:10.1016/j.gloenvcha.2012.07.005

CDP Worldwide. (2015). States and regions initiative. Retrieved from https://www.cdp.net/enUS/Programmes/Pages/states-and-regions.aspx

Chandra, A., Acosta, J., Stern, S., Uscher-Pines, L., Williams, M. V., Yeung, D., . . . Meredith, L. S. (2011). Building community resilience to disasters: A way forward to enhance national health security. RAND Corporation. Retrieved from http://www.rand.org/content/dam/rand/pubs/technical_reports/ 2011/RAND_TR915.pdf

City and County of San Francisco. (2010). City and County of San Francisco emergency response plan: ESF \#6: Mass care, housing, \& human services annex. Retrieved from http://www.sfdem.org/modules/ShowDocument. aspx?documentid=837

City and County of San Francisco. (2011). City and County of San Francisco disaster feeding plan [Presentation materials]. Retrieved from https://www.sfdph.org/dph/files/mtgsGrps/FoodSecTaskFrc/docs/ DisasterFeeding_08032011.pdf

City of Edmonton. (2010). The way we grow: Municipal development plan (bylaw 15100). Retrieved from http://www.edmonton.ca/city_government/documents/PDF/MDP_Bylaw_15100.pdf

City of Edmonton. (2011). The way we green: The City of Edmonton's environmental strategic plan. Retrieved from http://www.edmonton.ca/city_government/documents/PDF/TheWayWeGreen-approved.pdf

City of Greater Sudbury. (n.d.(a)). Compost food. Retrieved from http://www.greatersudbury.ca/living/ environmental-initiatives/earthcare-sudbury/food-2014/4-compost-food/

City of Greater Sudbury. (n.d.(b)). EarthCare Sudbury partner profile. Retrieved from http://www.greatersudbury.ca/living/environmental-initiatives/earthcare-sudbury/communitypartners/partner-profiles/list-of-earthcare-partner-profiles/the-foodshed-project/

City of Greater Sudbury. (n.d.(c)). Partner actions: Food. Retrieved from http://www.greatersudbury.ca/living/ environmental-initiatives/earthcare-sudbury/monitoring-progress/partner-actions/food/

City of Greater Sudbury. (n.d.(d)). Power outage. Retrieved from http://www.greatersudbury.ca/living/emerg ency-preparedness/prepare-for-emergencies/know-what-to-do/hazard-preparedness1/power-outage/

City of Greater Sudbury. (n.d.(e)). Progress indicators: Food. Retrieved from http://www.greatersudbury.ca/living/environmental-initiatives/earthcare-sudbury/monitoringprogress/progress-indicators/food/ 
City of Greater Sudbury. (2004). Official plan: Agricultural background study. Retrieved from http://www.greatersudbury.ca/linkservid/3DECB124-E610-91ED-D7B25B1445E1C7E8/showMeta/0/

City of Iqaluit. (2012). What we heard: A summary of past voices. Retrieved from https://sustainableiqaluit1.files.wordpress.com/2012/05/what-we-heard-final-eng-web.pdf

City of Iqaluit. (2014a). Iqaluit sustainable community plan: Part 1 - Overview. Retrieved from https://sustainableiqaluit1.files.wordpress.com/2014/01/final-part-1-overview-eng.pdf

City of Iqaluit. (2014b). Iqaluit sustainable community plan: Part 2 - Action plan. Retrieved from https://sustainableiqaluit1.files.wordpress.com/2014/03/final-part-2-action-plan-eng.pdf

City of Miami. (2008). MiPlan: City of Miami climate action plan. Retrieved from http://www.planningclimatechange.org/joomla/0_upload/MiPlan_20Final_20062608.pdf

City of Miami DCED (Department of Community and Economic Development). (2014). Five-year consolidated plan 2014-2018 \& annual action plan 2014-2015. Retrieved from http://www.miamigov.com/communitydevelopment/Docs/Reports/FINALConPlan20142018.pdf

City of Miami Emergency Management. (2015). Hurricane preparation. Retrieved from http://www.miamigov.com/EmergencyManagement/hurricaneprep.html

City of New Orleans. (2014, September 3). Fresh food retailers initiative. Retrieved from http://www.nola.gov/city/fresh-food-retailers-initiative/

City of New Orleans. (2015a, June). New Orleans preliminary resilience assessment. Available from http://www.nola.gov/resilience/pra/

City of New Orleans. (2015b, August). Resilient New Orleans: Strategic actions to shape our future city. Retrieved from http://resilientnola.org/wp-content/uploads/2015/08/Resilient_New_Orleans_Strategy.pdf

City of New Orleans. (2015c, October). City of New Orleans NDRC phase 2 - submitted application - October 2015. Available from http://www.nola.gov/resilience/national-disaster-resilience-competition/

City of New Orleans OHSEP (Office of Homeland Security and Emergency Preparedness), GCR \& Associates, Dewberry \& Davis LLC, Vissering Pardue \& Associates, Perez, \& Henry Consulting LLC. (2011, March 7). Orleans Parish 2010 hazard mitigation plan update. Retrieved from http://www.nola.gov/getattachment/Hazard-Mitigation/Hazards-and-Planning/Orleans-Parish-2010Hazard-Mitigation-Plan-Final-032311.pdf

City of New York. (n.d.). Critical infrastructure \& services: Food supply. Retrieved from http://www.nyc.gov/html/planyc/html/resiliency/food-supply.shtml

City of New York. (2013a). A stronger, more resilient New York. Retrieved from http://smedia.nyc.gov/agencies/sirr/SIRR_singles_Lo_res.pdf

City of New York. (2013b). New York City food policy: 2013 food metrics report. Retrieved from http://www.nyc.gov/html/planyc/downloads/pdf/publications/2013_food_metric_report_112513.pdf

City of New York. (2014). Progress report 2014: A greener, greater New York; a stronger, more resilient New York. Retrieved from http://www.nyc.gov/html/planyc2030/downloads/pdf/140422_PlaNYCPReport_FINAL_Web.pdf

City of New York. (2015). One New York: The plan for a strong and just city. Retrieved from http://www.nyc.gov/html/onenyc/downloads/pdf/publications/OneNYC.pdf

City of New York Department of City Planning. (2014a). Going to market: New York City's neighborhood grocery store and supermarket shortage. Retrieved from http://www.nyc.gov/html/dcp/html/supermarket/index.shtml

City of New York Department of City Planning. (2014b). Resilient retail. Retrieved from http://www.nyc.gov/html/dcp/html/resilient-retail/resilient-retail1.shtml

City of New York MOLTPS (Mayor's Office of Long-Term Planning and Sustainability), \& NYSDAM (New York State Department of Agriculture and Markets). (2014). Emergency preparedness guidelines for food retailers. Retrieved from http://www.nyc.gov/html/planyc/downloads/pdf/Emergency\%20Preparedness\%20 Guidelines.pdf 
City of Seattle. (2009, July). Seattle all-hazards mitigation plan. Retrieved from http://www.seattle.gov/ Documents/Departments/Emergency/PlansOEM/HazardMitigation/SeattleMitigationPlan.pdf

City of Sydney. (2015, January 14). Trigeneration. Retrieved from http://www.cityofsydney.nsw.gov.au/vision/towards-2030/sustainability/carbon-reduction/trigeneration

City of Toronto. (2013, October 8). Impacts from the July 8, 2013 storm event on the City of Toronto: City Council decision [adopted item 2013.EX34.4]. Retrieved from http://app.toronto.ca/tmmis/viewAgendaItemHistory.do?item=2013.EX34.4

City of Toronto Environment and Energy Division. (2014). Best practices in climate resilience from six North American cities. Retrieved from http://www1.toronto.ca/City\%200f\%20Toronto/ Environment\%20and\%20Energy/Programs\%20for\%20Businesses/Images/16-062014\%20Best\%20Practices\%20in\%20Climate\%20Resilience.pdf

City of Toronto Environment Office. (2011). Toronto's adaptation actions. Retrieved from http://www1.toronto.ca/City\%20Of\%20Toronto/Environment\%20and\%20Energy/Our\%20Goals/Files/pdf/ toronto_cc_adapt_actions.pdf

City of Toronto Environment Office. (2012, October 30). Toronto's future weather \& climate driver study: Outcomes report. Retrieved from http://www1.toronto.ca/city_of_toronto/environment_and_energy/ key_priorities/files/pdf/tfwcds-summary.pdf

City of Toronto Environment Office, City of Toronto Climate Adaptation Steering Group, \& Clean Air Partnership. (2008). Ahead of the storm: Preparing Toronto for climate change. Retrieved from http://www1.toronto.ca/City\%200f\%20Toronto/Environment\%20and\%20Energy/Our\%20Goals/Files/pdf/ A/ahead_of_the_storm.pdf

City of Toronto Fire Services. (n.d.). Emergency preparedness: Food. Retrieved from http://www1.toronto.ca/wps/portal/contentonly?vgnextoid=5a31a069d81f1410VgnVCM10000071d60f89R CRD\&vgnextchannel=dddf3840456e1410VgnVCM10000071d60f89RCRD

City of Toronto OEM (Office of Emergency Management). (2015a). Food safety. Retrieved from http://www1.toronto.ca/wps/portal/contentonly?vgnextoid=61d88077bef0d410VgnVCM10000071d60f89R CRD\&vgnextchannel=e0d36cbd2b95a410VgnVCM10000071d60f89RCRD

City of Toronto OEM (Office of Emergency Management). (2015b). Get emergency ready: High-rise living. Retrieved from http://www1.toronto.ca/City\%200f\%20Toronto/Office\%20of\%20Emergency\%20 Management/Files/pdf/O/OEM_HighRiseGuide.pdf

City of Toronto OEM (Office of Emergency Management). (2015c). Office of emergency management. Retrieved from http://www1.toronto.ca/wps/portal/contentonly?vgnextoid= 4b3307ceb6f8e310VgnVCM10000071d60f89RCRD

City of Toronto Public Health. (2008). The state of Toronto's food: Discussion paper for a Toronto food strategy. Available as Appendix F in http://www.toronto.ca/legdocs/mmis/2008/hl/bgrd/backgroundfile-13560.pdf

City of Toronto Public Health. (2010, May). Cultivating food connections: Toward a Healthy and Sustainable Food System for Toronto. Available by request: foodstrategy@toronto.ca

City of Toronto Public Health. (2015a). A climate of concern: Climate change and health strategy for Toronto 2015. Retrieved from http://www.toronto.ca/legdocs/mmis/2015/hl/bgrd/backgroundfile-81509.pdf

City of Toronto Public Health. (2015b). Food policy council history. Retrieved from http://www1.toronto.ca/ $\mathrm{wps} /$ portal/contentonly?vgnextoid=893616fbbf4f4410VgnVCM10000071d60f89RCRD

City of Toronto Public Health. (2015c). Nutritious food basket. Retrieved from http://www1.toronto.ca/wps/portal/contentonly?vgnextoid=5bc0ce7e2b322410VgnVCM10000071d60f89R CRD\&vgnextchannel $=3$ bd8ce7e2b322410VgnVCM10000071d60f89RCRD

City of Toronto Public Health. (2015d). Projects. Retrieved from http://www1.toronto.ca/wps/portal/contentonly? vgnextoid=80ca044e17e32410VgnVCM10000071d60f89RCRD

City of Toronto Purchasing and Materials Management Division. (2013, November 14). Local food procurement policy. Retrieved from http://www1.toronto.ca/City\%200f\%20Toronto/Purchasing\%20and\%20 Materials\%20Management/Selling\%20to\%20the\%20City/Purchasing\%20\&\%20Material\%20Management \%20Division/Policies-Legislation/local_food_policy.pdf 
City of Vancouver. (2012a). Climate change adaptation strategy. Retrieved from http://vancouver.ca/files/cov/Vancouver-Climate-Change-Adaptation-Strategy-2012-11-07.pdf

City of Vancouver. (2012b). Transportation 2040: Plan as adopted by Vancouver City Council on October 31, 2012. Retrieved from http://vancouver.ca/files/cov/Transportation_2040_Plan_as_adopted_by_ Council.pdf

City of Vancouver. (2013a). Greenest city: 2020 action plan. Retrieved from http://vancouver.ca/files/cov/Greenest-city-action-plan.pdf

City of Vancouver. (2013b). What feeds us: Vancouver food strategy. Retrieved from http://vancouver.ca/files/cov/vancouver-food-strategy-final.PDF

City of Vancouver Social Policy and Projects. (2015). Healthy city for all: Social indicators and trends 2014. Retrieved from http://vancouver.ca/files/cov/factsheet3-feeding-ourselves-well.PDF

Climate Change Advisory Task Force. (2010, August). Status of recommendations - August 2010. Retrieved from http://www.miamidade.gov/environment/library/reports/climate-change-recommendations-october-10.pdf

Clos, J. (2011). Introduction. In UN-Habitat, Cities and climate change: Global report on human settlements 2011 (vi-viii). London, UK: Earthscan. Available from http://unhabitat.org/books/cities-and-climatechange-global-report-on-human-settlements-2011/

Coastal Cities at Risk. (n.d.). About CCaR. Retrieved from http://coastalcitiesatrisk.org/wordpress/about-ccar/

Colten, C. E., Kates, R. W., \& Laska, S. B. (2008). Community resilience: Lessons from New Orleans and Hurricane Katrina. Community \& Regional Resilience Initiative (CARRI). Retrieved from http://www.resilientus.org/wp-content/uploads/2013/03/FINAL_COLTEN_9-25-08_1223482263.pdf

Consortium for a Healthier Miami-Dade. (2011). Miami-Dade community action plan: Communities putting prevention to work. Retrieved from http://www.miamidadematters.org/javascript/htmleditor/ uploads/CAP_Summary.pdf

Cummings, L. (2015). RE: Toronto area faith communities: Building resilience to extreme weather [deputation to the City of Toronto Subcommittee on Climate Change Mitigation and Adaptation]. Retrieved from http://www.toronto.ca/legdocs/mmis/2015/py/comm/communicationfile-51713.pdf

Cutter, S. L., Barnes, L., Berry, M., Burton, C., Evans, E., Tate, E., \& Webb, J. (2008). Community and regional resilience: Perspectives from hazards, disasters, and emergency management. Community and Regional Resilience Initiative. Retrieved from http://www.resilientus.org/wpcontent/uploads/2013/03/FINAL_CUTTER_9-25-08_1223482309.pdf

Dale, A., \& Hill, S. B. (2001). At the edge: Sustainable development in the 21st century. Vancouver, BC: UBC Press.

Deschamps, T. (2015, March 17). Decoding Toronto hydro problems. The Toronto Star. Retrieved from http://www.thestar.com/news/gta/2015/03/17/decoding-toronto-hydro-problems.html

Diamond, J. (1997). Guns, germs, and steel: The fates of human societies. New York, NY: W. W. Norton \& Company.

Diamond, J. (2005). Collapse: How societies choose to fail or succeed. New York, NY: Viking.

Dillon Consulting, de Romilly and de Romilly Ltd., \& ClimAdapt. (2007). Climate change risk management strategy for Halifax Regional Municipality. Retrieved from https://www.halifax.ca/climate/documents/ ClimateChangeRiskManagementStrategyforHRMDecember2007.pdf

Doolittle, R. (2014, March 9). Toronto to expand 'priority' neighbourhoods to 31. The Toronto Star. Retrieved from http://www.thestar.com/news/city_hall/toronto2014election/ 2014/03/09/toronto_to_expand_priority_neighbourhoods_to_31.html

Doumani, R. G., \& Foran, P. A. (2014). Ontario planning legislation \& commentary. Markham, ON: LexisNexus Canada Inc.

EarthCare Sudbury. (2008). The EarthCare Sudbury local action plan 2008 progress report. Retrieved from http://www.greatersudbury.ca/content/div_earthcare/documents/EarthCare_Sudbury_Progress_Report_2 008.pdf 
EarthCare Sudbury. (2010). 2010 EarthCare Sudbury action plan: Becoming a sustainable community. Retrieved from http://www.greatersudbury.ca/content/div_earthcare/documents/LAP\%20Book_En.pdf

EarthCare Sudbury. (2015). EarthCare Sudbury food access (map). Retrieved from http://sudbury.maps. arcgis.com/apps/OnePane/basicviewer/index.html?appid=bd08b0f44a8847bfb34d0656341b4927

Eegeesiak, J. (2015a). City of Iqaluit 2015-2019 community economic development plan: Part I - overview. Retrieved from http://www.city.iqaluit.nu.ca/sites/default/files/ced_plan_part1_overview_2015-19e.pdf

Eegeesiak, J. (2015b). City of Iqaluit 2015-2019 community economic development plan: Part II implementation. Retrieved from http://www.city.iqaluit.nu.ca/sites/default/files/ ced_plan_part2_implementation_2015-19e_0.pdf

El Akkad, O. (2015, July 18). The disaster scenario. The Globe and Mail, pp. F1, F3, \& F4.

Ekstrom, J. A., \& Moser, S. C. (2012). Climate change impacts, vulnerabilities, and adaptation in the San Francisco Bay area: A synthesis of PIER program reports and other relevant research. Retrieved from http://www.energy.ca.gov/2012publications/CEC-500-2012-071/CEC-500-2012-071.pdf

Elver, H. (2015, August 5). Interim report of the special rapporteur on the right to food. Retrieved from http://www.un.org/en/ga/search/view_doc.asp?symbol=A/70/287

Elton, S. (2012, October 18). The farm on top of the city: A new crop of urban farming businesses aims to feed locavores, save the planet - and turn a decent profit. Macleans. Retrieved from http://www.macleans.ca/society/technology/the-farm-on-top-of-the-city/

European Commission. (2014). Climate change. Retrieved from http://ec.europa.eu/research/environment/index_en.cfm?pg=climate

Faith \& the Common Good. (n.d.). Neighbourhood extreme weather resilience: Envisioning faith communities as neighbourhood resilience anchors. Retrieved from http://greeningsacredspaces.net/what-we-do/promotemulti-faith-community-engagement/faith-communities-extreme-weather-resilience-hubs/

FAO (Food and Agriculture Organization of the United Nations). (2013). FAO statistical yearbook 2013: World food and agriculture. Rome, Italy: FAO. Retrieved from http://www.fao.org/docrep/018/i3107e/i3107e.PDF

FCM (Federation of Canadian Municipalities). (2016). Partners for Climate Protection national measures report 2015: Local climate action across Canada. Ottawa, ON: Federation of Canadian Municipalities. Retrieved from http://www.fcm.ca/Documents/reports/PCP/2015/National_Measures_Report_2015_Local_ Climate_Action_Across_Canada_EN.pdf

Ferreira, S. (2012, October 29). Storm damages crops in Haiti, fueling food price woes. Reuters. Retrieved from http://www.reuters.com/article/storm-sandy-haiti-idUSL1E8LT5EX20121029

Fertig, B. (2013, August 12). How a massive power outage sent people out in the street. NPR. Retrieved from http://www.npr.org/2013/08/11/210700217/how-a-massive-power-outage-sent-people-dancing-in-thestreet

Fit NOLA. (2015, October). Fit NOLA strategic plan. Retrieved from http://www.nola.gov/getattachment/Health/Healthy-Lifestyles/Fit-NOLA_Strategic-Plan_2015.pdf/

Flavelle, D. (2014, July 5). A year after the Toronto flood. The Toronto Star. Retrieved from http://www. thestar.com/business/personal_finance/investing/2014/07/05/a_year_after_the_toronto_flood.html

Flesher, J. (2014, September 8). Cities prepare for warm climate without saying so. The Associated Press.

Florida Department of Transportation. (2013, January). Miami-Dade County freight \& logistics overview. Retrieved from http://www.dot.state.fl.us/planning/systems/programs/mspi/pdf/Freight/ onlineviewing/Miami-Dade.pdf

Flynn, S. (2011). Recalibrating homeland security: Mobilizing American society to prepare for disaster. Foreign Affairs. Retrieved from https://www.foreignaffairs.com/articles/united-states/2011-05-01/recalibratinghomeland-security

Food and Urban Agriculture Advisory Committee. (2012). Fresh: Edmonton's food \& urban agriculture strategy. Retrieved from http://www.edmonton.ca/city_government/documents/FRESH_October_2012.pdf

FoodShare. (n.d.). Mobile good food market. Retrieved from http://www.foodshare.net/mobilegoodfoodmarket 
Foodshed Project. (2009a). Food sustainability is. Retrieved from http://www.foodshedproject.ca/pdf/foods\%20sustainability\%20checklist.pdf

Foodshed Project. (2009b). The Sudbury and Manitoulin Districts Food Security Network [Presentation materials]. Retrieved from http://www.foodshedproject.ca/pdf/City\%20Council\%20PowerPoint\%20Food\%20 Security.ppt

Foodshed Project. (2010). Growing our foodshed sustainably [Presentation materials]. Retrieved from http://www.foodshedproject.ca/pdf/What\%20is\%20a\%20foodshed.ppt

Foodshed Project, \& Sudbury and Area FSN (Food Security Network). (2004). City of Greater Sudbury Food Charter. Retrieved from https://sudburyfoodpolicy.files.wordpress.com/2015/07/13_05_foodcharter_ eng_and_french.pdf

Foodshed Project, \& Sudbury-Manitoulin FSN (Food Security Network). (2007a). Community food security indicators report card of the City of Greater Sudbury: 2005 baseline report. Retrieved from http:// www. foodshedproject.ca/pdf/2007\%20FSN\%20Indicators\%20Baseline\%202005\%20Report\%20Card.pdf

Foodshed Project, \& Sudbury-Manitoulin FSN (Food Security Network). (2007b). Companion report: Community food security indicators baseline report card 2005: City of Greater Sudbury. Retrieved from http://www.foodshedproject.ca/pdf/2007\%20Companion\%20Report\%202005\%20Baseline\%20Communit y\%20Food\%20Security\%20Indicators\%20Greater\%20Sudbury.pdf

Fortin, L., \& Gionet, G. (2012). City of Greater Sudbury emergency management program [Presentation materials]. Retrieved from http://www.sudburyclimateaction.ca/images/stories/science_articles /Local/emergency\%20management\%20lynn\%20fortin.pdf

Gagnon, T., \& King, B. (2015, March 13.) RE: Local food and \#gs2025 [letter from the Greater Sudbury Food Policy Council to the Greater Sudbury Development Corporation]. Retrieved from https://sudburyfoodpolicy. files. wordpress.com/2015/05/foodpolicycouncilgs2025.pdf

Gallucci, M. (2013, June 20). 6 of the world's most extensive climate adaptation plans. InsideClimate News. Retrieved from http://insideclimatenews.org/news/20130620/6-worlds-most-extensive-climateadaptation-plans

Gerster, J. (2013, July 9). Toronto flooding: 'Lost' rivers reappear when nature takes charge. The Toronto Star. Retrieved from http://www.thestar.com/news/gta/2013/07/09/toronto_flooding_lost_rivers_reappear_ when_nature_takes_charge.html

GGLO Design. (2012, December). Seattle climate action plan: Green ribbon commission recommendations. Retrieved from http://www.seattle.gov/Documents/Departments/OSE/GRCReport_forweb-1-29-13.pdf

GGLO Design. (2013, June). Seattle climate action plan. Retrieved from http://www.seattle.gov/Documents/Departments/OSE/2013_CAP_20130612.pdf

GGLO Design. (2015, August 24). Climate preparedness: A mapping inventory of changing coastal flood risk. Available from http://www.seattle.gov/environment/climate-change/planning-for-climate-impacts

Goody Clancy, Camiros, Manning Architects, GCR \& Associates, Bright Moments, Concordia, . . Zimmerman/Volk. (2013). Plan for the 21st century: New Orleans 2030. Available from http://www.nola.gov/cityplanning/master-plan/

Google. (2016). Google Maps [Interactive maps, aerial photography, and street view photography]. Retrieved from http://maps.google.com/

Greater Sudbury Climate Change Consortium. (2011). Moving forward together: Climate change \& social justice conference. Retrieved from http://www.sudburyclimateaction.ca/images/stories/science_articles/Local/ full\%20report\%202011\%20workshop.pdf

Greater Sudbury Climate Change Consortium. (2014). FANS (Friends And Neighbors Sudbury) project. Retrieved from http://www.sudburyclimateaction.ca/en/fans-project.html

Greater Sudbury Food Policy Council. (2014a). Greater Sudbury Food Policy Council: Fact sheet. Retrieved from https://sudburyfoodpolicy.files.wordpress.com/2014/11/fact-sheet.pdf

Greater Sudbury Food Policy Council. (2014b). Growing a sustainable food culture: Greater Sudbury food system. Retrieved from https://sudburyfoodpolicy.files.wordpress.com/2014/11/infographic.pdf 
Gremillion, T. M. (2011). Setting the foundation: Climate change adaptation at the local level. Environmental Law, 41(4), 1221-1253. Available from http://go.galegroup.com/

Gunders, D. (2012, August). Wasted: How America is losing up to 40 percent of its food from farm to fork to landfill. IP:12-06-B, Natural Resources Defense Council. Retrieved from http://www.nrdc.org/food/files/wasted-food-IP.pdf

Halifax Food Policy Alliance. (2015). Food counts: Halifax food assessment. Retrieved from https://halifaxfoodpolicy.files.wordpress.com/2015/03/foodcounts-assessment-web-fin4.pdf

Halifax Regional Municipality. (2007). Climate change: Developer's risk management guide. Retrieved from https://www.halifax.ca/climate/documents/DevelopersGuidetoRiskManagment.pdf

Halifax Regional Municipality. (2010). HRM climate smart community action guide to climate change and emergency preparedness. Retrieved from https://www.halifax.ca/climate/documents/ ClimateSmartGuide_Final_PressRes.pdf

Halifax Regional Municipality. (2015). Proposed operating budget: 2015/16. Retrieved from https://www.halifax.ca/budget/documents/PROPOSED_OPERATING_BOOK_Revised_GL.pdf

Hallegatte, S., \& Corfee-Morlot, J. (2010). Understanding climate change impacts, vulnerability and adaptation at city scale: An introduction. Climatic Change, 104(1), 1-12. doi:10.1007/s10584-010-9981-8

Handwerk, B. (2013, May 1). Pro-environment light bulb labeling turns off conservatives, study finds. National Geographic News. Retrieved from http://news.nationalgeographic.com/news/energy/2013/04/130430light-bulb-labeling/

Harry Cummings and Associates Inc. (2009). Blue Sky Region agricultural economic sector profile. Retrieved from http://hcaconsulting.ca/pdfs/2009\%20Blue\%20Sky\%20Region\%20Agri\%20Economic\%20Impact.pdf

Havlík, P., Leclère, D., Valin, H., Herrero, M., Schmid, E., Soussana, J-F., Müller, C., \& Obersteiner, M. (2015). Global climate change, food supply and livestock production systems: A bioeconomic analysis. In A. Elbehri (Ed.), Climate change and food systems: Global assessments and implications for food security and trade (pp. 177-208). Rome, Italy: Food and Agriculture Organization of the United Nations (FAO). Retrieved from http://www.fao.org/3/a-i4332e.pdf

Hawkes, C. (2009). Identifying innovative interventions to promote healthy eating using consumption-oriented food supply chain analysis. Journal of Hunger \& Environmental Nutrition, 4, 336-356. doi:10.1080/19320240903321243

Humes, G. (2015, September 24). Talk transformation: Preparing Toronto for an extreme weather future community and infrastructure resilience [Panel discussion]. Innis Town Hall, Toronto, ON.

Humphrey, J., \& Memedovic, O. (2006). Global value chains in the agrifood sector. Vienna, Austria: United Nations Industrial Development Organization. Retrieved from https://www.unido.org/fileadmin/ user_media/Publications/Pub_free/Global_value_chains_in_the_agrifood_sector.pdf

Hunt, A., \& Watkiss, P. (2010). Climate change impacts and adaptation in cities: a review of the literature. Climatic Change, 104(1), 13-49. doi:10.1007/s10584-010-9975-6

ICLEI. (n.d.). Who we are. Retrieved from http://www.iclei.org/about/who-is-iclei.html

ICLEI. (2012). ICLEI timeline 1990-2012: 22 years of local government action toward global sustainability. Retrieved from http://www.iclei.org/fileadmin/user_upload/ICLEI_WS/Documents/ICLEI_Timeline.pdf

ICLEI Canada. (n.d.). Join the BARC Program: Building Adaptive \& Resilient Communities. Retrieved from http://www.icleicanada.org/programs/adaptation/barc

ICLEI USA. (2013, March 12). Member list. Retrieved via the Internet Archive Wayback Machine: https://web.archive.org/web/20120313213856/http://www.icleiusa.org/about-iclei/staff/abouticlei/members/member-list

Internal Revenue Service. (2015, March 5). Food industry overview. Retrieved from https://www.irs.gov/Businesses/Food-Industry-Overview

International Development Research Centre. (n.d.). International research initiative on adaptation to climate change. Retrieved from http://www.idrc.ca/EN/Programs/Science_and_Innovation/ IDRC_Challenge_Fund/IRIACC/Pages/default.aspx 
International Federation of Red Cross and Red Crescent Societies. (2010). World disasters report 2010: Focus on urban risk. Retrieved from http://www.ifrc.org/Global/Publications/disasters/WDR/WDR2010-full.pdf

IPCC (Intergovernmental Panel on Climate Change). (2014). Climate Change 2014: Synthesis Report. Contribution of Working Groups I, II and III to the Fifth Assessment Report of the Intergovernmental Panel on Climate Change [Core Writing Team, R. K. Pachauri and L. A. Meyer (eds.)]. Geneva, Switzerland: IPCC. Available from http://www.ipcc.ch/report/ar5/syr/

Jacobs, J. (1963). The death and life of great American cities (First vintage ed.). New York, NY: Vintage Books.

Jäggi, M. (2013). A peek over the fence: Urban agriculture as an instrument of social and environmental policy (a case study from Toronto). In I. Wallimann (Ed.), Environmental policy is social policy - social policy is environmental policy: Toward sustainability policy (pp. 135-152). New York, NY: Springer.

Joakim, E. P., Mortsch, L., \& Oulahen, G. (2015). Using vulnerability and resilience concepts to advance climate change adaptation. Environmental Hazards, 14(2), 137-155. doi:10.1080/17477891.2014.1003777

Johnson, N. C., \& Cain, K. L. (2015, March). Programming options to promote utilization of a new fresh foods market in Central City New Orleans: A health impact assessment report. Retrieved from http://www.nola.gov/getattachment/Health/Data-and-Publications/Myrtle-Banks-HIA-Report-FINAL_ALLAppendices.pdf/

Jones, P. (2010). Executive directive on healthy and sustainable food 09-03 (issued July 9, 2009 by Mayor Gavin Newsom): Summary report. San Francisco Department of Public Health. Retrieved from http://sfgov.org/sffood/sites/sfgov.org.sffood/files/migrated/FileCenter/Documents/sffood/FPC_Summary _Report_December_2010_final1.pdf

Jones, P., Ona, F., Rimkus, L., \& Wells, Z. (2005). 2005 San Francisco collaborative food system assessment. San Francisco, CA: San Francisco Food Systems. Retrieved from http://www.sfgov3.org/Modules/ShowDocument. aspx?documentid=780

Kameshwari, P., \& Kaufman, J. L. (2000). The food system: A stranger to the planning field. Journal of the American Planning Association, 66(2), 113-124. doi:10.1080/01944360008976093

Kamizaki, K. (2014). Reassembling community food flow: The making and remaking of community food distribution and procurement in Toronto's west central neighbourhoods. Retrieved from http://tfpc.to/wordpress/wp-content/uploads/2014/02/CFP-Community-Food-Flow.pdf

Keown, M. K. (2015, February 21). Sudbury considers impact of climate change. Sudbury Star. Retrieved from http://www.thesudburystar.com/2015/02/21/sudbury-considers-impact-of-climate-change

King, A. (2014, February 27). I was trapped in my apartment. Toronto Life. Retrieved from http://www.torontolife.com/informer/features/2014/02/27/toronto-holiday-icestorm/?page=all\#tlb_multipage_anchor_5

King, R. P., Hand, M. S., DiGiacomo, G., Clancy, K., Gomez, M. I., Hardesty, S. D., . . . McLaughlin, E. W. (2010, June). Comparing the structure, size, and performance of local and mainstream food supply chains. ERR 99, U.S. Department of Agriculture, Economic Research Service. Retrieved from http://www.ers.usda.gov/media/122609/err99_1_.pdf

King County. (2013a, August 8). King County human health and economic impacts of climate change. Retrieved from http://www.kingcounty.gov/environment/climate/climate-change-resources/impacts-of-climatechange/health-economic-impacts.aspx

King County. (2013b, September). Disaster recovery - CEO leadership summit. Retrieved from http://www.kingcounty.gov/ /media/safety/prepare/documents/SpecialEvents/CEOSummit_Resiliency/CE OSummit_SummaryReport_2013.ashx?la=en

King County. (2014, December 16). Building a farm-to-plate pipeline will better connect local farmers and communities. Retrieved from http://www.kingcounty.gov/elected/executive/constantine/News/release/ 2014/June/23_local-food-initiative.aspx

King County. (2015a). Local food initiative: A roadmap to strengthening King County's local food system and increasing access to healthy, affordable food. Retrieved from http://your.kingcounty.gov/dnrp/localfood/documents/2015-KC-Local-Food-Report.pdf 
King County. (2015b, June 3). What you can do as an individual. Retrieved from http://www.kingcounty.gov/environment/climate/individual.aspx

King County. (2015c, June 30). What businesses can do. Retrieved from http://www.kingcounty.gov/environment/climate/business.aspx

King County. (2015d, September 28). Animals, plants and habitat: Biodiversity in King County, Washington. Retrieved from http://www.kingcounty.gov/environment/animalsAndPlants/biodiversity/ threats/ClimateChange.aspx

King County. (2015e, October 15). Local food initiative. Retrieved from http://kingcounty.gov/elected/executive/constantine/initiatives/local-food-initiative.aspx

King County - Cities Climate Collaboration. (2015). Joint letter of commitment: Climate change actions in King County. Retrieved from http://your.kingcounty.gov/dnrp/library/dnrp-directors-office/climate/2014-K4CLetterOfCommitments.pdf

King County, \& KCIT DNRP GIS. (2015, November). Strategic climate action plan: November 2015. Retrieved from http://your.kingcounty.gov/dnrp/climate/documents/2015_King_County_SCAP-Full_Plan.pdf

King County, \& King County Agricultural Commission. (2009, December). FARMS report: Future of agriculture, realize meaningful solutions. Available from http://www.kingcounty.gov/environment/water-andland/agriculture/documents/farms-report-future-of-agriculture.aspx

King County DNRP (Department of Natural Resources and Parks). (n.d.(a)). KingStat: Agricultural production \& protection. Retrieved from http://your.kingcounty.gov/dnrp/measures/2011/indicators/Ir-agriculture.aspx

King County DNRP (Department of Natural Resources and Parks). (n.d.(b)). KingStat: Climate protection. Retrieved from http://your.kingcounty.gov/dnrp/measures/2011/performance/en-climate-protection.aspx

King County Farms and Food Roundtable, Staff Team Members, \& Cedar River Group. (2014, June). Recommendations of the King County Farms and Food Roundtable. Retrieved from http://your. kingcounty.gov/dnrp/library/water-and-land/agriculture/farm-food-roundtable-report-june-2014.pdf

King County OEM (Office of Emergency Management). (2013a, May 13). Regional hazard mitigation plan (RHMP). Retrieved from http://www.kingcounty.gov/safety/prepare/EmergencyManagementProfessionals/ Plans/RegionalHazardMitigationPlan.aspx

King County OEM (Office of Emergency Management). (2013b, December). King County comprehensive emergency management plan. Available from http://www.kingcounty.gov/safety/prepare/Emergency ManagementProfessionals/Plans/ComprehensiveEmergencyManagementPlan.aspx

King County OEM (Office of Emergency Management). (2013c, December). King County comprehensive emergency management plan: Emergency support function (ESF) 11 agriculture and natural resources. Available from http://www.kingcounty.gov/safety/prepare/EmergencyManagement Professionals/Plans/ComprehensiveEmergencyManagementPlan.aspx

King County OEM (Office of Emergency Management). (2015a, July). King County regional hazard mitigation plan update volume 1: Planning-area-wide elements. Available from http://www.kingcounty.gov/safety/ prepare/EmergencyManagementProfessionals/Plans/RegionalHazardMitigationPlan.aspx

King County OEM (Office of Emergency Management). (2015b, July). King County regional hazard mitigation plan update volume 2: Planning partner annexes. Available from http://www.kingcounty.gov/safety/prepare/ EmergencyManagementProfessionals/Plans/RegionalHazardMitigationPlan.aspx

King County Solid Waste Division. (2015, December 17). Food: too good to waste. Retrieved from https://your.kingcounty.gov/solidwaste/wasteprevention/too-good-to-waste.asp

KLIMZUG. (2015). About KLIMZUG. Retrieved from http://www.klimzug.de/en/160.php

Kubursi, A. A., Cummings, H., MacRae, R., \& Kanaroglou, P. (2015). Dollars \& sense: Opportunities to strengthen Southern Ontario's food system. Retrieved from https://d3n8a8pro7vhmx.cloudfront.net/greenbelt/ pages/1231/attachments/original/1422904616/2015-02-04_Dollars_Sense_report_final.pdf?1422904616

Lerman, S., Haima, K., \& Mehus-Roe, K. (2012, October). City of Seattle food action plan. Retrieved from http://www.seattle.gov/Documents/Departments/OSE/Seattle_Food_Action_Plan_10-24-12.pdf 
Lewis, J., \& Miller, K. (2010). Climate change adaptation action plan for Iqaluit. Retrieved from http://climatechangenunavut.ca/sites/default/files/iqaluit_community_adap_plan_eng.pdf

Lin-Conrad, J., Jones, P., O'Farrell, L., \& Ferreira, T. (2009). Increased hunger: A summary of food program trends. San Francisco Food Security Task Force. Retrieved from http://sfgov.org/sites/sfgov.org.sffood/ files/migrated/ftp/uploadedfiles/sffood/policy_reports/SFFoodProgramTrendData0708.pdf

Lipton, B. (2010). Food security for Edmonton: Is it really something we should care about? The Edmonton Sustainability Papers. Retrieved from http://www.edmonton.ca/city_government/documents/ PDF/Discussion_Paper_7_Food_Security_in_Edmonton.pdf

Lister, N-M. (2007). Placing food. Retrieved from http://www.ryerson.ca/foodsecurity/publications/articles/lister_2007.pdf

Local Food Assets Task Force. (2013). The local food action plan of the Vancouver Park Board. Retrieved from http://vancouver.ca/files/cov/Local-food-action-plan.pdf

London Assembly Economy Committee. (2015). Weathering the storm: The impact of climate change on London's economy. Retrieved from https://www.london.gov.uk/sites/default/files/Economy\%20Committee\%20 Weathering\%20the\%20Storm_0.pdf

Macht, W. (2015, July 20). Developing resilient waterfront blocks. Urban Land Magazine. Retrieved from http://urbanland.uli.org/development-business/developing-resilient-waterfront-blocks/

MacRae, R., \& Donahue, K. (2013, June). Municipal food policy entrepreneurs: A preliminary analysis of how Canadian cities and regional districts are involved in food system change. Retrieved from http://capiicpa.ca/pdfs/2013/Municipal_Food_Policy_Entrepreneurs_Final_Report.pdf

Margolies, J. (Ed.). (2014). The City of New York hazard mitigation plan 2014. Retrieved from http://www.nyc.gov/html/oem/downloads/pdf/hazard_mitigation/plan_update_2014/final_nyc_hmp.pdf

Martinez, S., Hand, M., Da Pra, M., Pollack, S., Ralston, K., Smith, T., . . . Newman, C. (2010, May). Local food systems: Concepts, impacts, and issues. ERR 97, U.S. Department of Agriculture, Economic Research Service. Retrieved from http://www.ers.usda.gov/media/122868/err97_1_.pdf

Matheny, K., \& Homewood, G. (2015). Climate change adaptation \& resilience [Presentation]. Planning Information Exchange Quarterly Webinar Series. Retrieved from https://attendee.gotowebinar.com/recording/3384347736030181377

Mazzella, T., \& Pascal, J. (2014a, June 17). Seattle industrial areas freight access project: Summary of future conditions [Presentation materials]. Retrieved from http://www.seattle.gov/transportation/docs/ FAB\%20Meeting\%2006172014.pdf

Mazzella, T., \& Pascal, J. (2014b, July 15). Seattle industrial areas freight access project: Future conditions - part II [Presentation materials]. http://www.seattle.gov/transportation/docs/FAB\%20Meeting\% 2007152014.pdf

Mckeown, D. (2012, June 8). Toronto food strategy: 2012 update [City of Toronto staff report]. Retrieved from http://www.toronto.ca/legdocs/mmis/2012/hl/bgrd/backgroundfile-48282.pdf

McKeown, D. (2013a, October 21). Exploring health and social impacts of climate change in Toronto [City of Toronto staff report]. Retrieved from http://www.toronto.ca/legdocs/mmis/2013/hl/bgrd/backgroundfile62786.pdf

McKeown, D. (2013b, October 21). Toronto food strategy: 2013 update [City of Toronto staff report]. Retrieved from http://www.toronto.ca/legdocs/mmis/2013/hl/bgrd/backgroundfile-62765.pdf

McKeown, D. (2015, June 12). Climate change and health strategy for Toronto [City of Toronto staff report]. Retrieved from http://www.toronto.ca/legdocs/mmis/2015/hl/bgrd/backgroundfile-81508.pdf

McMillan, E. (2012). Climate action Sudbury's ongoing story: Opening the gate. Retrieved from http://www.sudburyclimateaction.ca/images/stories/science_articles/Local/gateway_report_web.pdf

Metcalf Foundation. (2008). Food connects us all: Sustainable local food in Southern Ontario. Retrieved from http://d3n8a8pro7vhmx.cloudfront.net/greenbelt/pages/268/attachments/original/1381244422/Food_Con nects_Us.pdf?1381244422 
Miami Intermodal Center. (2015). Miami central station. Retrieved from http://www.micdot.com/miami_central_station.html

Miami-Dade County. (2010). GreenPrint: Our design for a sustainable future. Retrieved from http://www.miamidade.gov/greenprint/pdf/plan.pdf

Miami-Dade County. (2011). Miami-Dade County sustainability-related legislation. Retrieved from http://www.miamidade.gov/greenprint/planning/library/resolutions.pdf

Miami-Dade County. (2015). Regulatory \& economic resources: Community gardens. Retrieved from http://www.miamidade.gov/zoning/districts-urban-center.asp

Miami-Dade County Climate Change Advisory Task Force. (2008, April). Second report and initial recommendations. Retrieved from http://www.miamidade.gov/environment/library/brochures/08-10-04ccatf-recommendations.pdf

Miami-Dade County, NOAA (National Oceanic and Atmospheric Administration), \& NACO (National Association of Counties). (2011). Miami-Dade County roadmap for adapting to coastal risk: Vulnerability assessment \& planning workshop results \& recommendations. Retrieved from https://www.mwcog.org/environment/ climate/adaptation/Miami\%20Dade\%20Vulnerability\%20Assessment.pdf

Miami-Dade MPO \& Gannett Fleming. (2009, March). Miami-Dade freight plan: Final plan March 2009. Retrieved from http://miamidadempo.org/library/studies/miami-dade-freight-plan-final-2009-03.pdf

Mitanis, M. (2015, April 7). Stanton Renaissance proposes creative hub for Keele and St. Clair. Urban Toronto. Retrieved from http://urbantoronto.ca/news/2015/04/stanton-renaissance-proposes-creative-hub-keeleand-st-clair

Morgenstern, T. (2013, October). Seattle climate action plan: Implementation strategy. Retrieved from http://www.seattle.gov/Documents/Departments/OSE/FinalCAPImplementationStrategy.pdf

Müller, C., \& Elliott, J. (2015). The Global Gridded Crop Model Intercomparison: Approaches, insights and caveats for modelling climate change impacts on agriculture at the global scale. In A. Elbehri (Ed.), Climate change and food systems: Global assessments and implications for food security and trade (pp. 29-59). Rome, Italy: Food and Agriculture Organization of the United Nations (FAO). Retrieved from http://www.fao.org/3/a-i4332e.pdf

Neuman, W. L. (2011). Social research methods: Qualitative and quantitative approaches (7th ed.). Boston, MA: Allyn \& Bacon.

New Orleans Food Policy Advisory Committee. (n.d.). School food. Retrieved from http://nolafpac.org/schoolfood/

New Orleans Food Policy Advisory Committee. (2008). Building healthy communities: Expanding access to fresh food retail. Retrieved from http://nolafpac.org/wp-content/uploads/2013/01/FPAC-Report-Final.pdf

New Orleans Food Policy Advisory Committee. (2015, October 9). New Orleans Food Policy Advisory Committee 2015 recap. Retrieved from http://nolafpac.org/new-orleans-food-policy-advisory-committee-2015-recap/

New Orleans Food Policy Advisory Committee \& Market Umbrella. (2015, July 29). Recap of Market Umbrella's fruit and vegetable prescription program. Retrieved from http://nolafpac.org/recap-of-market-umbrellasfruit-and-vegetable-prescription-program/

New Orleans Health Department, \& Healthy Start New Orleans. (2013, December). Child and family health in New Orleans: A life course perspective of child and family health at a neighborhood level. Retrieved from http://www.nola.gov/getattachment/Health/Data-and-Publications/Child-and-Family-Health-in-NewOrleans-December-2013.pdf/

Newsom, G. (2009, July 9). Executive Directive 09-03: Healthy and sustainable food for San Francisco. Available as Appendix A of http://sfgov.org/sffood/sites/sfgov.org.sffood/files/migrated/ FileCenter/Documents/sffood/FPC_Summary_Report_December_2010_final1.pdf

Newsom, G. (2010, April 19). Executive Directive 10-01: Healthy food \& beverage options in vending machines. Available as Appendix D of http://sfgov.org/sffood/sites/sfgov.org.sffood/files/migrated/FileCenter/ Documents/sffood/FPC_Summary_Report_December_2010_final1.pdf 
New York City Economic Development Corporation. (2014, May 13). Mayor's Office of Recovery and Resiliency announces request for proposals to study resiliency of city's food supply system. Retrieved from http://www.nycedc.com/press-release/mayors-office-recovery-and-resiliency-announces-requestproposals-study-resiliency

Nickson, A., Woolston, H., Daniels, J., Dedring, I., Reid, K., Ranger, K., . . . Reeder, T. (2011). Managing risks and increasing resilience: The mayor's climate change adaptation strategy. Retrieved from https://www.Iondon.gov.uk/sites/default/files/Adaptation-oct11.pdf

NOAA Office of Aquaculture. (2011). What is aquaculture? Retrieved from http://www.nmfs.noaa.gov/aquaculture/what_is_aquaculture.html

NOCSF (New Orleans Community Support Foundation), \& CSO (Community Support Organization). (2014). The unified New Orleans plan: Citywide strategic recovery and rebuilding plan. Retrieved from http://www.nolaplans.com/plans/UNOP/UNOP_Citywide.pdf

Nordhaus, W. D. (2012a, April 26). In the climate casino: An exchange [See reply by Nordhaus]. The New York Review of Books. Retrieved from http://www.nybooks.com/articles/archives/2012/apr/26/climate-casinoexchange/

Nordhaus, W. D. (2012b, March 22). Why the global warming skeptics are wrong. The New York Review of Books. Retrieved from http://www.nybooks.com/articles/archives/2012/mar/22/why-global-warmingskeptics-are-wrong/

Northwest Hydraulic Consultants. (2014). City of Vancouver coastal flood risk assessment: Final report. Retrieved from http://vancouver.ca/files/cov/CFRA-Phase-1-Final_Report.pdf

Nunavut Food Security Coalition. (2014). Nunavut food security strategy and action plan 2014-16. Retrieved from http://www.nunavutfoodsecurity.ca/sites/default/files/files/Resources/Strategy/Nunavut FoodSecurityStrategy_ENGLISH.pdf

Oates, L. (2010, August 3). Climate change risk assessment process and tool [City of Toronto staff report]. Retrieved from http://www.toronto.ca/legdocs/mmis/2010/ex/bgrd/backgroundfile-32902.pdf

Odlum, L. (2015, May 4). City of Toronto helping inform residents how to prepare for emergencies [City news release]. Retrieved from http://www1.toronto.ca/wps/portal/contentonly?vgnextoid= af71df79b2df6410VgnVCM10000071d60f89RCRD\&nrkey=A5C34BC62D6BA3F985257E3B004F468C

OMAFRA (Ontario Ministry of Agriculture, Food and Rural Affairs), CSCA (Centre for the Study of Commercial Activity), \& Ryerson University. (2010). Downtown Sudbury's trade area report: Analyzing local market conditions for effective downtown revitalization. Retrieved from https://sudburyfoodpolicy.files. wordpress.com/2013/06/2010-09-downtown-sudbury-trade-area-report.pdf

Ontario Ministry of Natural Resources. (2012, September 25). Greater Toronto Area digital elevation model 2002 [GIS dataset]. Retrieved from https://www.ontario.ca/data/greater-toronto-area-elevation

Oved, M. C. (2014, January 25). Ice storm: The last man in the GTA without power. The Toronto Star. Retrieved from http://www.thestar.com/news/gta/2014/01/25/ice storm_the_last_man_in_the_gta_without_power.html

Oved, M. C. (2015, June 8 ). Why growing vegetables on the roof is the future of Toronto architecture. The Toronto Star. Retrieved from http://www.thestar.com/news/gta/2015/06/08/why-growing-vegetableson-the-roof-is-the-future-of-toronto-architecture.html

Parent, C. M., \& Barthé-Prevost, A. (2015, May). New Orleans community health improvement plan. Retrieved from http://www.nola.gov/getattachment/Health/Data-and-Publications/New-Orleans_Community-HealthImprovement-Plan_May-2015-\%281\%29.pdf/

Parsons Brinkerhoff, Cambridge Systematics, Inc., \& Quest Corporation of America. (2014, August). 2014 MiamiDade County freight plan update. Retrieved from http://miamidadempo.org/library/studies/freight-planupdate-2014-08.pdf

Pasqualetti, M. J. (2009). Energy landscapes and the growth of Arizona. In P. Lusk \& A. Simon (Eds.), Building to endure: Design lessons of arid lands (pp. 155-180). Albuquerque, NM: University of New Mexico Press.

Pereira, C. (2015, July 13). Social media connecting neighbours and neighbourhoods. The 416 Magazine. Retrieved from http://the416magazine.com/social-media-connecting/ 
Pinto, E., Penney, J., Ligeti, E., Gower, S., \& Mee, C. (2011). Climate change adaptation and health equity: Background report. Retrieved from http://www.cleanairpartnership.org/files/climate_change_health_ equity.pdf

Putnam, R. D. (2000). Bowling alone: The collapse and revival of American community. New York, NY: Simon \& Schuster.

Randall, S. (2010). San Francisco fisheries report. Available as Appendix K of http://sfgov.org/sffood/sites/sfgov. org.sffood/files/migrated/FileCenter/Documents/sffood/FPC_Summary_Report_December_2010_final1.pdf

Rapp, S. (2014). To the reader. Available as preface to http://www.haassr.org/wpcontent/uploads/2014/10/wehfDisasterFoodSystems.pdf

Reckien, D., Flacke, J., Dawson, R., Heidrich, O., Olazabal, M., Foley, A., . . Pietrapertosa, F. (2014). Climate change response in Europe: What's the reality? Analysis of adaptation and mitigation plans from 200 urban areas in 11 countries. Climatic Change, 122(1-2), 331-340. doi:10.1007/s10584-013-0989-8

Refuge in the Storm. (2015). Refuge in the storm [Video file]. Retrieved from https://www.youtube.com/watch?v=0IXV9klunCs

Resilience Alliance. (2015). About. Retrieved from http://www.resalliance.org/index.php/about_ra

Resilient Communities for America. (n.d.). About the campaign. Retrieved from http://www.resilientamerica.org/join-the-leaders/about-the-campaign/

Resilient Miami, Kresge Foundation, Catalyst Miami, \& Urban Impact Lab. (2015) Resilient Miami: Building a resilient Miami. Retrieved from http://www.resilientmiami.com/blog/2015/4/20/building-a-resilient-miami

Resilient Miami, Kresge Foundation, Catalyst Miami, Urban Impact Lab, Florida Atlantic University's Climate Change Initiative, \& Wanless, H. (2015) Resilient Miami: Answers to common questions regarding sea level rise in South Florida. Retrieved from http://www.resilientmiami.com/sea-level-rise-faqs/

Roaf, S., Crichton, D., \& Nicol, F. (2009). Adapting buildings and cities for climate change: A 21st Century survival guide (2nd ed.). Oxford, UK: Architectural Press.

Robinson, P. J., \& Gore, C. D. (2005). Barriers to Canadian municipal response to climate change. Canadian Journal of Urban Research, 14(1), 102-120.

Robinson, P., \& Gore, C. (2015). Municipal climate reporting: Gaps in monitoring and implications for governance and action. Environment and Planning C: Government and Policy, 33, 1058-1075. doi: $10.1177 / 0263774 X 15605940$

Romero-Lankao, P. (2012). Governing carbon and climate in the cities: An overview of policy and planning challenges and options. European Planning Studies, 20(1), 7-26. doi:10.1080/09654313.2011.638496

Rossini, R. (2014). Resilient city - preparing for a changing climate [City of Toronto staff report]. Retrieved from http://www.toronto.ca/legdocs/mmis/2014/pe/bgrd/backgroundfile-70623.pdf

Ruvin, H., Murley, J., Enfield, D., Fain, S. E., Fair, T. W., Gonzalez, J., \& Milian, A. (2014). Miami-Dade sea level rise task force report and recommendations. Retrieved from http://www.miamidade.gov/planning/library/ reports/sea-level-rise-report-recommendations.pdf

Saavedra, C., Budd, W. W., \& Lovrich, N. P. (2012). Assessing resilience to climate change in US cities. Urban Studies Research, 2012. doi:10.1155/2012/458172

San Francisco Department of Emergency Management. (2015). SF72: SF map \& updates. Retrieved from http://www.sf72.org/em/home

San Francisco Department of Public Health. (n.d.(a)). Environmental health: Publications. Retrieved from https://www.sfdph.org/dph/EH/publs/default.asp

San Francisco Department of Public Health. (n.d.(b)). Program on health, equity and sustainability: Food. Retrieved from http://www.sfhealthequity.org/elements/food

San Francisco Department of the Environment. (2013). San Francisco climate action strategy: 2013 update. Retrieved from http://sfenvironment.org/sites/default/files/engagement_files/ sfe_cc_ClimateActionStrategyUpdate2013.pdf 
Schulz, K. (2015, July 20). The really big one: An earthquake will destroy a sizable portion of the coastal Northwest. The question is when. The New Yorker. Retrieved from http://www.newyorker.com/magazine/2015/07/20/the-really-big-one

Scioli, J. (2013, November 22). Resilient city: Preparing for extreme weather events [City of Toronto staff report]. Retrieved from http://www.toronto.ca/legdocs/mmis/2013/pe/bgrd/backgroundfile-64016.pdf

Seattle \& King County Public Health. (2015a, January 2). Nutrition guidelines, tips, recipes and more. Retrieved from http://www.kingcounty.gov/healthservices/health/nutrition/tips.aspx

Seattle \& King County Public Health. (2015b, December 21). Addressing good food. Retrieved from http://www.kingcounty.gov/healthservices/health/ehs/healthyplaces/food.aspx

Seattle \& King County Public Health. (2016). Disaster preparedness fact sheets and flyers. Retrieved from http://www.kingcounty.gov/healthservices/health/preparedness/disaster.aspx

Seattle City Light. (2015, December 9). Solar incentive program overview. Retrieved from http://www.seattle.gov/light/solarenergy/SIP.asp

Seattle Department of Transportation. (n.d.). Alaskan Way Viaduct emergency traffic management and closure plan. Retrieved from http://www.seattle.gov/transportation/viaductemergencyclosure.htm

Seattle OEM (Office of Emergency Management). (2012, November 13). Seattle disaster readiness and response plan. Retrieved from http://www.seattle.gov/Documents/Departments/Emergency/PlansOEM/ SDRRP/Final\%20SDRRP\%20V11-13-12.pdf

Seattle OEM (Office of Emergency Management). (2014, April 23). Seattle hazard identification and vulnerability analysis: Power outages. Retrieved from http://www.seattle.gov/Documents/Departments/ Emergency/PlansOEM/SHIVA/2014-04-23_PowerOutages.pdf

Seattle OEM (Office of Emergency Management). (2015, May). Comprehensive emergency management plan: Base plan and ESF annexes. Retrieved from http://www.seattle.gov/Documents/Departments/ Emergency/PlansOEM/SDRRP/Final_CEMP_V15_08_08.pdf

Seijas, N., Torriente, S. M., \& Hefty, N. (2010). Reality check: Climate adaptation on the ground in Miami-Dade County [Presentation materials]. Retrieved from http://resilient-cities.iclei.org/fileadmin/sites/resilientcities/files/docs/E5-Bonn2010-Seijas_Torriente_Hefty.pdf

Shenker, S. (2012, June 14). Who, what, why: Why does a cabbage cost $\$ 28$ in Canada? BBC Magazine. Retrieved from http://www.bbc.com/news/world-us-canada-18413043

Shi, L., Chu, E., \& Debats, J. (2015). Explaining progress in climate adaptation planning across 156 U.S. municipalities. Journal of the American Planning Association, 81(3), 191-202. doi: $10.1080 / 01944363.2015 .1074526$

Social Compact Inc. (2007). Miami neighborhood market drilldown phase 1: Catalyzing business investment in inner city neighborhoods. Retrieved from http://redevco.org/dfiles/Miami_DrillDown.pdf

Social Compact Inc. (2009). City of Miami neighborhood market drilldown: Catalyzing business investment in inner-city neighborhoods. Retrieved from http://www.miamigov.com/economicdevelopment/ docs/Miami\%20DrillDown\%20Report.pdf

Soma, T., \& Wakefield, S. (2011). The emerging role of a food system planner: Integrating food considerations into planning. Journal of Agriculture, Food Systems, and Community Development, 2(1), 1-12.

Southeast Florida Regional Compact. (2012, October). A region responds to a changing climate: Southeast Florida regional climate change compact counties: Regional climate action plan. Retrieved from https://southeastfloridaclimatecompact.files.wordpress.com/2014/05/regional-climate-action-plan-finalada-compliant.pdf

Spears, J. (2013, August 13). Blackout 2003: How Ontario went dark. The Toronto Star. Retrieved from http://www.thestar.com/business/economy/2013/08/13/blackout_2003_how_ontario_went_dark.html

Spears, J. (2014, June 18). Highrises need backup generators, says ice storm panel. The Toronto Star. Retrieved from http://www.thestar.com/business/2014/06/18/high_rises_need_backup_generators_ says_icestorm_panel.htm 
Statistics Canada. (2011). 2011 Census - cartographic boundary file - provinces/territories [GIS data]. Available from http://www12.statcan.gc.ca/census-recensement/2011/geo/bound-limit/bound-limit-eng.cfm

Stead, D. (2014). Urban planning, water management and climate change strategies: Adaptation, mitigation and resilience narratives in the Netherlands. International Journal of Sustainable Development \& World Ecology, 21(1), 15-27. doi:10.1080/13504509.2013.824928

Stricker, L. (2013, March 5). Urban food touted. Sudbury Star. Retrieved from http://www.thesudburystar.com/2013/03/05/urban-food-touted

Sudbury and District Health Unit. (2015). Community food directory. Retrieved from https://sudburyfoodpolicy.files.wordpress.com/2015/08/fsdirectory_revised_aug19_2015.pdf

Surjan, A., Sharma, A., \& Shaw, R. (2011). Understanding urban resilience. In R. Shaw \& A. Sharma (Eds.), Climate and disaster resilience in cities (pp. 17-46). Bingley, UK: Emerald Group Publishing Limited.

Tacoli, C., Bukhari, B., \& Fisher, S. (2013, March). Urban poverty, food security and climate change (Human settlements working paper no. 37). London, UK: International Institute for Environment and Development (IIED). Retrieved from http://pubs.iied.org/pdfs/10623IIED.pdf

The Economist. (2009, March 30). Vertical integration. Retrieved from http://www.economist.com/node/13396061

Tomalty, R., \& Komorowski, B. (2011). Climate change adaptation: Ontario's resilient Greenbelt. Retrieved from http://d3n8a8pro7vhmx.cloudfront.net/greenbelt/pages/41/attachments/original/1376571502/Climate_Ch ange_Adaption_Ontario's_Resilient_Greenbelt.pdf?1376571502

Toronto and Region Conservation Authority, \& City of Toronto OEM (Office of Emergency Management). (2014). City of Toronto emergency plan: Risk specific plan: Flooding. Retrieved from http://www1.toronto.ca/city_of_toronto/office_of_emergency_management/files/pdf/flood_rsp.pdf

Toronto Food Policy Council. (1999a). A wealth of food: A profile of Toronto's food economy. Retrieved from http://www1.toronto.ca/city_of_toronto/toronto_public_health/healthy_families/nutrition/toronto_food_po licy_council/files/pdf/tfpc_wealth.pdf

Toronto Food Policy Council. (1999b). Feeding the city from the back 40: A commercial food production plan for the City of Toronto. Retrieved from http://www1.toronto.ca/city_of_toronto/toronto_public_health/ healthy_families/nutrition/toronto_food_policy_council/files/pdf/tfpc_feeding.pdf

Toronto Food Policy Council. (2000). Food secure city: Toronto Food Policy Council submission to the Toronto Official Plan. Retrieved from http://www1.toronto.ca/city_of_toronto/toronto_public_health/ healthy_families/nutrition/toronto_food_policy_council/files/pdf/tfpc_secure.pdf

Toronto Food Policy Council. (2015). Toronto food policy archive. Retrieved from http://tfpc.to/wordpress/wpcontent/uploads/2015/05/Toronto-Food-Policy-Archive-Spring-2015.pdf

Toronto Hydro-Electric System Limited. (2015). What Causes Power Outages? Retrieved from https://outages.torontohydro.com/about-outages/

Toronto Hydro Electric System Limited, \& City of Toronto OEM (Office of Emergency Management). (2015). City of Toronto emergency plan: Risk specific plan: Power disruption (electricity). Retrieved from http://www1.toronto.ca/city_of_toronto/office_of_emergency_management/files/pdf/power_rsp.pdf

Totten, A. (2015, July 23). Mobile food market pilot project. Retrieved from http://www.halifax.ca/boardscom/sccped/documents/mobilemarketcped.pdf

Trento, L., \& Allen, S. (2014). Hurricane Sandy: Nutrition support during disasters. Nutrition in Clinical Practice 29(5), 576-584. doi:10.1177/0884533614536927

Uens, G. (2014, July 10). South Niagara planning strategy - final report [City of Toronto staff report]. Retrieved from http://www.toronto.ca/legdocs/mmis/2014/pg/bgrd/backgroundfile-71922.pdf

UKCIP. (2014). About us. Retrieved from http://www.ukcip.org.uk/about-us/

UN-Habitat (United Nations Human Settlements Programme). (2011). Cities and climate change: Global report on human settlements 2011. London, UK: Earthscan. Available from http://unhabitat.org/books/cities-andclimate-change-global-report-on-human-settlements-2011/ 
United States Census Bureau. (2014). 2014 cartographic boundary file, state for United States, 1:500,000 [GIS data]. Available from https://www.census.gov/geo/maps-data/data/tiger-cart-boundary.html

United States Conference of Mayors. (2008). About the Mayors Climate Protection Center. Retrieved from http://www.usmayors.org/climateprotection/about.asp

USAID. (n.d.). Climate-resilient development: A framework for understanding and addressing climate change. Retrieved from http://www.usaid.gov/climate/climate-resilient-development-framework

USDHS (United States Department of Homeland Security). (2011). Homeland security advisory council: Community resilience task force recommendations. Retrieved from http://www.dhs.gov/xlibrary/assets/hsac-community-resilience-task-force-recommendations-072011.pdf

USDOC (United States Department of Commerce). (2008, June). US Department of Commerce industry report: Food manufacturing NAICS 311. Retrieved from http://trade.gov/td/ocg/report08_processedfoods.pdf

USEPA (United States Environmental Protection Agency). (2015, December 11). Global greenhouse gas emissions data. Retrieved from http://www3.epa.gov/climatechange/ghgemissions/global.html

Vasseur, L. (2007). Promoting community sustainability through adaptive responses to socio-economic and risk assessments of the potential impacts of climate change scenarios in a natural resource-based, mid-sized Canadian Shield community: Greater Sudbury Ontario. Retrieved http://www.sudburyclimateaction.ca/images/stories/science_articles/Local/7_img_529132440_0001.pdf

Vermeulen, S. J., Campbell, B. M., \& Ingram J. S.I. (2012). Climate change and food systems. Annual Review of Environment and Resources, 37, 195-222. doi:10.1146/annurev-environ-020411-130608

Washington State Homeland Security Region 6 (geographic King County). (2005, September). Critical infrastructure protection plan. Available from http://www.kingcounty.gov/safety/prepare/Emergency ManagementProfessionals/Plans/CriticalInfrastructureProtectionPlan.aspx

Wastewater Treatment Division. (2015, November 6). Responding to climate change. Retrieved from http://www.kingcounty.gov/environment/wtd/About/RespondingToClimateChange.aspx

Wheeler, T. (2015). Climate change impacts on food systems and implications for climate-compatible food policies. In A. Elbehri (Ed.), Climate change and food systems: Global assessments and implications for food security and trade (pp. 315-336). Rome, Italy: Food and Agriculture Organization of the United Nations (FAO). Retrieved from http://www.fao.org/3/a-i4332e.pdf

WHO (World Health Organization). (2010). Community resilience in disasters: How the primary health care approach made a difference in recent emergencies in the WHO South-East Asia region. Retrieved from http://reliefweb.int/report/bangladesh/community-resilience-disasters-how-primary-health-careapproach-made-difference

Whyte, B. (2011). Planning tools for improving food access: Lessons for Ontario's municipal planners (Master's research paper). Toronto, ON: Ryerson University.

Wolff, M., \& Comerford, C. (2014). San Francisco climate \& health profile. Retrieved from http://www.sfclimatehealth.org/wp-content/uploads/2015/01/SFDPH_ClimateHealthProfile_FinalDraft.pdf

World Bank. (2008). From agriculture to nutrition: Pathways, synergies and outcomes. Washington DC: World Bank. Available from http://documents.worldbank.org/curated/en/2008/01/17732539/agriculturenutrition-pathways-synergies-outcomes

World Bank. (2015, April 1). Food security: Overview. Retrieved from http://www.worldbank.org/en/topic/foodsecurity/overview\# 1

Xuereb, M. (2005). Food miles: Environmental implications of food imports to Waterloo Region. Retrieved from http://chd.region.waterloo.on.ca/en/researchResourcesPublications/resources/FoodMiles_Report.pdf

Young, C., Karpyn, A., \& Treering, D. (2012, March). A healthier future for Miami-Dade County: Expanding supermarket access in areas of need. Retrieved from http://thefoodtrust.org/uploads/media_items/ miami-dade-supermarket-report.original.pdf

Zerbisias, A. (2014, January 31). Power to the highrise people: Should blackout generate new laws? The Toronto Star. Retrieved from http://www.thestar.com/news/gta/2014/01/31/power_to_the_highrise_people_ should_blackout_generate_new_laws.html

Zimmerman, R., \& Faris, C. (2011). Climate change mitigation and adaptation in North American cities. Current Opinion in Environmental Sustainability, 3(3), 181-187. doi:10.1016/j.cosust.2010.12.004 